\title{
FEASIBILITY OF FUSED DEPOSITION OF CERAMICS WITH ZIRCONIA AND ACRYLIC BINDER
}

\author{
A Thesis \\ presented to \\ the Faculty of California Polytechnic State University, \\ San Luis Obispo
}

\begin{abstract}
In Partial Fulfillment
of the Requirements for the Degree

Master of Science in Industrial Engineering
\end{abstract}

\author{
by \\ Lindsay V. Page \\ June 2016
}


(C) 2016

Lindsay V. Page

ALL RIGHTS RESERVED 


\section{COMMITTEE MEMBERSHIP}

TITLE:

AUTHOR:

DATE SUBMITTED:

COMMITTEE CHAIR:

COMMITTEE MEMBER:

COMMITTEE MEMBER:
Feasibility of Fused Deposition of Ceramics with Zirconia and Acrylic Binder

Lindsay V. Page

June 2016

Dr. Xuan Wang, Ph.D.

Assistant Professor of Industrial and Manufacturing Engineering

Dr. Daniel Waldorf, Ph.D.

Professor of Industrial and Manufacturing

Engineering

Ethan Escowitz

AREVO Labs

Director of Sales \& Additive Manufacturing

Services 


\begin{abstract}
Feasibility of Fused Deposition of Ceramics with Zirconia and Acrylic Binder Lindsay V. Page
\end{abstract}

Processing of ceramics has always been difficult due to how hard and brittle the material is. Fused Deposition of Ceramics (FDC) is a method of additive manufacturing which allows ceramic parts to be built layer by layer, abetting more complex geometries and avoiding the potential to fracture seen with processes such as grinding and milling. In the process of FDC, a polymeric binder system is mixed with ceramic powder for the printing of the part and then burned out to leave a fully ceramic part. This experiment investigates a new combination of materials, zirconia and acrylic binder, optimizing the process of making the material into a filament conducive to the printer system and then performing trials with the filament in the printer to assess its feasibility. Statistical analysis was used to determine optimal parameter levels using response surface methodology to pinpoint the material composition and temperature yielding the highest quality filament. It was discovered that although the mixture had adequate melting characteristics to be liquefied and printed into a part, the binder system did not provide the stiffness required to act as a piston to be fed through the printer head. Further studies should be completed continuing the investigation of zirconia and acrylic binder, but with added components to increase strength and rigidity of the filament. 


\section{ACKNOWLEDGMENTS}

I would like to thank my thesis advisor Dr. Xuan Wang for all of his guidance through this process. Additionally, thanks to my other committee members Dr. Daniel Waldorf and Ethan Escowitz for contributing their time to help me reach this milestone. I would also like to express appreciation for the faculty of the IME Department for making my five years at Cal Poly so rewarding, and thank you to my friends and family who helped me throughout my entire education. 


\section{TABLE OF CONTENTS}

Page



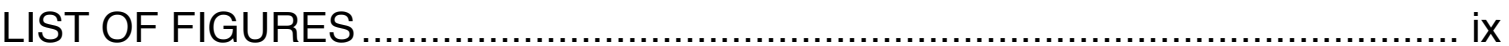

\section{CHAPTER}

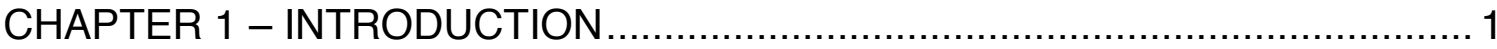

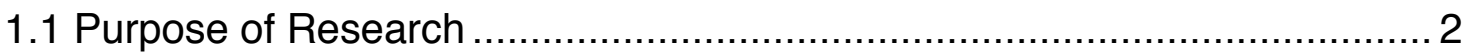

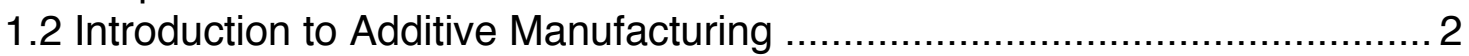

1.3 Fused Deposition of Ceramics ............................................................... 3



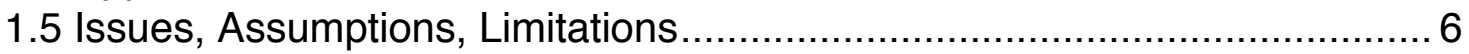

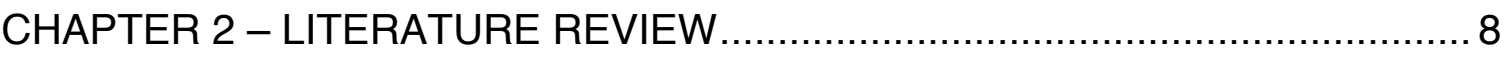

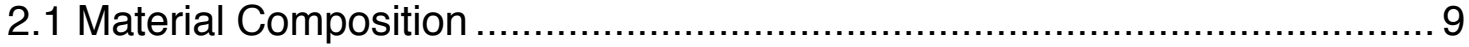

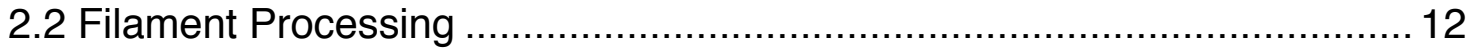

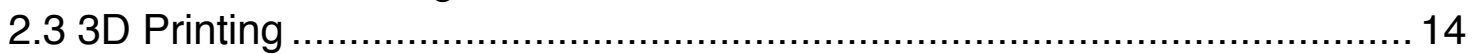

2.3.1 Best Printing Practices .............................................................. 14

2.3.2 Printing with Ceramic Filament .................................................. 17

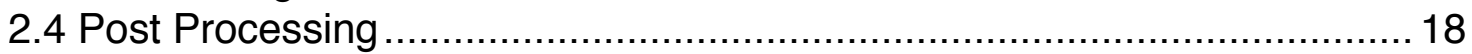

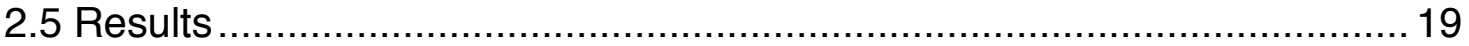

2.5.1 Measurement Methods .......................................................... 19

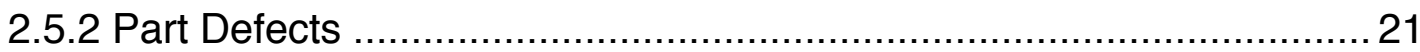

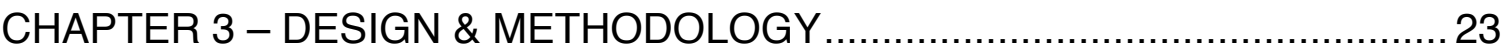

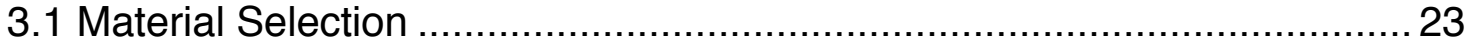

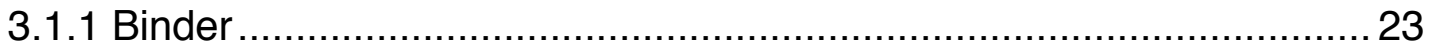



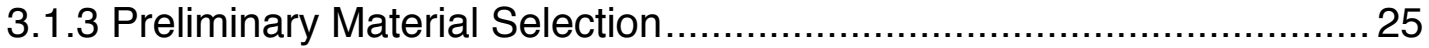

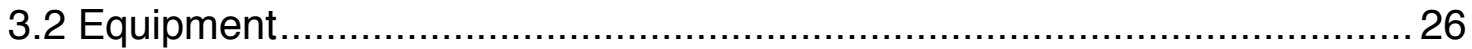

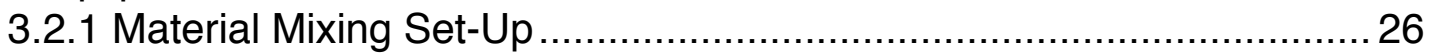

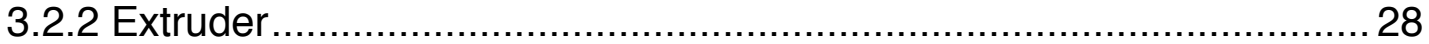

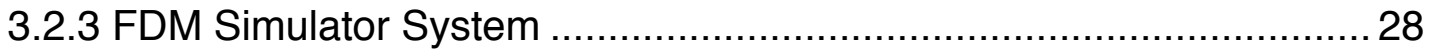

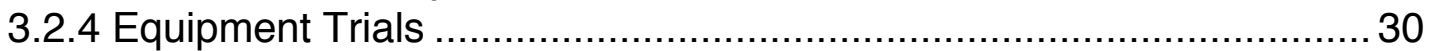

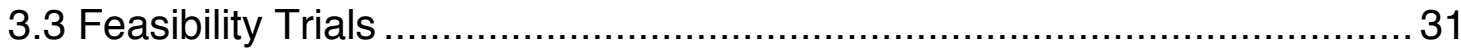

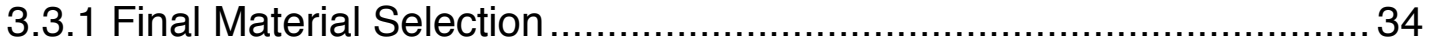

3.4 DOE

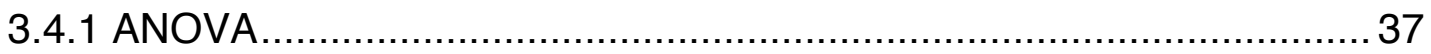

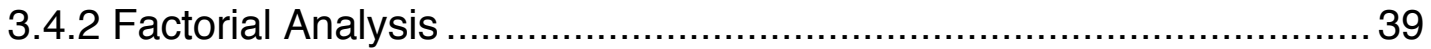

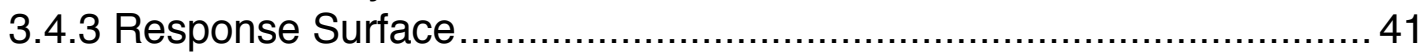

3.4.4 Analysis of Optimized Filament .................................................... 41

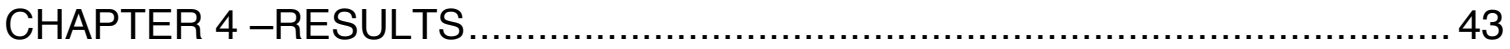

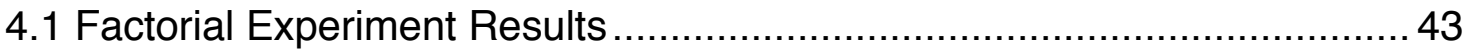


4.2 Response Surface Optimization ......................................................... 49

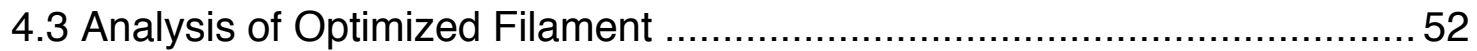

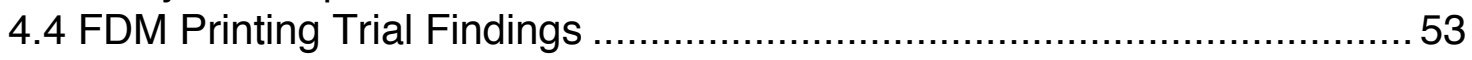

4.5 Steps for Further Development ........................................................ 55

CHAPTER 5 - SUMMARY AND CONCLUSIONS ……................................. 57

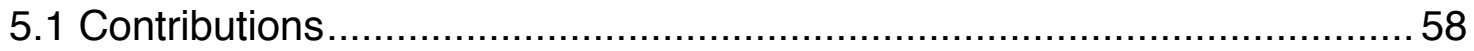

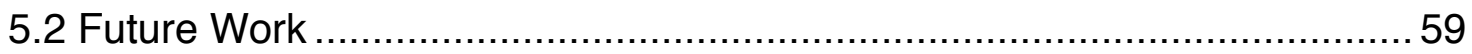



APPENDICES

Appendix A: Summary of Previous FDC Experiments.................................6 67

Appendix B: ANOVA Extrusion Temp vs. Diameter Assumptions ...................68

Appendix C: Factorial Analysis Residual Plots for Diameter .........................69

Appendix D: Factorial Analysis Residual Plots for Diameter Standard

Deviation ......................................................................................... 70

Appendix E: Factorial Analysis Residual Plots for Length .............................. 71

Appendix F: Factorial Analysis Residual Plots for Length ............................ 72

Appendix G: Results for First Factorial Analysis (Listed by Response) ........... 73

Appendix H: Results for Second Factorial Analysis (Listed by Response)...... 78

Appendix I: Assumptions for Response Surface Analysis .............................81

Appendix J: Response Surface Optimization Results ................................. 83

Appendix K: Raw Data Used in Factorial and Response Surface Analyses ... 87 


\section{LIST OF TABLES}

Table

Page

Table 3-1: Preliminary Material Selection................................. 26

Table 3-2: Material Composition........................................... 31

Table 3-3: Final Material Selection........................................ 35

Table 3-4: 2^4 Factorial Design Factor Levels............................ 41

Table 4-1: Summary of Significant Terms Identified in Factorial Analysis... 47

Table 4-2: Response Surface Optimization Goal Values.................. 50

Table 4-3: Summary of Optimized Filament Measurements................ 52 


\section{LIST OF FIGURES}

Figure

Figure 1-1: Fused Deposition Modeling (Source: FDM (Fused Deposition Modeling) [Diagram]. Retrieved from http://swiatdruku3d.pl/fdm -fused-deposition-modeling/)............................................ 4

Figure 1-2: Flowchart of FDC Process.................................... 5

Figure 2-1: Filament Extrusion Process................................... 13

Figure 2-2: Strains Associated with Printing Patterns (Source: Kantaros \& Karalekas, 2013)..................................................... 15

Figure 2-3: Build Orientations Upright (left), Side Up (middle), Face Up (right) (Source: Smith \& Dean, 2013)

Figure 2-4: Stress-Strain Curves by Print Orientation (Source: Smith \& Dean, 2013)....

Figure 2-5: Staircase Effect with Different Layer Thicknesses (Source:

Sabourin, Houser \& Bohn, 1997) ............................. 21

Figure 2-6: Chordal Effect on Rounded Surface........................... 22

Figure 3-1: Material Compounding Set-Up................................ 27

Figure 3-2: Air Filtration Chamber......................................... 27

Figure 3-3: Filastruder Used to Create Filament........................... 28

Figure 3-4: FDM Simulator System..................................... 29

Figure 3-5: Hot End .................................................... 30

Figure 3-6: FDM Simulator System Set-Up............................. 30

Figure 3-7: HA-12 with Zirconia.......................................... 32

Figure 3-8: B-1022 with Zirconia......................................... 33

Figure 3-9: B-1000 with Zirconia (left) and Alumina (right)................. 33

Figure 3-10: Down-Selected B-1000 Binder and Zirconia Mixture............ 35

Figure 3-11: B-1000 and Zirconia Filament.............................. 35

Figure 3-12: DOE Process Flow......................................... 36

Figure 3-13: ANOVA Table for Diameter vs. Extrusion Temperature......... 37

Figure 3-14: Results of Tukey Comparison Study.......................... 38

Figure 3-15: 2^4 Factorial Design.......................................... 39

Figure 4-1: Initial Half Normal Plot for Diameter ............................. 43

Figure 4-2: Initial Half Normal Plot for Diameter Standard Deviation.......... 44

Figure 4-3: Initial Half Normal Plot for Length .............................. 44

Figure 4-4: Initial Half Normal Plot for Breaking Weight ....................... 45

Figure 4-5: Second Analysis Half Normal Plot for Diameter ................. 46

Figure 4-6: Second Analysis Half Normal Plot for Breaking Weight ........... 46

Figure 4-7: Interaction Effect Between Powder, Water and Dispersant....... 48

Figure 4-8: Main Effects for Extrusion Temperature ....................... 48

Figure 4-9: Visual Depiction of Response Surface Optimization ............. 51 
Figure 4-10: Filament Buckling..................................................... 53

Figure 4-11: Ceramic Filament with ABS Plastic Filament as Piston ......... 54

Figure 4-12: Printed Ceramic Filament ........................................ 54

Figure 5-1: Future Steps for FDC Development ......................... 60 


\section{CHAPTER 1 - INTRODUCTION}

Ceramics have been used by humans dating back to $24,000 \mathrm{BC}$, formed and fired at high temperatures, the material has many desirable qualities (Ceramic History, n.d.). In recent years, research effort has increased to continually develop and expand the application base for ceramics due to the favorable qualities associated with this material. High strength and ability to withstand high temperatures have drawn attention to ceramics as a candidate material for success in industries such as aerospace, medical and electronics (Steyer, 2013). Further possible application of ceramics includes tooling, cores and shells used in investment casting as well as structural and functional components (Agarwala, van Weeren, Bandyopadhyay, Whalen, Safari \& Danforth, 1996). The issue with developing ceramics for these types of applications lies in the manufacturability realm due to the level of processing difficulty associated with the material. Being a brittle material with high potential to fracture, subtractive manufacturing methods have long posed issues in working with ceramics due to the hardness of ceramic, and the limitations of the shapes and forms of parts which can be made with these processes. Processing of ceramics leads to porosity which can lead to micro cracks within the part, starting on a small scale but reducing part strength and ending up as detrimental fracturing of the part (Eckel, Zhou, Martin, Jacobsen, Carter \& Schaedler, 2016). 


\subsection{Purpose of Research}

The purpose of this thesis is to try to address some of these ceramic processing limitations by exploring the use of previously untried materials in the process of Fused Deposition of Ceramics, a type of additive manufacturing. In particular, the research question is: What are the effects of combining zirconia powder and an acrylic binder system in the process of creating ceramic filaments to be used in FDC? Additionally, what are the characteristics of such filaments and are they robust enough to withstand 3D printing?

\subsection{Introduction to Additive Manufacturing}

Additive Manufacturing (AM), has been identified in recent years as a groundbreaking technology which could lead to more efficient and cost-effective methods of building small parts. General Electric (GE) is an example of a company exploring AM as a new technology, investigating producing jet engine fuel nozzles using AM rather than their traditional method of casting and welding. Some of the benefits of this alternative method for building fuel nozzles include less material waste and lighter weight parts, which in the application of aircrafts can reduce fuel consumption (LaMonica, 2013). With AM being more commonplace, many companies are beginning to design for AM rather than designing for traditional subtractive manufacturing. AM allows for more complex parts and can create part attributes such as cavities which are not possible with subtractive manufacturing methods. 
The growth of $\mathrm{AM}$ has led to the development of new methods for manufacturing ceramic parts in which the layers are built up one-by-one. AM processes such as Stereolithography and Selective Laser Sintering (SLS) which use UV and CO2 lasers respectively to sinter and solidify selectively placed ceramic powders, result in highly brittle and porous end parts with restricted part geometry and lower than desired strength (Walton, 2016). Another method of additive manufacturing of ceramics which has been investigated is the use of different combinations of materials in different extrusion heads, for example alumina and carbon black, which creates parts with more than one material and having enhanced physical properties impossible to create with traditional manufacturing processes (Gasdaska, Clancy, Ortiz \& Jamalabad, 1998). In an effort to optimize additive manufacturing techniques to make ceramic parts, another technology has become a focus in both academic and commercial research: Fused Deposition of Ceramics.

\subsection{Fused Deposition of Ceramics}

Fused Deposition of Ceramics (FDC) is a ceramic-specific version of Fused Deposition Modeling (FDM) which is shown visually in Figure 1-1 below. FDM is a 3D printing technology based on the concept of building parts layer-by-layer traditionally used with thermoplastic. The thermoplastic, in the form of a strand, is heated to a semi-liquid state and extruded through a printer head. The printer head operates in $\mathrm{X}$ and $\mathrm{Y}$ coordinates using computer controlled paths as it deposits material in single layers. When the layer is completed, the tray lowers in 
the $Z$ axis and the next layer begins. Some types of FDM printers use two types of material, a support material and a build material, while others use only a build material. Support material provides infrastructure for the part during the build and is dissolved off when the part is finished. The support material allows for printing of geometries with voids or cavities which would not be structurally possible if only the build material is being used. A major benefit of FDM technology is that it produces accurate and repeatable parts (FDM Technology, n.d.).



Figure 1-1: Fused Deposition Modeling (Source: FDM (Fused Deposition Modeling) [Diagram]. Retrieved from http://swiatdruku3d.pl/fdm-fused-deposition-modeling/) 
FDC (shown as a flowchart in Figure 1-2 below) is a ceramic-specific process based on the FDM concept. The ceramic material must first be formed into a strand to be fed into the FDM printer which requires a thermoplastic binder system requiring particular melting characteristics and physical properties. Once the strand shaped filament is created, it can be used to print green parts in an FDM printer which must be sintered at high temperatures to burn out the binder and additional components, after which, the end product is a fully processed ceramic part [Agarwala et al., 1996].

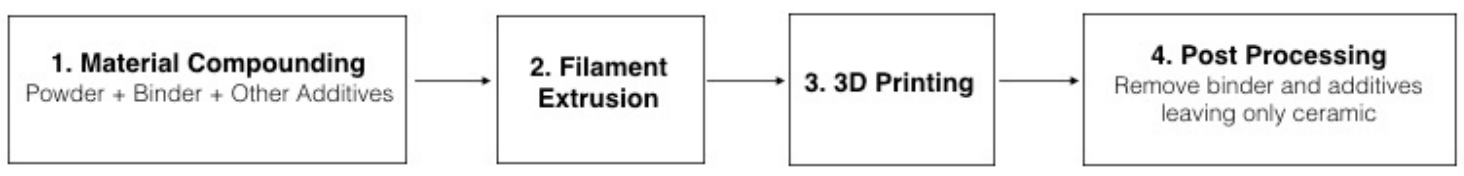

Figure 1-2: Flowchart of FDC Process

Each process step in the FDC method plays a strong role in the quality of the end part. The components chosen for the material composition as well as their proportions dictates what the structural and material properties of the part will be, for example, the mixing process directly relates to how homogenous the mixed material will be (Agarwala, van Weeren, Bandyopadhyay, Safari \& Danforth, 1996). Internal defects are a big issue with the FDC process and they result in strength limitations of the end part. Internal defects can occur due to previously 
mentioned process steps such as material composition and parameters associated with the equipment used to extrude the feedstock and print the parts (Agarwala, Jamalabad, Langrana, Safari, Whalen \& Danforth, 1996). Another hard hitting issue which is a main driver of internal defects is the constant flow of material during the printing process. If there are any gaps in the feed of material through the extrusion nozzle while the part is being printed, an air pocket will be present (Bellini, Shor \& Guceri, 2005).

\subsection{Approach}

Experiments will be set up to evaluate the feasibility of zirconia and acrylic binder in the FDC process. Properties of the produced filament will be characterized, and if successful, parts will be 3D printed using FDM technology to be compared to traditional ceramic parts.

\subsection{Issues, Assumptions, Limitations}

This experiment is being performed with existing equipment and donated materials and a small amount of funding available for purchase of new equipment and supplies. As such, it may not be possible to explore avenues which require the purchase of expensive equipment or materials especially considering the unknown effects of the chemicals being used on this equipment which would render it unusable for other applications after the experiment has concluded. Additionally, it is assumed that all materials from the suppliers are representative of the specifications reported by the suppliers, for example, ingredient compositions and particle sizes. Given that this experiment is being performed in 
the laboratories operated by the Industrial and Manufacturing Engineering

Department at Cal Poly, there is a limited infrastructure for mixing chemicals and if needed, sintering activities will have to be outsourced to a vendor due to a lack of the necessary equipment.

This document is comprised of five chapters; the introduction, a literature review detailing the research which has already been done, the design and methodology for the experimentation, the results and a summary and conclusions section. 


\section{CHAPTER 2 - LITERATURE REVIEW}

In order to fully understand the problems faced in FDC as well as the research that has already been completed in the area, a thorough literature review was conducted to include the research which has been done on the subject. This literature review section moves through the research which was conducted on each part of the experimental process: material composition, filament processing and optimization, printing the parts, post processing and measurement of the end parts.

Numerous experiments in the area of FDC have been conducted, with the majority of them concentrated at the Center for Ceramic Research at Rutgers University in New Jersey. Led by M.K. Argarwala, FDC experiments have been performed using a broad range of ceramics including Si3N4, SiO2, Al2O3, PZT, SS, WC-Co and a thermoplastic binder series developed by Rutgers called the RU binder series (1996, 1995, 1996). Also from Rutgers, McNulty, Mohammadi, Bandyopadhyay, Shanefield, Danforth \& Safari (1998) of the Ceramic and Materials Engineering Department put a twist on the Agarwala experiments and created piezoelectric ceramic devices using FDC and the same RU binder series. Similar to the experiments conducted at Rutgers were several experiments conducted at the University of Arizona led by R.S. Crockett. Crockett, O'Kelly, Calvert, Fabes, Stuffle, Creegan \& Hoffman (1995) experimented with FDC using several combinations of powders and binders: silicon nitride, alumina, SS and 
thermoplastic binder, alumina and nylon binder, silicon carbide and acrylic binder and silica and borosilicate glass objects with sol-gel solution binder. Another group at Lone Peak Engineering in Utah, Griffin \& McMillin (1995) performed FDC with alumina and a thermoplastic binder series which they created in-house. All of the research on FDC at Rutgers University, University of Arizona and Lone Peak Engineering was conducted in the late 1990s with no research from any of these sources following that time frame. Later on in the early 2000s, several experiments were conducted at Washington State University, Pullman College of Mechanical and Materials Engineering based on the Rutgers, University of Arizona and Lone Peak research. The first experiment performed by Onagoruwa, Bose \& Bandyopadhyay (2001) was an FDC experiment with mullite (a powder comprised of fused silica and titanium dioxide) and polypropylene binder. The second experiment, by Bandyopadhyay, Das, Marusich \& Onagoruwa (2006) was FDC using Al2O3 and fused silica with polypropylene-based thermoplastic binder to create metal-ceramic composite parts with increased strength. These main experiments are the basis for this thesis and will be referred to throughout the literature review and following sections, in which they will be spoken about in more detail.

\subsection{Material Composition}

The composition of the ceramic powder and binder slurry is arguably the most important aspect of the FDC process, as it has the most impact on the structural properties of the end part. When considering the material composition, it's 
necessary to think through the entire FDC process and what the role of the material needs to be for each step. Stated by M.K. Agarwala et al., there are two main objectives of the filament processing step: uniform diameter and favorable mechanical and thermal properties (1996). In order for the filament to effectively feed into the printer, the diameter must stay within $1.75 \mathrm{~mm}+/-.01$. The filament is pushed through to the extrusion nozzle by a stationary and a notched rotating wheel, so if the diameter is too big, the filament will not feed through the wheels and if it is too small it might slip through and not be gripped by the wheels. Another effect of filament diameter being less than $1.75 \mathrm{~mm}$ is an inconsistent flow rate of the melted material coming out of the extruder which leads to voids inside of the part (Agarwala et al., 1996). Buckling is a commonly seen phenomenon in the FDM process, defined as the pressure on the filament from the printing process exceeding the critical load per unit area for the filament (Venkataraman, Rangarajan, Matthewson, Harper, Safari, Danforth, Wu, Langrana, Guceri \& Yardimci (2000). Agarwala et al. also state that the filament must act as a piston for extrusion to avoid buckling. Properties of the filament which give it the ideal printing characteristics include high stiffness and strength, and low viscosity. It must also have a high flexural modulus in order to be wrapped around a spool and then unwrapped without breaking. Lastly, the material must have good adhesion behavior to ensure effective bonding between the roads and layers on the printed part (1996). 
The main components for the ceramic filament material are ceramic powder, binders, plasticizers, tackifiers, elastomers, waxes and dispersants. Several of the referenced experiments used a binder series developed by Rutgers University for the purpose of FDC. The RU binder series is comprised of $20 \%$ elastomer, $15 \%$ tackifier, $30 \%$ wax and $35 \%$ polymer. This composition is optimized with the intention of creating a filament that has the previously mentioned favorable properties for the FDM process (Agarwala et al., 1996). The binder can analogically be seen as a carrier for the ceramic powder through the formation of the part (Agarwala et al., 1995), and as such, it includes several other constituents which each play a different role in this purpose. As described by Onogoruwa et al. the base polymer, commonly polypropylene, is the "backbone" giving strength to the filament, the tackifier is what gives flexibility to the filament, the elastomer also provides flexibility as well as elasticity, the plasticizer helps enable spooling of the filament without permanent deformation and the wax reduces the viscosity (2001). The binder must encompass solidification at a particular rate to work well in the printing process. If the solidification of the binder is too rapid or too slow, the bonding of the layers within the part might be compromised and the part could be more porous (Crockett et al., 1997).

Beyond the binder composition, selection of the ceramic powder for the material composition is also integral to the quality of the end product. Maximum powder loading is ideal because when the binder is burned out, the part will maintain its 
dimensions best with the highest possible amount of ceramic powder. Griffin et al. found success in powder loading from 45-55\% (1995), while Agarwala et al. managed to reach a powder loading of $65 \%$ (1996). Measures of ceramic powder include grain surface area, chemical composition, particle size and distribution. Onagoruwa et al. advise that fine-grained and wide size distribution powders result in lower viscosity of the mixture (2001).

Mixing the compound thoroughly ensures that conglomerations of powder will be broken up and distributed evenly throughout the other components of the mixture. For all of the experiments introduced, the type of binder used required shear and heat to effectively mix. Processes for all of the previous experiments varied in their mixing procedures due to the differences in the types of ceramic powder and binder they were using. In their experiment with mullite and a polypropylene binder, Onorgoruwa et al. allowed their mixture to cool to room temperature, granulated it and used a vacuum to remove moisture (2001).

\subsection{Filament Processing}

Once the material is thoroughly compounded, it must be transformed into a form conducive to FDM 3D printer processes. FDM printers are fed continuous spools of filament with consistent diameter, and the easiest way to create feedstock of this form is to extrude it. The goal of the filament processing step is to create a continuous filament, although in the previous experiments, segments of filament had to be used because it is difficult to make a continuous strand long enough to print the entire part. Griffin et al. found that the longest continuous filaments they 
could extrude were 6 to 8 inches long due to the nature of the extrusion process (1995). Most of the experiments used a single screw extruder (shown in Figure 21 below) to perform the filament processing and some used heated extrusion, dependent on the ceramic and binder being used. In their experiment making piezoelectric ceramic devices, McNulty et al. extruded 20-inch filament segments at $100^{\circ} \mathrm{C}(1998)$ while Onogoruwa et al. extruded at $160-170^{\circ} \mathrm{C}$ for their mullite experiment (2001). Extrusion temperature is a factor of the viscosity of the material compound and would likely require experimentation to see how it affects any given combination of powder and binder.

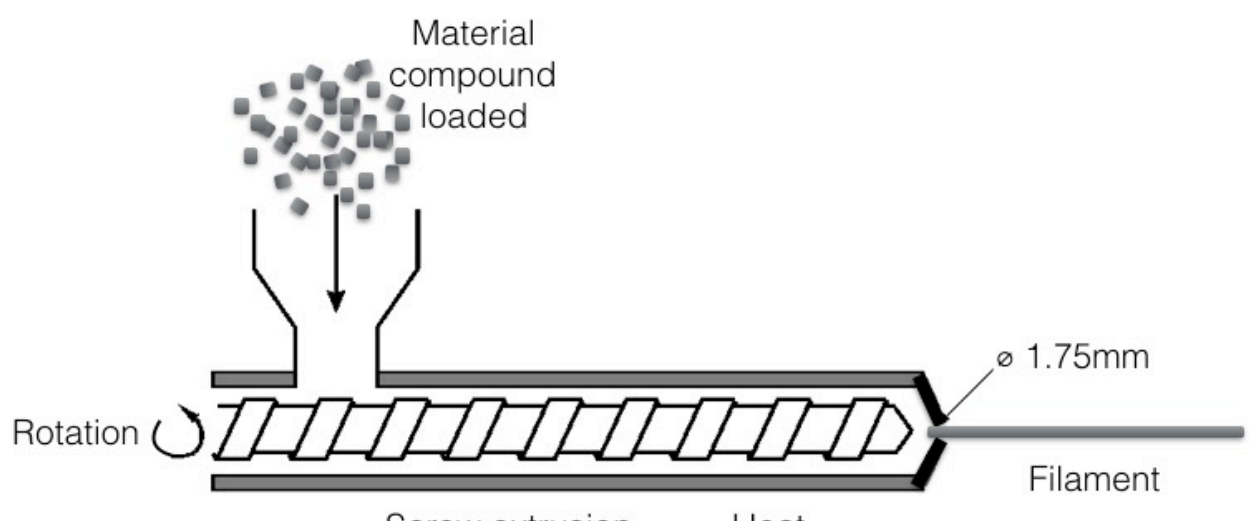

$$
\text { Screw extrusion Heat }
$$

Figure 2-1: Filament Extrusion Process

Due to FDM printers' sensitivity to changes in diameter, it is vital that the hole through which the filament is extruded is exactly $1.75 \mathrm{~mm}$ so the diameter of the filament will be precise. Some of the experimenters allowed the filament to hang down as it extruded, while others handled it more delicately by fashioning a 
conveyor belt to carry the extruded filament which moved at the exact same rate as extrusion. Once the segments of filament are extruded, they can be trialed in the FDM printing process.

\subsection{D Printing}

There are some commonly used FDM terms which will appear in this paper relating to the way that material is deposited to create the part. "Roads" refer to the material paths deposited by the printer head which must adhere to the already deposited material underneath them as well as the roads laid next to them (Boschetto \& Bottini, 2014). The first area of focus on 3D printing literature encompasses basics about how settings for the equipment impact the end part and best printing practices, and the second area of focus is how past experimenters printed parts with their ceramic filaments.

\subsubsection{Best Printing Practices}

Kantaros \& Karalekas (2013) investigated residual strains in parts produced with FDM technology and found that different process parameters such as layer thickness and build orientation had an effect on the induced strains in the part. Residual stresses and strains build up during the extrusion process and this can lead to cracking or delamination within the individual layers. Additionally, the material is rapidly heated and then cooled down throughout the process which creates an uneven temperature gradient and can lead to distortion and dimensional inaccuracy within the object. Such implications lead to the conclusion that the mechanical properties of parts produced with FDM 
technology are influenced by the material they are made of in addition to the build parameters by which the machine builds them. As shown in Figure 2-2 below, the group observed that the magnitude of residual strains on an object was greater with a greater layer thickness. A part with a smaller layer thickness results in a smaller air gap and therefore has a stronger bond can withstand forces more effectively than parts with greater layer thicknesses. In terms of orientation, they found that in most cases, parts printed longitudinally had lower magnitudes of residual strains than those printed transversely or with a crosshatching pattern. Given the high risk of voids within FDC parts due to the discontinuous filaments and changes in diameter, any effort to reduce air gaps and increase the strength of parts helps. By reducing layer thickness and printing parts longitudinally in the FDC process, parts could see lower levels of residual strain.

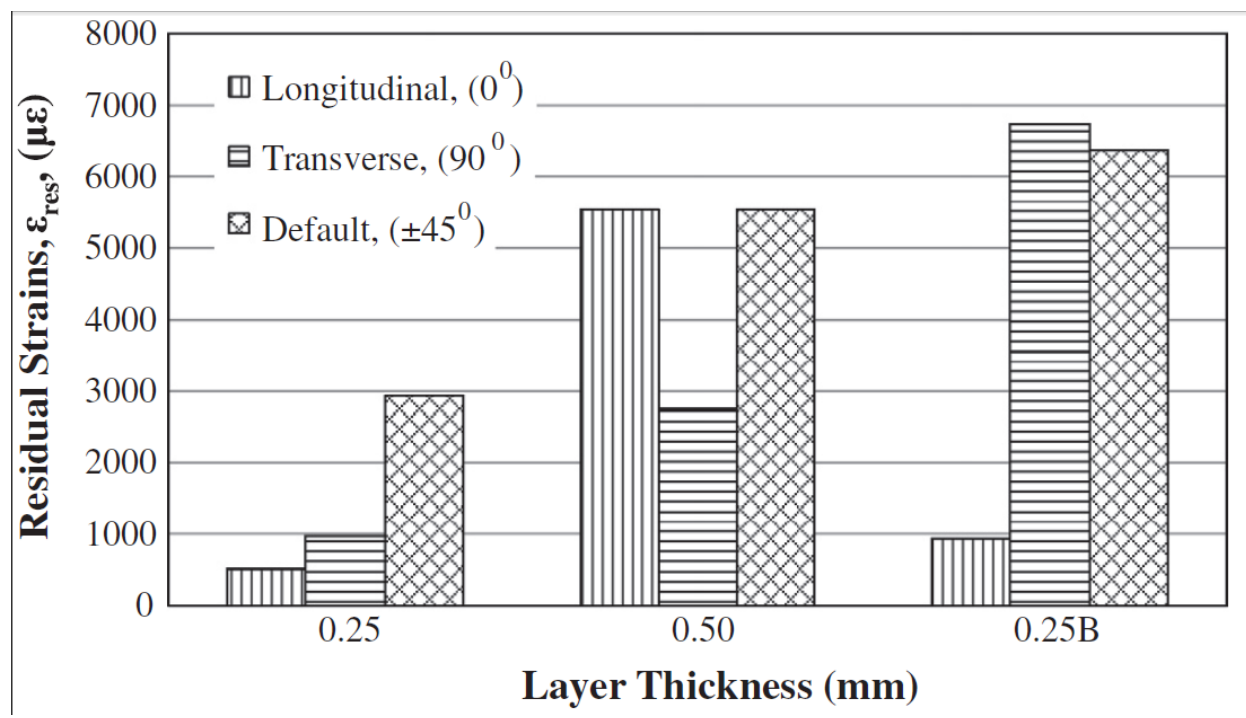

Figure 2-2: Strains Associated with Printing Patterns (Source: Kantaros \& Karalekas, 2013) 
Smith \& Dean (2013) performed a similar study to determine how print orientation affects the strength of a part. Since FDM technology prints one layer on top of another, the part's weakest points are between the layers. Tensile test bars were printed to be pull tested to determine their peak stress. Printing a thin strip from bottom to top in an upright orientation creates very low strength to resist the force from the pulling apparatus. Printing the part lying flat, face up, results in the layers lining up in the opposite direction of the force from the pulling apparatus and this turned out to be true in the actual tests. Visual representations of the three build orientations are shown in Figure 2-3 and stress-strain curves from the tensile testing can be seen in Figure 2-4. The ultimate tensile strength of the upright specimen turned out to be 20.6 MPa compared to $35.7 \mathrm{MPa}$ for the specimen that was printed face up on the tray. The measurement of Young's Modulus shows a similar relationship with $1373 \mathrm{MPa}$ for the upright specimen and $1576 \mathrm{MPa}$ for the face-up specimen. A higher Young's Modulus value translates to a stiffer or more rigid part in relation to the direction of the force acting on it. The Young's Modulus is greater for the part that was printed lying face up because the pulling forces are in the opposite direction of the "grain" or tool path. This knowledge is helpful to determine in which orientation to print a parts based on the predicted stresses it will encounter. 

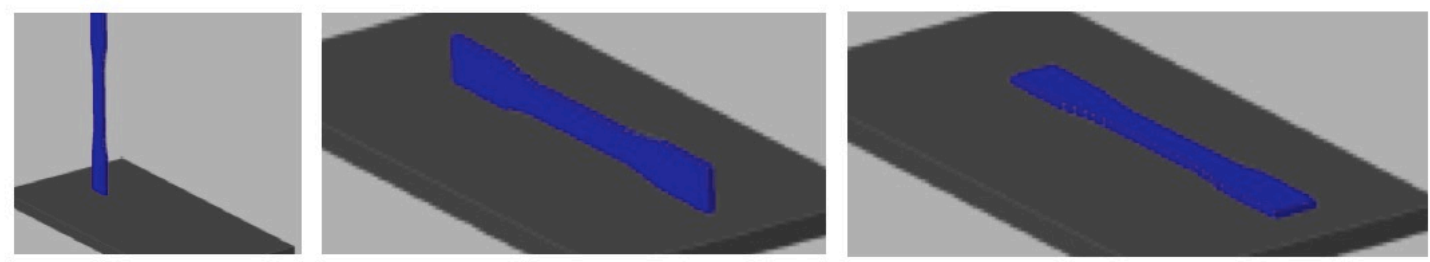

Figure 2-3: Build Orientations Upright (left), Side Up (middle), Face Up (right) (Source: Smith \& Dean, 2013)

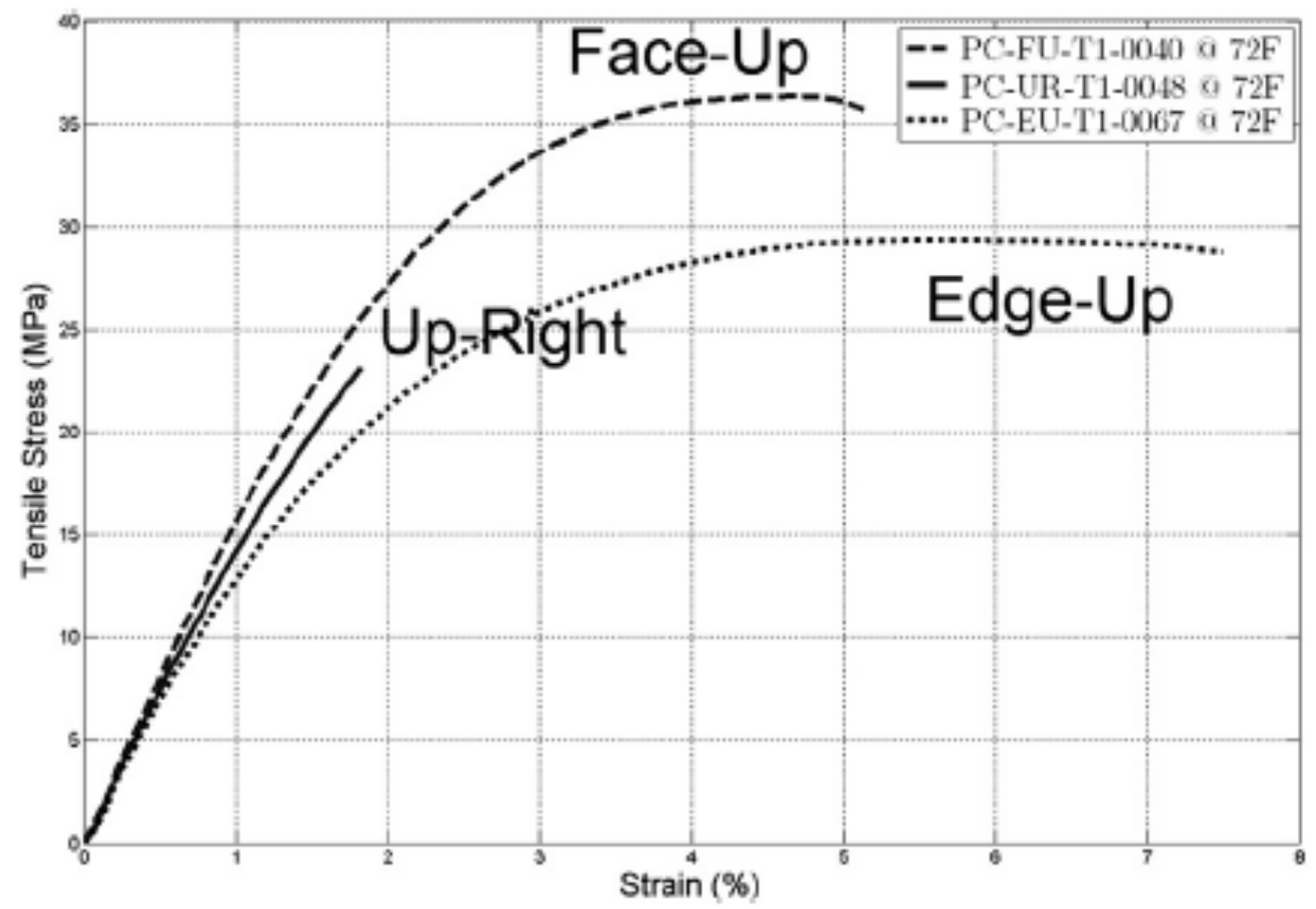

Figure 2-4: Stress-Strain Curves by Print Orientation (Source: Smith \& Dean, 2013)

\subsubsection{Printing with Ceramic Filament}

When it comes to printing with ceramic filament, there are added complications due to the FDC process. There are established settings for parameters of the FDM process such as temperature, flow rate and layer thickness for commonly used materials, but for FDC, usually these settings are unknown and vary by 
material composition. Agarwala et al. optimized these parameters by feeding a small segment of filament into the printer and experimenting with different levels of the settings until the resulting paths created by the printer head looked right (1996). Another issue is that filaments are not continuous, but instead in segments, which introduces the risk of air gaps between two segments being fed into the printer. When the air gap reaches the hot end, there is a brief moment when material is not being dispensed but the printer head is still moving through the path building the part and the result is an internal void in the part (Bellini et al., 2005). Keeping the segments in contact as they are fed into the printer can eliminate this type of defect.

\subsection{Post Processing}

After the FDC part is printed, it is comprised of ceramic powder, binder and small amounts of organic components, so the next step of the process is to remove the binder to leave a fully ceramic part. The goal of the post-processing of the part is to remove the additional components without damage to the structure and without leaving any residue of the organic components (Agarwala et al., 1995). There are two steps to the post processing of FDC parts: debinding and sintering. Debinding is also referred to as Binder Burn Out (BBO) and essentially uses thermal degradation to remove the binder from the composition of the part. Parts are placed on a bed of charcoal, alumina or another material and then heated slowly over several hours in nitrogen or air depending on what type of ceramic is being used (Agarwala et al., 1996). The required temperatures and 
heating times are specific to the binder system, but for example, McNulty et al. heated their piezoelectric ceramic devices on a bed of $\mathrm{PZT}$ granules at $30^{\circ} \mathrm{C}$ per hour up to $500^{\circ} \mathrm{C}(1998)$. Once the debinding step has been completed, the part is sintered. Sintering is the process which transforms a green ceramic part into a solid part by fusing particles together. Sintering is performed at a temperature below melting temperature and hardens and strengthens the part (Sintering in the Powder Metallurgy Process, n.d.). Like the debinding parameters, sintering parameters depend on the materials being used but the sintering temperatures

are much higher than debinding temperatures. For example, Griffin et al. sintered their alumina parts at $1550^{\circ} \mathrm{C}$ for two hours (1995). Once these post-processing steps have been performed, solid ceramic parts have been created and are comparable to ceramic parts created using traditional ceramic processing methods.

\subsection{Results}

Once the FDC parts have been created, their characteristics must be measured. The experimenters who completed work with FDC in the past approached measurement of the parts differently and also shared discoveries they made about the types of defects seen in FDC parts due to the process.

\subsubsection{Measurement Methods}

Fodran et al. (1996) detail several measures of FDM parts which are commonly used for ABS plastic parts but could be translated over to FDC parts made of ceramic. Tensile bar testing is one of the most obvious and could be used to 
determine the peak stress $(\mathrm{MPa})$ of the part. Other measures include the fracture stress $(\mathrm{MPa})$ and elongation at fracture $(\mathrm{mm})$. Vaidyanathan et al. also suggested some measures of final parts including a four-point bend test which was used to determine flexural strength, and a single edge notched beam to determine fracture toughness (2000). Both of these tests would yield valuable information, as the flexural strength and fracture toughness are telling of the strength of ceramic parts as well as how brittle they are.

McNulty et al. approached strength measurement differently in their experiment with piezoelectric ceramic devices. Rather than measuring only strength of the finished parts, they performed tensile testing on the filament material to determine the peak stress and used this information in their binder down selection process (1998).

With FDC parts it's also important to consider the change of the part due to removal of the organic materials during post-processing. Total density, weight loss, porosity and linear shrinkage are all measurements which can be taken before and after post-processing to characterize how the part is changed. Griffin et al. found values of $96 \%$ total density, $15 \%$ weight loss and $3-5 \%$ porosity for their piezoelectric ceramic devices. With the total density requirement of a structural ceramic part being around $90 \%$, their parts could be used in structural applications (1995). Agarwala et al. emphasized their linear shrinkage measurements because dimensional accuracy is an important aspect of manufacturing and shrinkage due to the post-processing methods is a concern. 
They found linear shrinkage of $8-12 \%$ but managed to end up with all of their part dimensions within $1 \%$ of the original design, showing that it is possible to make dimensionally accurate parts using FDC (1995).

\subsubsection{Part Defects}

There are several types of visual defects due to the FDM printing process. The first is the "staircase effect" which essentially looks like steps along the curved surfaces of the part. The staircase effect can be avoided by reducing the layer thickness which will show less drastic, and thus less noticeable layers, shown in Figure 2-5 (2001).
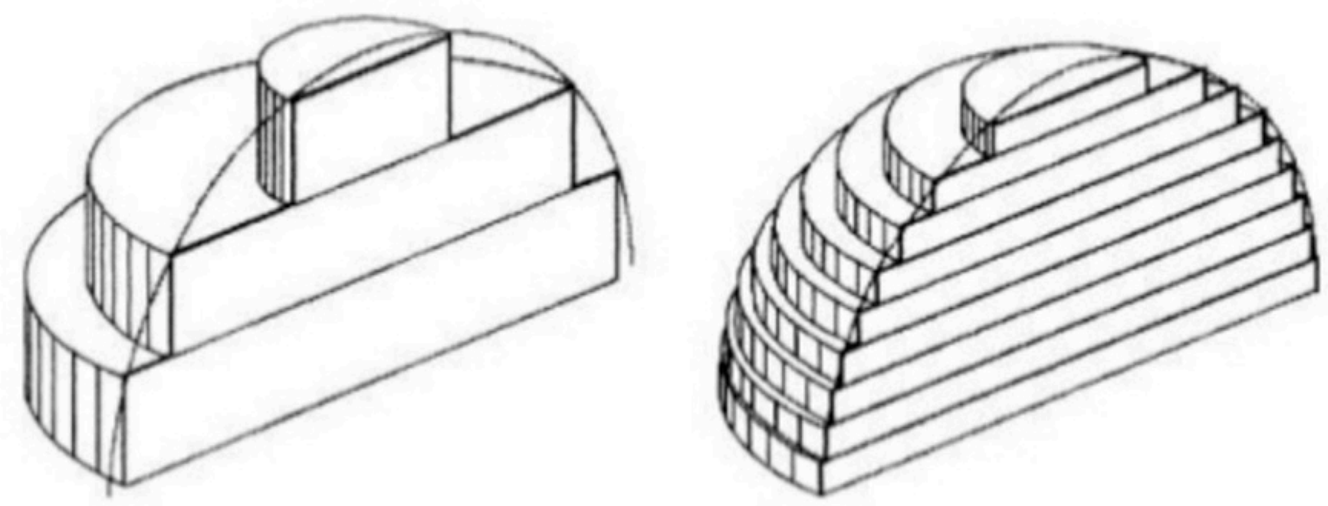

Figure 2-5: Staircase Effect with Different Layer Thicknesses (Source: Sabourin, Houser \& Bohn, 1997)

Another defect commonly seen in FDM parts is the "chordal effect" (Figure 2-6) which looks like triangles on curved features of a part. Usually increasing the quality of the part file sent to the printer smooths out these defects. Lastly, voids within the part are common and can be mitigated with different settings of the printing process. Using a negative offset can ensure that the "roads" of material 
being laid down are touching. Flow rate can also be increased to ensure that the roads are filled in enough to contact those next to them (Onagoruwa et al., 2001).

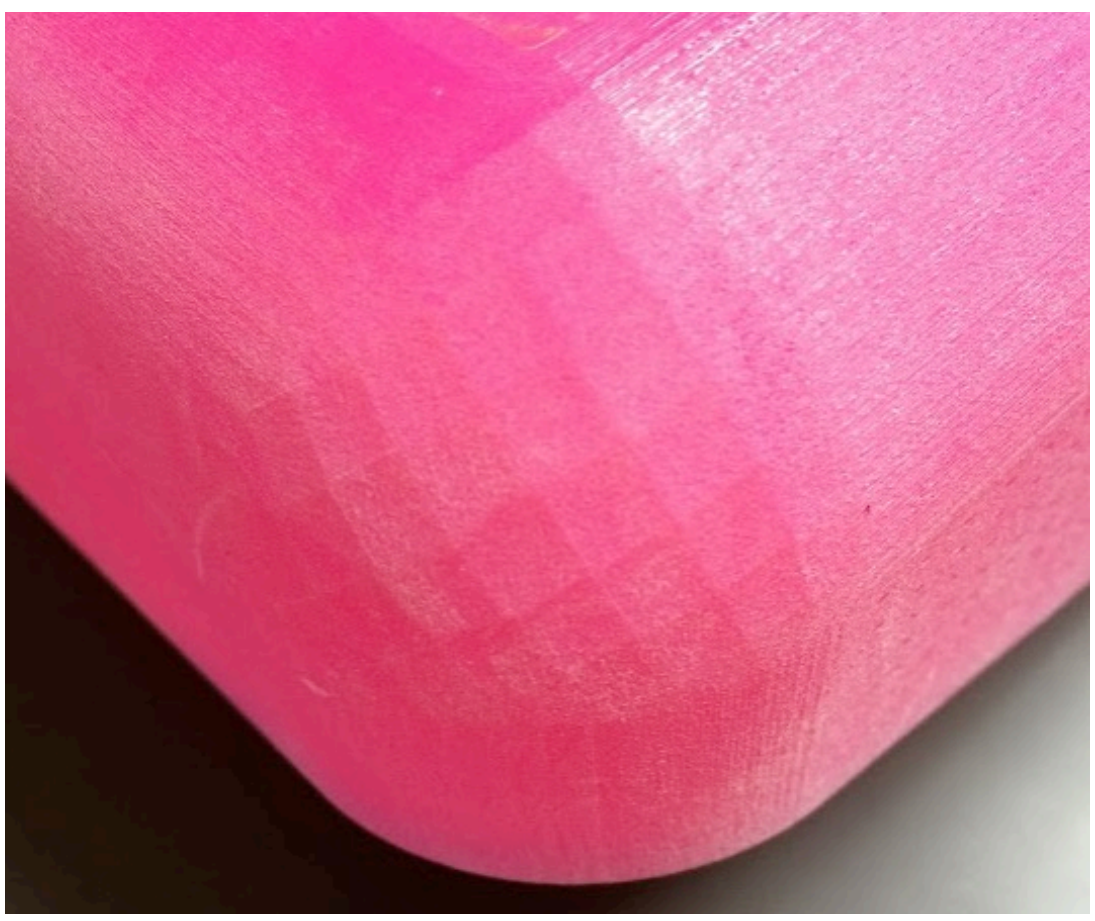

Figure 2-6: Chordal Effect on Rounded Surface 


\section{CHAPTER 3 - DESIGN \& METHODOLOGY}

The goal of the experiment was to create a high strength filament of consistent diameter and test it in an FDM printer system to assess the feasibility of printing parts with it.

\subsection{Material Selection}

There were two categories of materials to be selected for the experiment; the binder and the ceramic powder. As mentioned in the literature review, the materials which go into the compound greatly influence the quality of the end part. Research from the literature review as well as advice from the material suppliers went into choosing the materials to be used in the experiment.

\subsubsection{Binder}

The majority of the previously performed experiments introduced in the literature review used polypropylene or similar thermoplastic binders and a variety of different types of ceramics. Many mixed their own binders, such as the RU binder series developed at Rutgers University. Mixing chemicals to this extent requires expensive dedicated mixing equipment and laboratory space with the proper ventilation for these processes. Due to University restrictions and issues with getting access to laboratories and equipment not directly within the ownership of the Engineering College, some ready-made acrylic binder products produced by Dow were identified as good candidates for the experiment as shown below in Table 3-1. Crockett et al. found favorable results making parts using acrylic binder and silicon carbide (1995). These acrylic binders do not require heat to be 
mixed with ceramic powders like some of the other thermoplastic binders used by the experimenters in the literature review did, making the mixing equipment requirements much more simple and cost effective. Three acrylic binder products were recommended by Dow for the application: HA-12, B-1022 and B-1000, which have varying viscosities and glass transition temperatures. These three products are acrylate emulsion polymers, a type of transparent thermoplastic which is elastic and resistant to breakage. The products are designed to enhance the green strength and flexibility of ceramic parts.

\subsubsection{Ceramic Powder}

As mentioned in the literature review, fine grained and wide size distribution are favorable qualities for the ceramic-binder slurry used in FDC. Previous experiments conducted on the subject of FDC used a variety of ceramics but none had tried zirconium oxide ( $\mathrm{ZrO} 2)$, also known as zirconia, despite its favorable properties and wide range of applications. Zirconia is very tough, resists fracture, is wear resistant and withstands temperatures up to $2400^{\circ} \mathrm{C}$. Zirconia has a much lower thermal conductivity than other ceramics such as alumina (Zirconium Oxide: ZrO2 Ceramic Properties, 2013). One of the most favorable qualities of zirconia as compared to other ceramics, especially in the space of FDC, is its high crack propagation resistance. Since many FDC process parameters already yield high likelihood of internal fracture, any level of heightened resistance to fracture is an improvement. The most common applications include dies, fuel cell membranes, cutters, dental ceramics, pipes, 
rings and bearings (Oxide Ceramics: Zirconium Oxide (ZrO2), n.d.). The Tosoh zirconia powder which was selected for the experiment has a fine grain of $40 \mathrm{~nm}$ and a wide size distribution in addition to being an easily sintered grade (Advanced Ceramics: Zirconia Powders, n.d.)

As a secondary ceramic to explore and compare to zirconia, aluminum oxide (Al2O3), also called alumina, was selected. Alumina is inexpensive and had successfully been used in several of the past FDC experiments. Alumina is also hard and wear resistant, but in contrast to zirconia, it's thermally conductive. There are endless applications for alumina, but some of the most common are circuit boards, heat sinks, medical implants and seal rings (Aluminum Oxide: Al2O3 Ceramic Properties, n.d.). The alumina powder selected for the experiment was from Alcoa and was a fine grained grade.

\subsubsection{Preliminary Material Selection}

Table 3-1 summarizes the candidate binders and powders selected for the experiment and their important specifications. 
Table 3-1: Preliminary Material Selection

\begin{tabular}{|c|c|c|c|c|c|}
\hline & \multirow[t]{2}{*}{ Manufacturer } & \multirow[b]{2}{*}{$\begin{array}{l}\text { Viscosity } \\
\text { (cP) }\end{array}$} & \multirow[b]{2}{*}{$\operatorname{Tg}\left({ }^{\circ} \mathrm{C}\right)$} \\
\hline & & & & & \\
\hline \multirow[t]{3}{*}{ Binder } & HA-12 & Acrylic Polymer & \multirow{3}{*}{$\begin{array}{l}\text { Dow Chemical } \\
\text { Company }\end{array}$} & $100-750[1]$ & 19 [1] \\
\hline & B-1022 & $\begin{array}{l}\text { Styrene/Acrylic } \\
\text { Copolymer }\end{array}$ & & 400 [2] & 39 [2] \\
\hline & B-1000 & Acrylic Polymer & & $<140[3]$ & $-26[3]$ \\
\hline & & & & $\begin{array}{l}\text { Particle } \\
\text { Size }(\mathrm{nm})\end{array}$ & \\
\hline \multirow{2}{*}{$\begin{array}{l}\text { Ceramic } \\
\text { Powder }\end{array}$} & TZ-3Y-E & $\mathrm{ZrO} 2$ & Tosoh & 40 & \\
\hline & A-16SG & $\mathrm{AlO} 2$ & Alcoa & 30 & \\
\hline
\end{tabular}

\subsection{Equipment}

Equipment used in the experiment included a material mixing set-up with ventilation, a filament extruder to transform the mixed material into filament for the printing process and a FDM simulation system to assess the feasibility of printing the ceramic material.

\subsubsection{Material Mixing Set-Up}

The material compounding set-up (Figure 3-1) was comprised of a mixing bowl and spatula which was set on a scale to measure material quantities by weight. All mixtures were compounded by hand consistently for four minutes to ensure that the ingredients were fully incorporated. Mixing was performed inside an air filtration chamber (Figure 3-2) to ensure that no harmful fumes were inhaled or introduced into the lab environment in the process. 


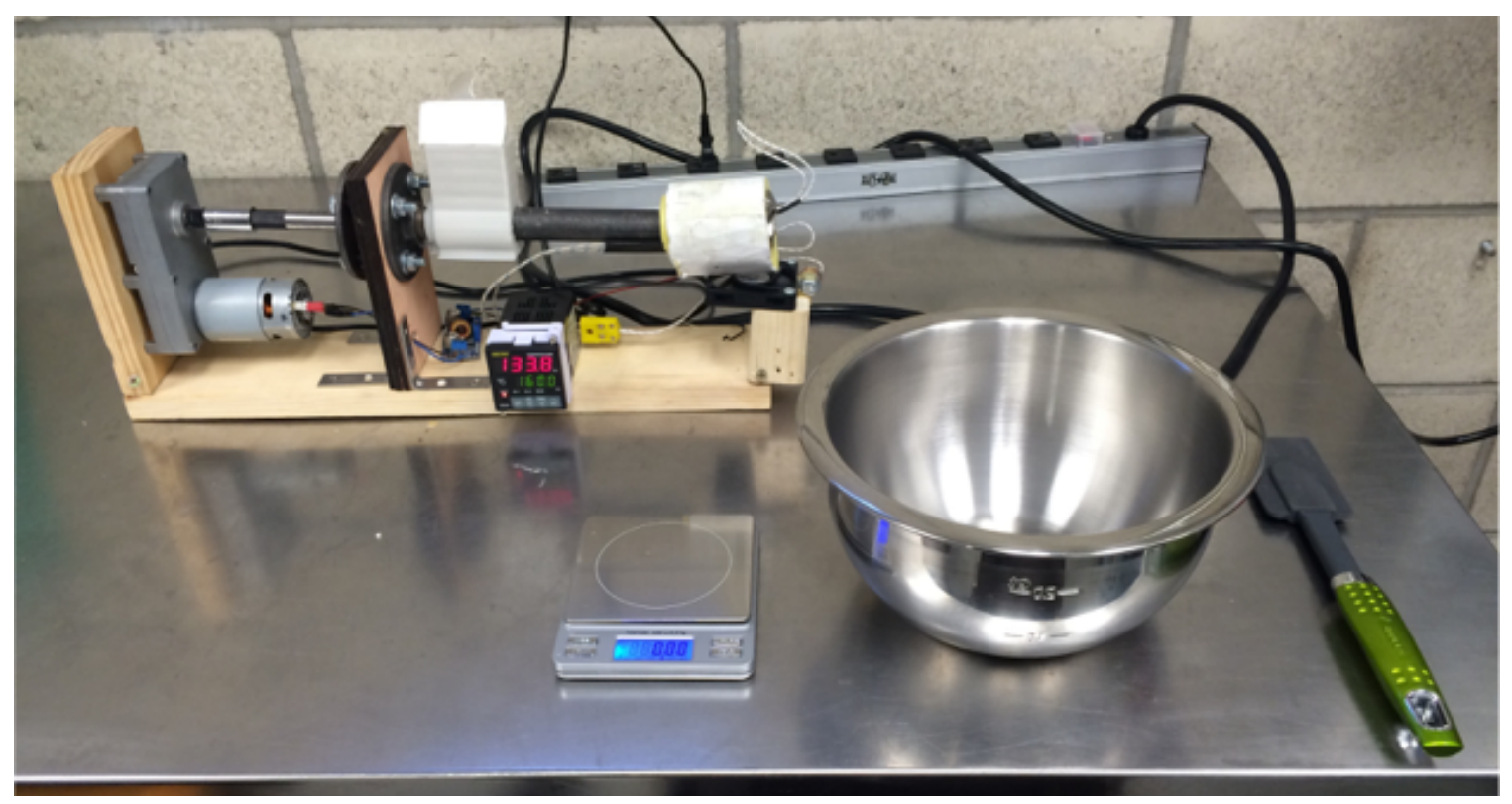

Figure 3-1: Material Compounding Set-Up

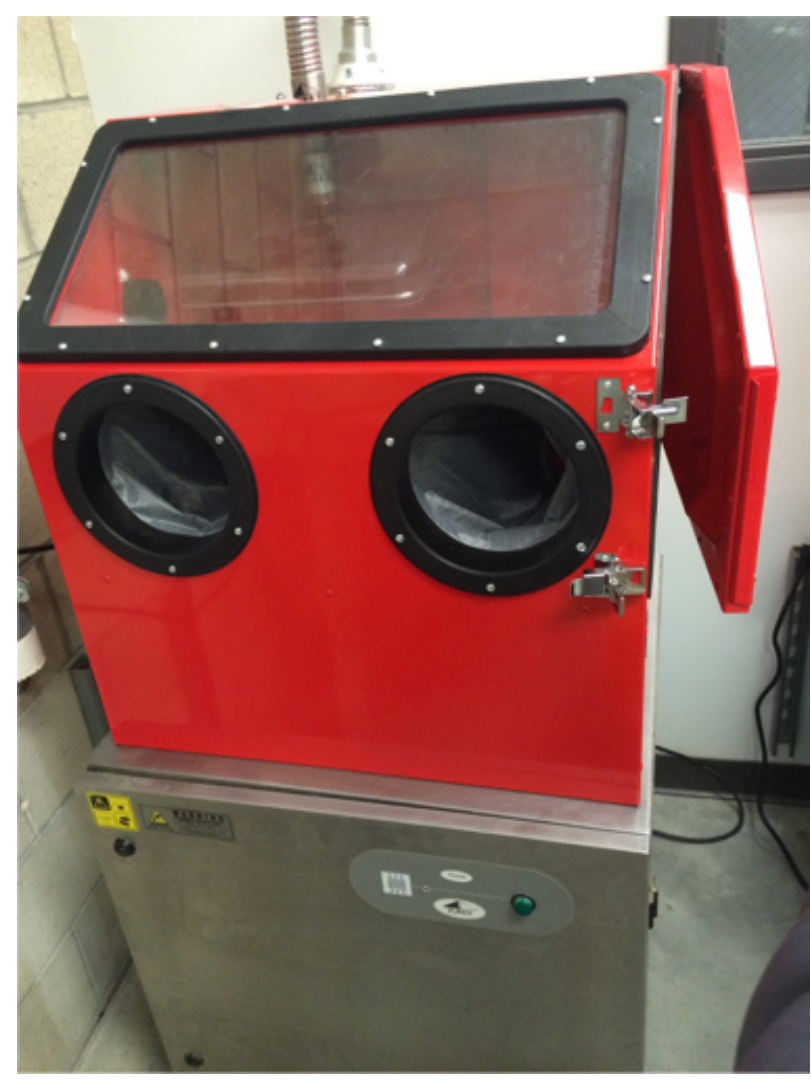

Figure 3-2: Air Filtration Chamber 


\subsubsection{Extruder}

The filament extruder used in the experiment was a product called the Filastruder (Figure 3-3), made for people who intend to create their own FDM filament rather than purchasing it by the spool. Material is fed into the top of the shaft through the hopper and a gear motor drives a screw thread which carries the material toward the heated extruder end. The extruder end heats up to about $240^{\circ} \mathrm{C}$ at maximum and the filament is extruded from it. The filastruder has the capability of extruding at room temperature or with increased heat allowing the flexibility needed for this experiment, given the unknowns about how the material would react and how extrusion temperature would affect the quality of the filament.

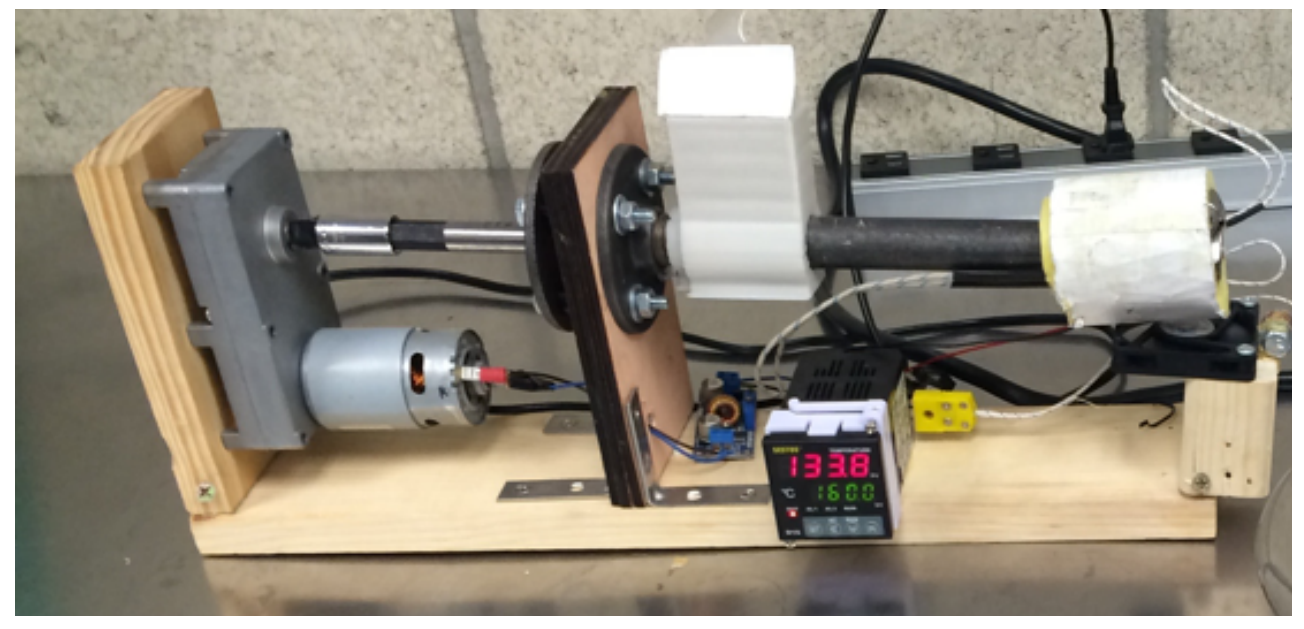

Figure 3-3: Filastruder Used to Create Filament

\subsubsection{FDM Simulator System}

It was difficult to anticipate how the material would impact the equipment, so rather than risk damaging one of the existing FDM printers which are quite expensive, an FDM simulator system (Figure 3-4) was built for the purpose of 
determining whether the filament was feasible for the process. The FDM simulator system was comprised of two notched wheels, on stationary and one which rotated powered by a stepper motor and fed the filament into the system toward the hot end (Figure 3-5). The system used two Arduino boards, one controlling the stepper motor and the other using a running control algorithm to drive a ceramic resistive heating element. The ceramic heating element used a thermistor as the feedback loop variable with PID control to calculate an error value between the temperature set point and the measured temperature.

Settings including temperature and feed speed were changed using Arduino software on a laptop (Figure 3-6). The hot end is the component of the FDM system where the material's melting characteristics are assessed and technical difficulties such as clogging of the print head would occur, so it's the best part of the system to use to assess overall feasibility.

\section{Rotating notched wheel powered}

by stepper motor feeds filament to

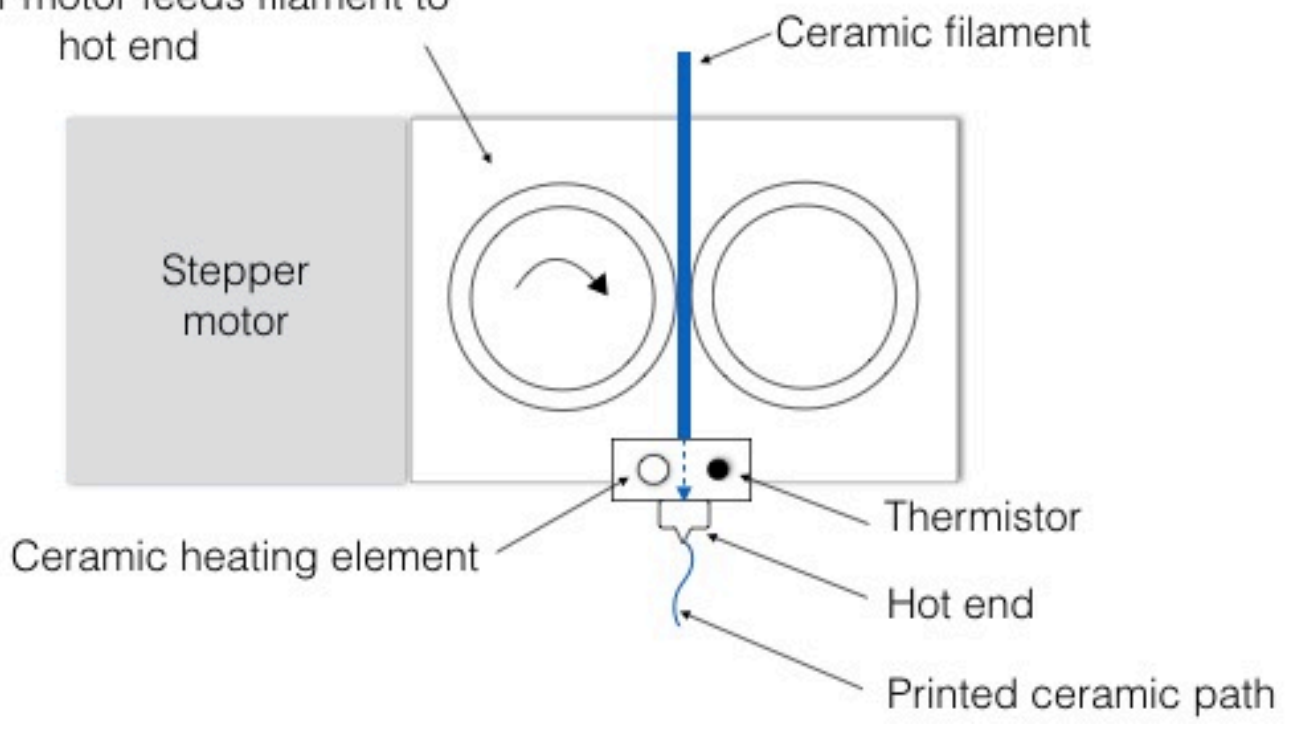

Figure 3-4: FDM Simulator System 


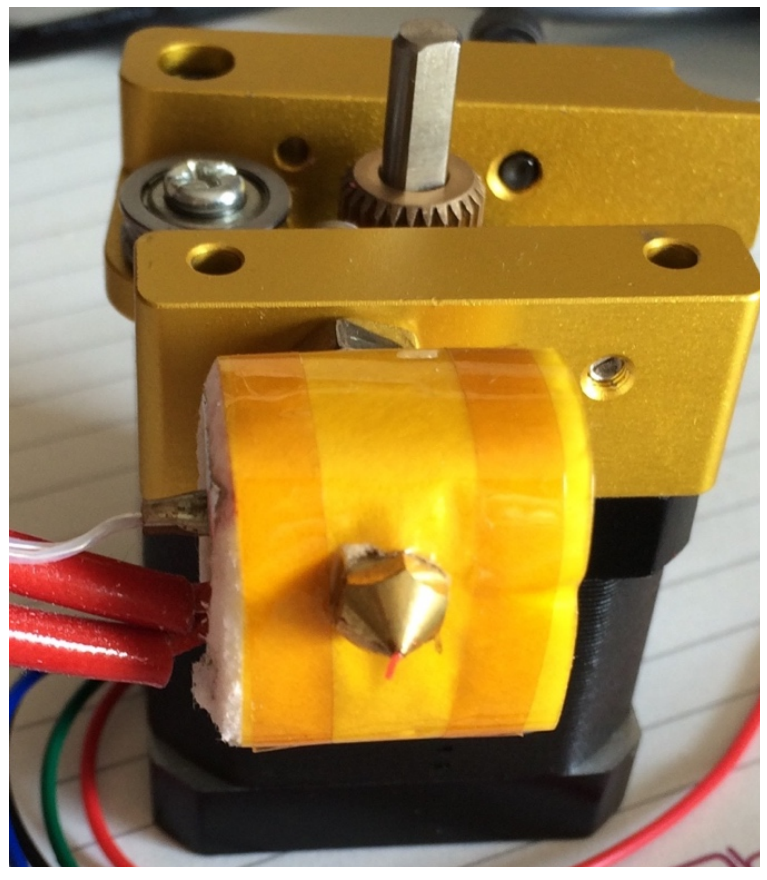

Figure 3-5: Hot End

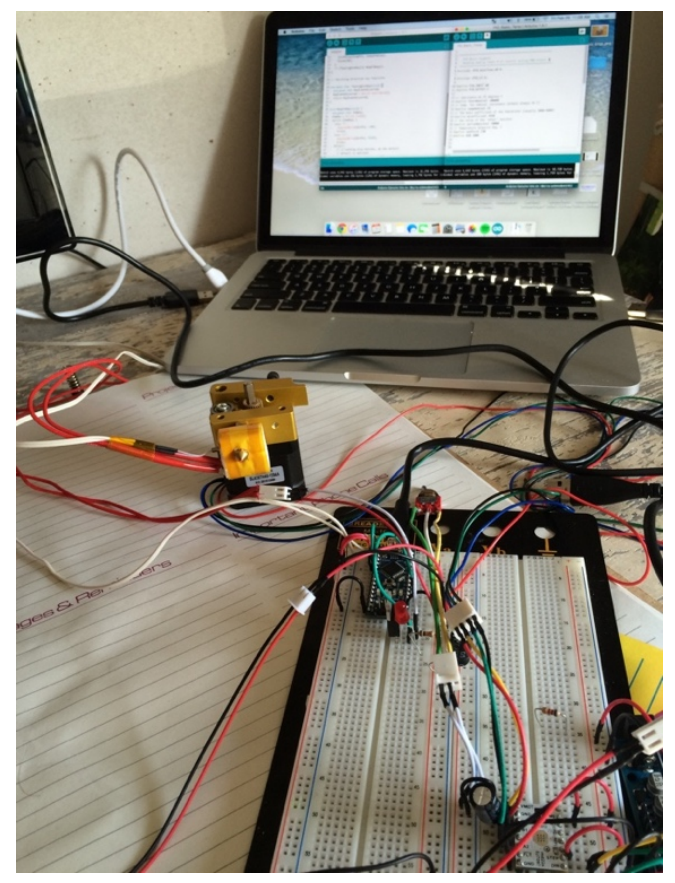

Figure 3-6: FDM Simulator System SetUp

\subsubsection{Equipment Trials}

Given that equipment which is traditionally used for FDM printing is usually used for ABS or PLA plastics, trial runs were performed with the Filastruder and the FDM simulator system to ensure that they functioned properly. ABS filament was produced with the Filastruder and diameter measurements were taken, revealing that the filament was within the necessary diameter specification for use in an FDM system. After the FDM simulator system was built, ABS filament was fed through and a print simulation was performed. Parameter controls including temperature and flow rate were tested and ABS was successfully "printed" from the hot end. 


\subsection{Feasibility Trials}

Upon receiving the binder and ceramic powder products, preliminary mixing was performed to see what the physical form of the mixture would be with different levels of each constituent. Since there was no past experimentation with the binder products used, there wasn't any way to predict how thick the mixture would be or how it would behave. Research and product instructions gave rough ranges for the weight percent of each component (Table 3-2).

Table 3-2: Material Composition

\begin{tabular}{|l|l|l|}
\hline Component & Weight \% & Source \\
\hline Ceramic Powder & $50-60$ & Comparable Experiments (Literature Review) \\
\hline Dispersant & $1-2$ & $\begin{array}{l}\text { Product Instructions } \\
\text { (Rohm and Haas Company, DURAMAXTM D-3005 } \\
\text { Dispersant Technical Data Sheet, 2008) }\end{array}$ \\
\hline Water & $2-3$ & Product Instructions \\
\hline Binder & Varies & Based on the other component values \\
\hline
\end{tabular}

Mixtures were made with the three different binder products and varying amounts of the other constituents and spread out on foil. The mixtures were left to dry overnight to see if they would change significantly.

In order to design the experiment, the next step was to determine which of the mixtures possessed the right qualities to be used with the filastruder. Given that the material would need to travel through the shaft on the rotating screw thread 
without sticking to it, it needed to be more solid than liquid. As can be seen in Figure 3-7 below, the HA-12 binder solidified and caused the foil to warp. The resulting material was extremely tough but bendable, and unable to be peeled off of the foil. HA-12 was determined to be unfeasible because it would have hardened on the inside of the filastruder and been too difficult, or maybe impossible to remove. Additionally, the rapid hardening of the material would have been a difficult to control factor with the temperature gradients inside the equipment and changing environment in the lab.

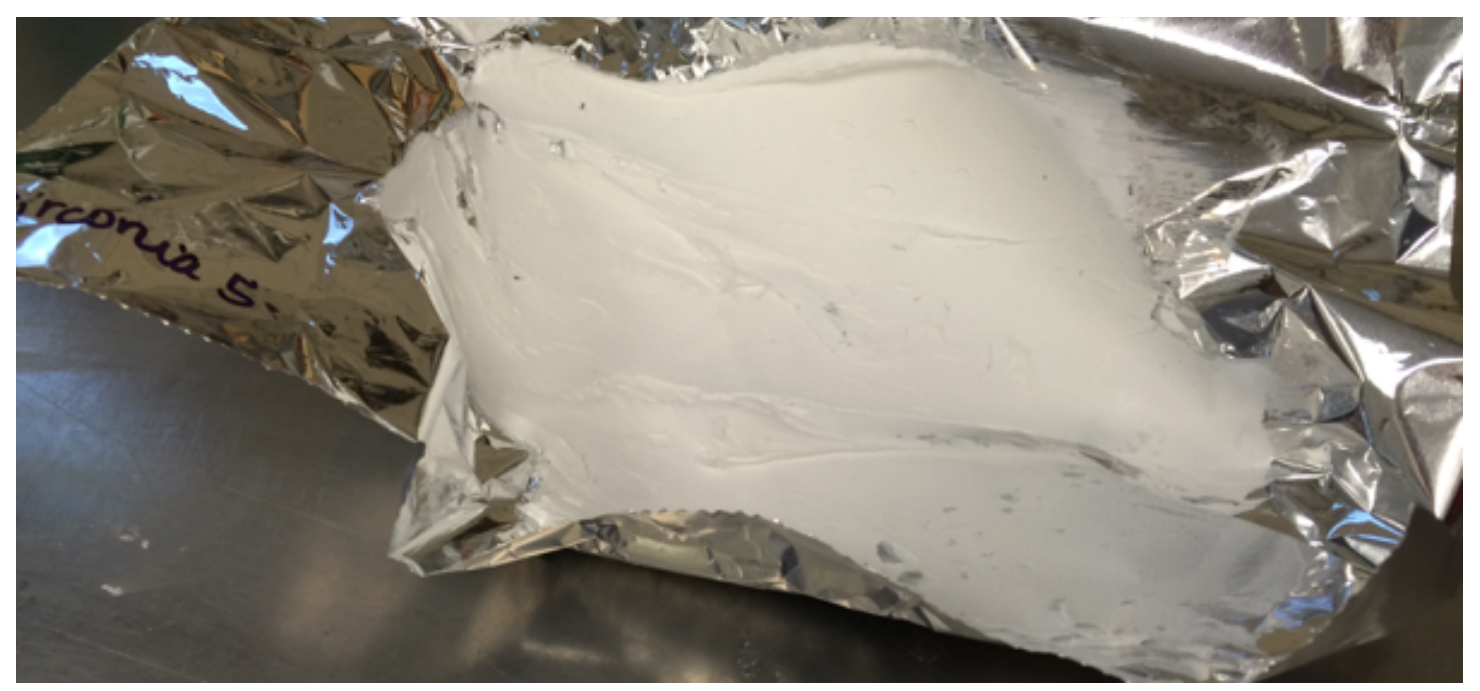

Figure 3-7: HA-12 with Zirconia

The next binder, B-1022, hardened on the foil but cracked (Figure 3-8). The material was easily peeled from the foil but immediately crumbled into a powder. B-1022 was also determined unfeasible because the filament must be strong and not break easily. 


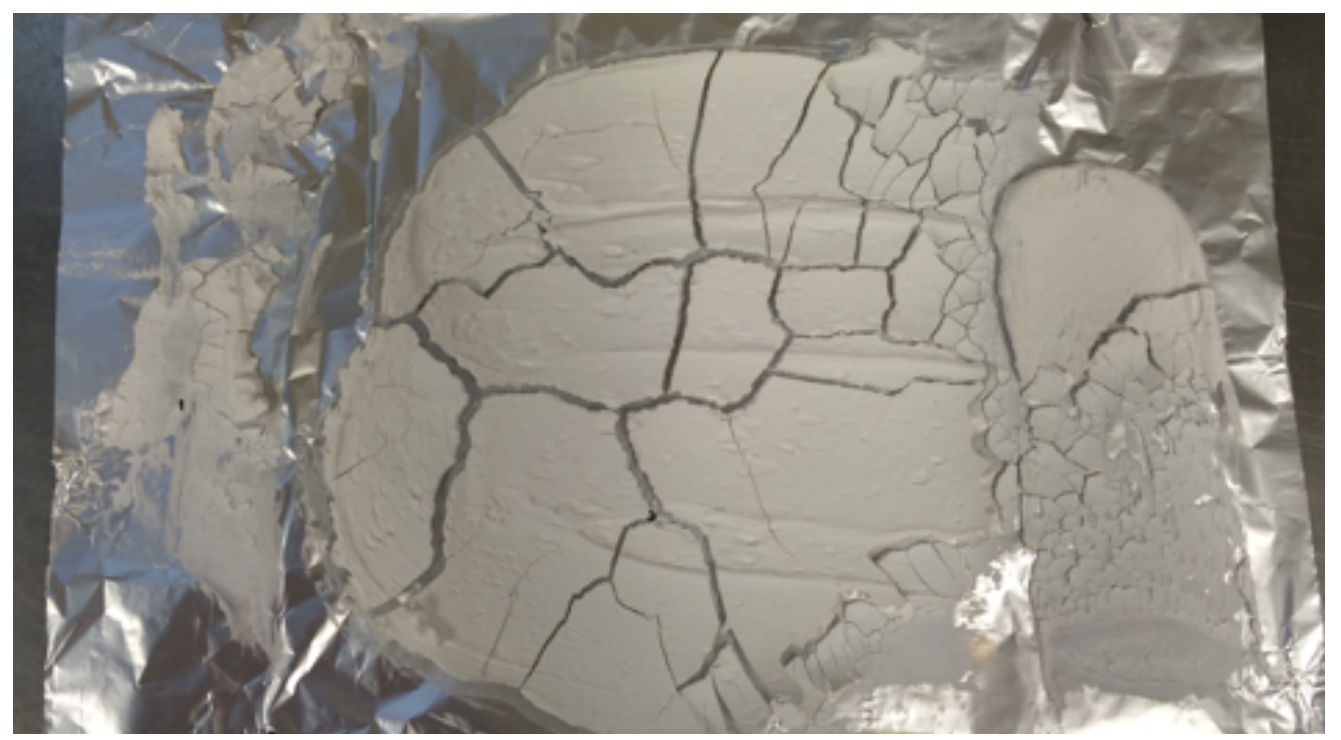

Figure 3-8: B-1022 with Zirconia

The third binder, B-1000, resulted in mixtures which never actually hardened.

The materials were spongy and elastic which were similar to the consistency of paste when there was less powder load, and tended to get clumpy with more powder load (Figure 3-9). Out of the available binder products, B-1000 seemed the most feasible for use with the Filastruder.

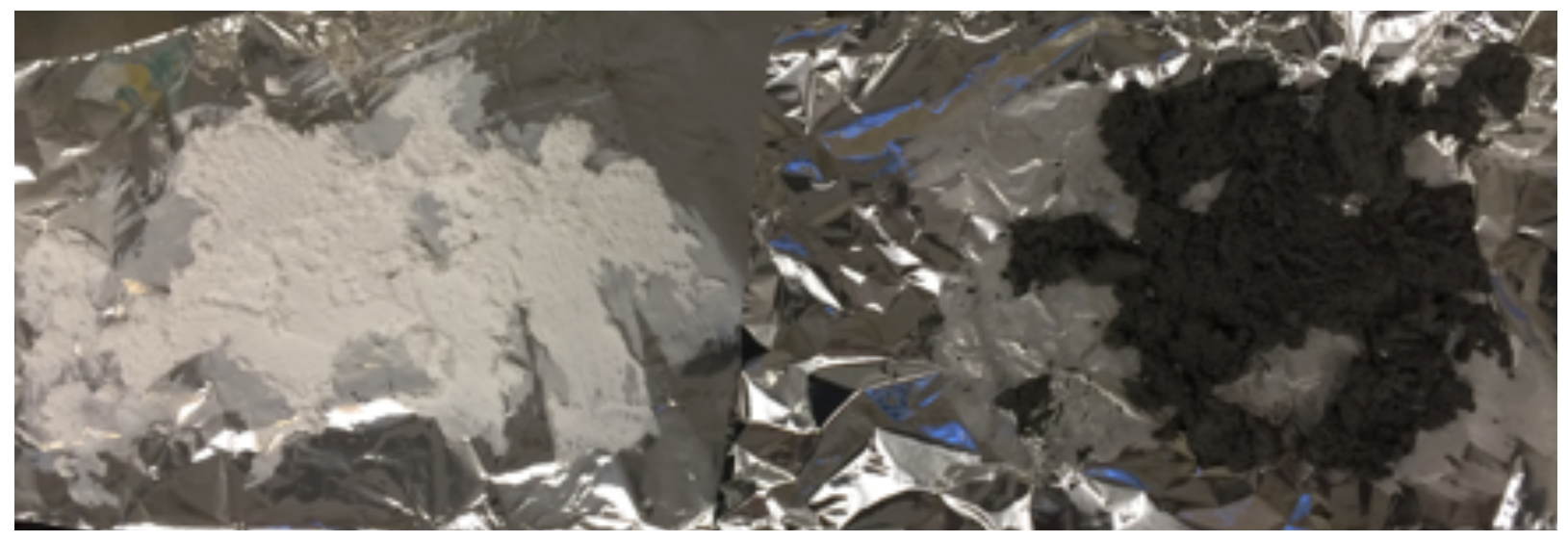

Figure 3-9: B-1000 with Zirconia (left) and Alumina (right) 
After it had been determined that B-1000 was the most feasible binder to make filament with, a few trial runs of the mixture through the filastruder were performed. It was discovered in the initial equipment trials that the only way to purge all of the material out of the filastruder is to disassemble it and clean off the parts, which was a time consuming step between material runs but ensured that there was no contamination of the equipment from previous runs. Several compositions of both zirconia and alumina with varying amounts of dispersant, water and binder were fed through the filastruder starting with room temperature until they started to extrude. The temperature was increased by $5^{\circ} \mathrm{C}$ every few minutes until the material had solidified too much to extrude, which was between 85 and $90^{\circ} \mathrm{C}$ depending on the viscosity of the mixture. The mixtures with alumina proved to be too tacky to extrude from the filastruder. At room temperature, the material stuck to the inside of the barrel and was too thick to come out the other end. Due to this difficulty with the equipment, alumina was eliminated from the materials to be used in the experiment.

\subsubsection{Final Material Selection}

With the binders HA-12 and B-1022 and the alumina powder removed in the feasibility trials, the final material selection for the experiment is summarized in Table 3-3 below with B-1000 as the selected binder and $\mathrm{ZrO} 2$ as the selected ceramic powder. The mixture was spongy and wet with a tendency to clump (Figure 3-10), and when extruded into filament it was very stretchy and elastic, similar to a rubber band (Figure 3-11). 
Table 3-3: Final Material Selection

\begin{tabular}{|l|l|l|l|l|l|}
\hline \multicolumn{3}{|l|}{} & Manufacturer & Viscosity (cP) & Tg $\left(^{\circ} \mathbf{C}\right)$ \\
\hline Binder & B-1000 & Acrylic Polymer & Dow & $<140$ & -26 \\
\hline \multicolumn{3}{|l|}{} & $\begin{array}{l}\text { Particle Size } \\
\text { (nm) }\end{array}$ & \\
\hline $\begin{array}{l}\text { Ceramic } \\
\text { Powder }\end{array}$ & TZ-3Y-E & ZrO2 & Tosoh & 40 & \\
\hline
\end{tabular}

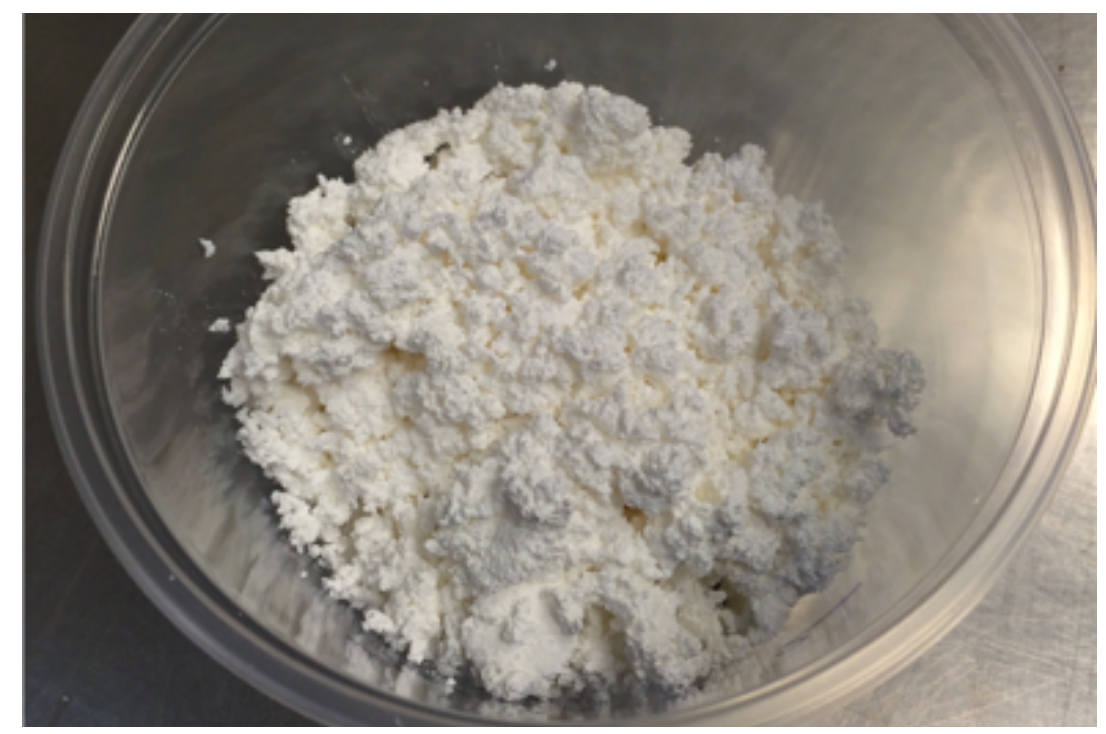

Figure 3-10: Down-Selected B-1000 Binder and Zirconia Mixture

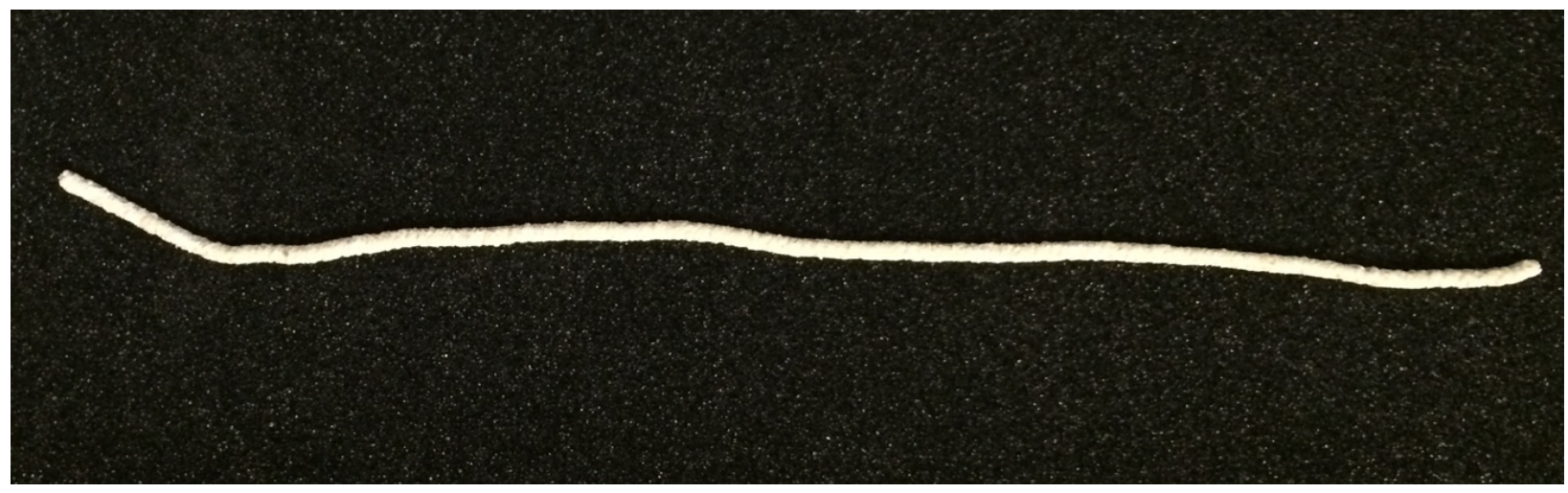

Figure 3-11: B-1000 and Zirconia Filament 


\subsection{DOE}

After the down selection of the candidate materials to one powder and one binder, the experimental design was considered (See Figure 3-12). First, an ANOVA was performed on the extrusion temperature to identify how the temperature was effecting the quality of the filament. Using the information about extrusion temperature, a factorial experiment was created in order to eliminate insignificant factors. With the significant factors, a response surface design was created to identify the optimal composition of the ceramic-binder slurry and extrusion temperature. After the optimal parameters had been identified, filament was produced with those parameters, measured, and trialed in the FDM printer.

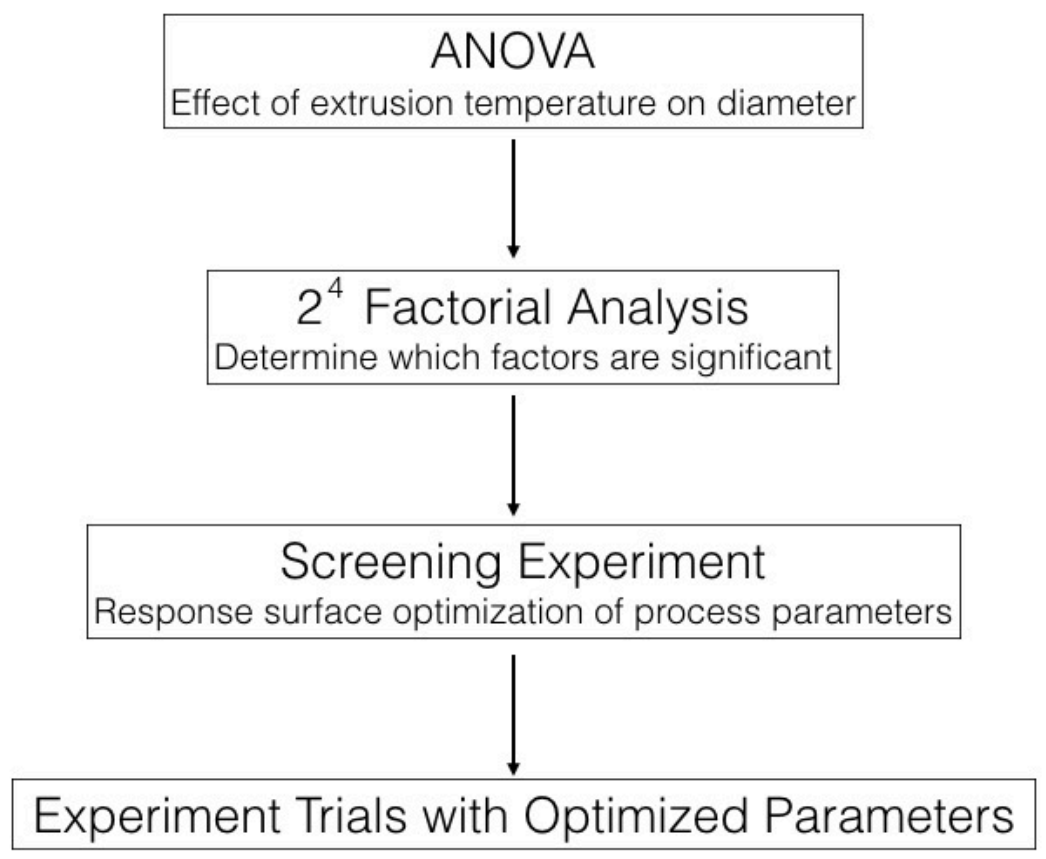

Figure 3-12: DOE Process Flow 


\subsubsection{ANOVA}

From research and in performing the initial feasibility trials it was known that the extrusion temperature plays an important role in the quality of the filament. The need for increased temperature during the extrusion process is dependent on the materials being used and since no previous experiments had been performed with zirconia and acrylic binder, the best way to characterize the effect of extrusion temperature on filament quality was with an ANOVA. Filament was extruded starting at $23^{\circ} \mathrm{C}$ (room temperature) increasing by about 5 degrees until it became too solidified and dry from the heat to continue extruding at about $90^{\circ} \mathrm{C}$. Diameters of each segment were measured in several places along its length with a digital caliper. The results were analyzed using a one-way ANOVA with $p$-values considered and a Tukey comparison test and the following hypotheses:

$H_{0}: \mu_{25}=\mu_{30}=\cdots=\mu_{90}$ where $\mu$ is the mean diameter $H_{A}$ : At least one $\mu$ for some temperature not equal to $\mu$ of some other temperature

\section{One-way ANOVA: Diameter (mm) versus Extrusion Temperature (C)}

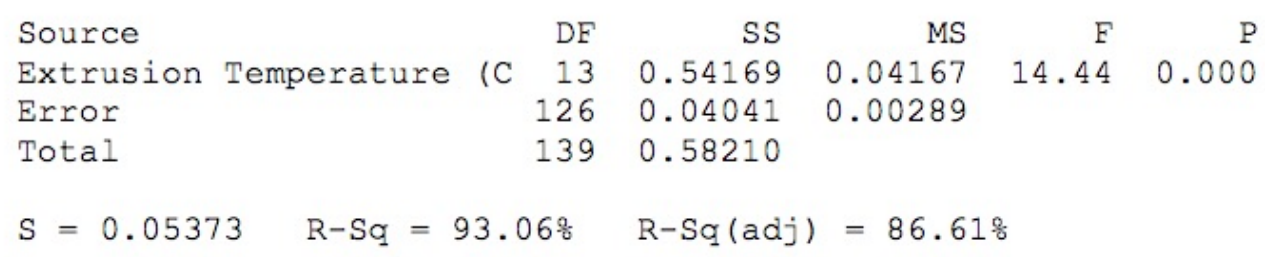

Figure 3-13: ANOVA Table for Diameter vs. Extrusion Temperature 
Figure 3-13 gives the ANOVA result revealing a $p$-value of 0 for extrusion temperature, so at the $99 \%$ confidence level, the null hypothesis can be rejected. This suggests that there are differences between the mean diameters of the filaments extruded at different temperatures. All ANOVA assumptions were met by the data including normality, equal variance and independence (graphs can be found in Appendix B). In order to identify trends in the diameters of filaments produced at different temperatures, a Tukey Comparison Study was performed (See Figure 3-14). The comparison study found that there are two groups of significantly different diameter means, with one group in the $25-55^{\circ} \mathrm{C}$ range and the other group in the $55-90^{\circ} \mathrm{C}$ range. This results confirms that mean diameters for filaments produced in each range are generally comparable to those also within those ranges. With this information, it was decided that two levels of extrusion temperature would be used to in the factorial design: $25^{\circ} \mathrm{C}$ and $80^{\circ} \mathrm{C}$.

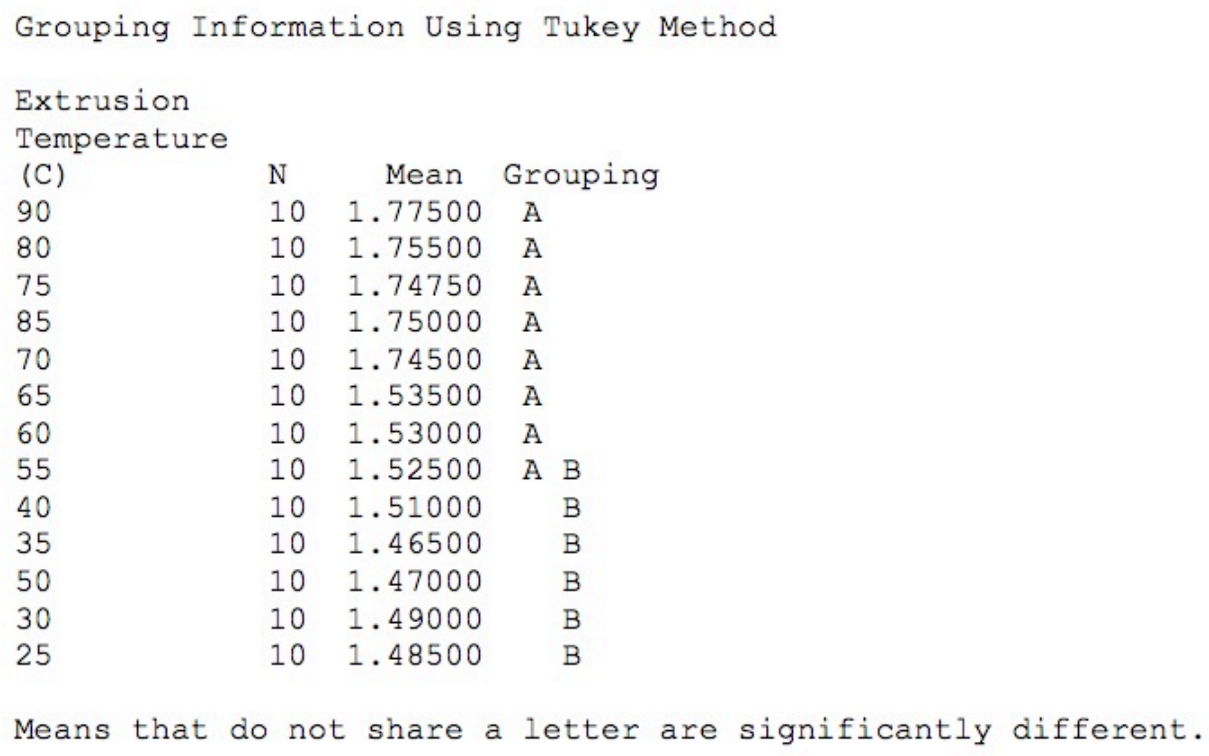

Figure 3-14: Results of Tukey Comparison Study 


\subsubsection{Factorial Analysis}

The factorial experiment performed was a $2^{\wedge} 4$ design (Visual depiction in Figure 3-15). The factors included the weight percent of powder, dispersant and water as well as the extrusion temperature.

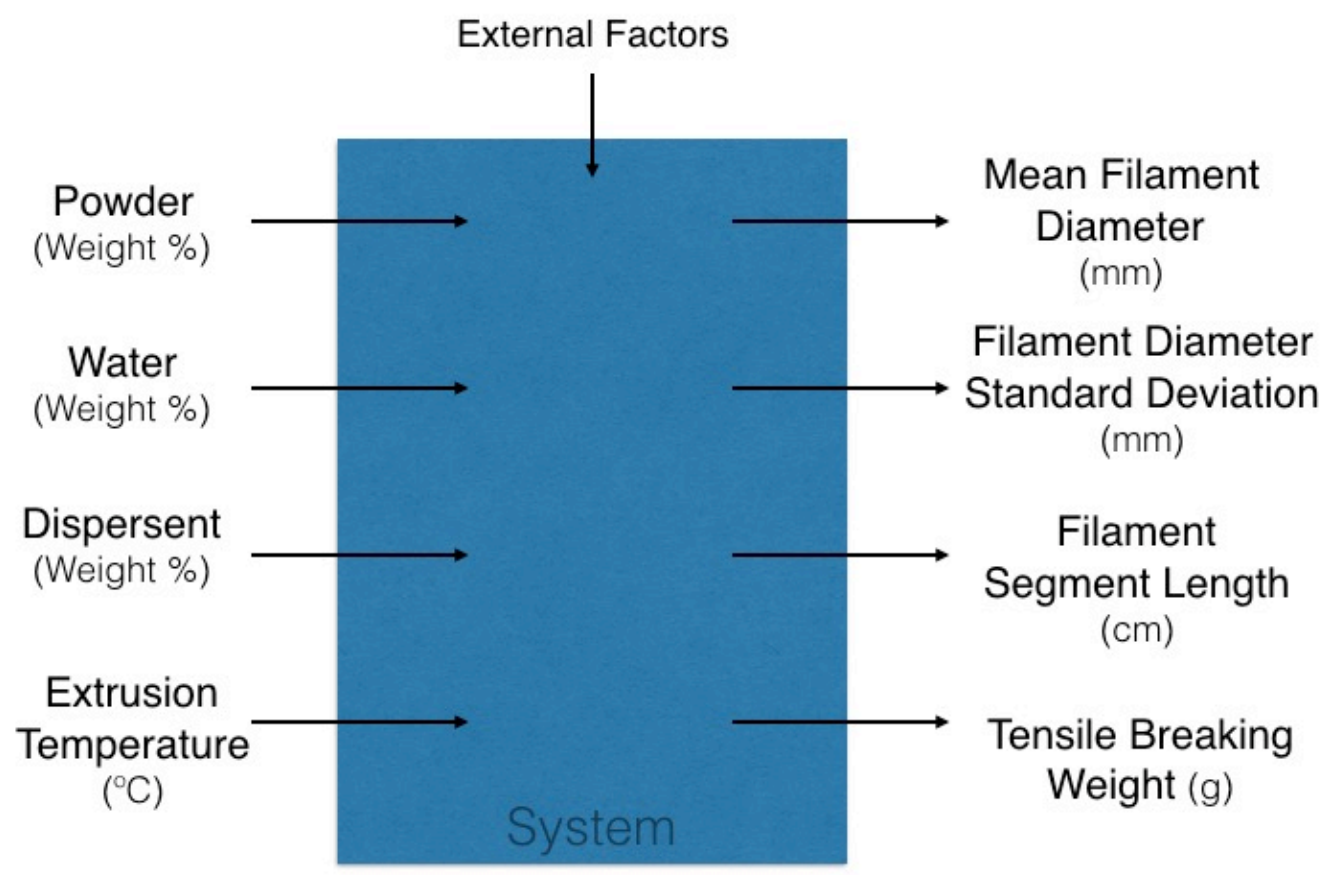

Figure 3-15: 2^4 Factorial Design

In order to assess the quality of filament produced by each of the material compositions in the factorial design, four methods of measurement were chosen as responses. As mentioned earlier, consistent diameter is among the most important characteristics of the filament, as it may impact a filament's physical ability to be used in the FDM system. Diameter of the filament was measured in ten places down the length of the filament with the mean of those measurements used as the response for each run. Consistency of diameter is also very 
important, so in order to account for this in the experiment, the standard deviation of diameter measurements specific to the segment was used as a response. A high standard deviation for the diameter measurements of a given segment would be seen as negative because it would mean that there were areas of the segment with different diameters and could affect the consistency of the material flow rate during the printing process. Filament segment length is the third response which was measured and this is because it is indicative of the strength of the filament. As the filament is extruded and starts to hang down off the table that the extruder is sitting on, it breaks when it can no longer support its length. If there are air pockets in the filament, it's likely to break at those weak points. The last response which was included in the factorial experiment was the tensile breaking weight. It is important for the filament to be sturdy and have strength during the printing process, so a method of measurement similar to a tensile test was used with the weight it took to break a segment recorded.

As previously seen in Table 3-1 in the feasibility trials section, ranges for the weight percent of each component were identified from previously performed experiments detailed in the literature review and the product instructions. The feasibility trials (introduced in section 3.3) also played a very strong role deciding what factors should be used and with what levels. Chosen for each of the four factors were a high and low value which can be seen in Table 3-4. The high and low values were chosen from the range of values found in the feasibility trials and 
one-way ANOVA. The factorial experiment was analyzed and the significant main effects and interactions were noted as those important for inclusion in the response surface optimization.

Table 3-4: 2^4 Factorial Design Factor Levels

\begin{tabular}{|l|l|l|l|l|}
\hline & $\begin{array}{l}\text { Powder Load } \\
\text { (Weight \%) }\end{array}$ & $\begin{array}{l}\text { Dispersant } \\
\text { (Weight \%) }\end{array}$ & $\begin{array}{l}\text { Water } \\
\text { (Weight \%) }\end{array}$ & $\begin{array}{l}\text { Extrusion } \\
\text { Temperature }\left({ }^{\circ} \mathbf{C}\right)\end{array}$ \\
\hline Low (-) & 50 & 1 & 2 & 23 \\
\hline High (+) & 60 & 2 & 3 & 85 \\
\hline
\end{tabular}

\subsubsection{Response Surface}

Response Surface Methodology (RSM) adds squared terms to the model which allows for the modeling of curvature in the responses. RSM is used to refine experiments once significant factors have been identified using a factorial experiment. The purpose of the response surface screening experiment in this DOE was to understand how the process parameters affected the quality of the filament and to identify which factors played a valuable role in creating the desired filament characteristics. The response surface analysis was performed with the terms which were found to be significant in the factorial analysis, and the Minitab response optimizer feature was used to find the system parameters to be used as the optimized filament.

\subsubsection{Analysis of Optimized Filament}

With the optimized powder, water and dispersant values and the optimal extrusion temperature, several replicates of filament were created with the same responses measured. Statistical analysis of the consistency of the values was 
performed and the filament was trialed in the FDM simulation system to assess feasibility of its ability to withstand the FDM process. 


\section{CHAPTER 4 -RESULTS}

\subsection{Factorial Experiment Results}

As previously mentioned, the purpose of the factorial experiment was to identify terms which did not have an effect on the quality of the filament. The $2^{\wedge} 4$ experiment included a total of 16 runs and all of the assumptions were met including normality, equal variance and independence (Graphs for reference in Appendices $\mathrm{C}, \mathrm{D}, \mathrm{E}$ and $\mathrm{F}$ ). The half normal plots were used to remove terms from the factorial analysis. As can be seen below in Figures 4-1, 4-2, 4-3 and 44, the significant terms include A, B, C, BC, BD and BCD. Significant terms, ones which are identified on the half normal plots, have a $p$ value of less than 0.05 which means that their effects are statistically significant at the $95 \%$ confidence level. The factorial fit tables and results for this first factorial analysis can be found in Appendix G.

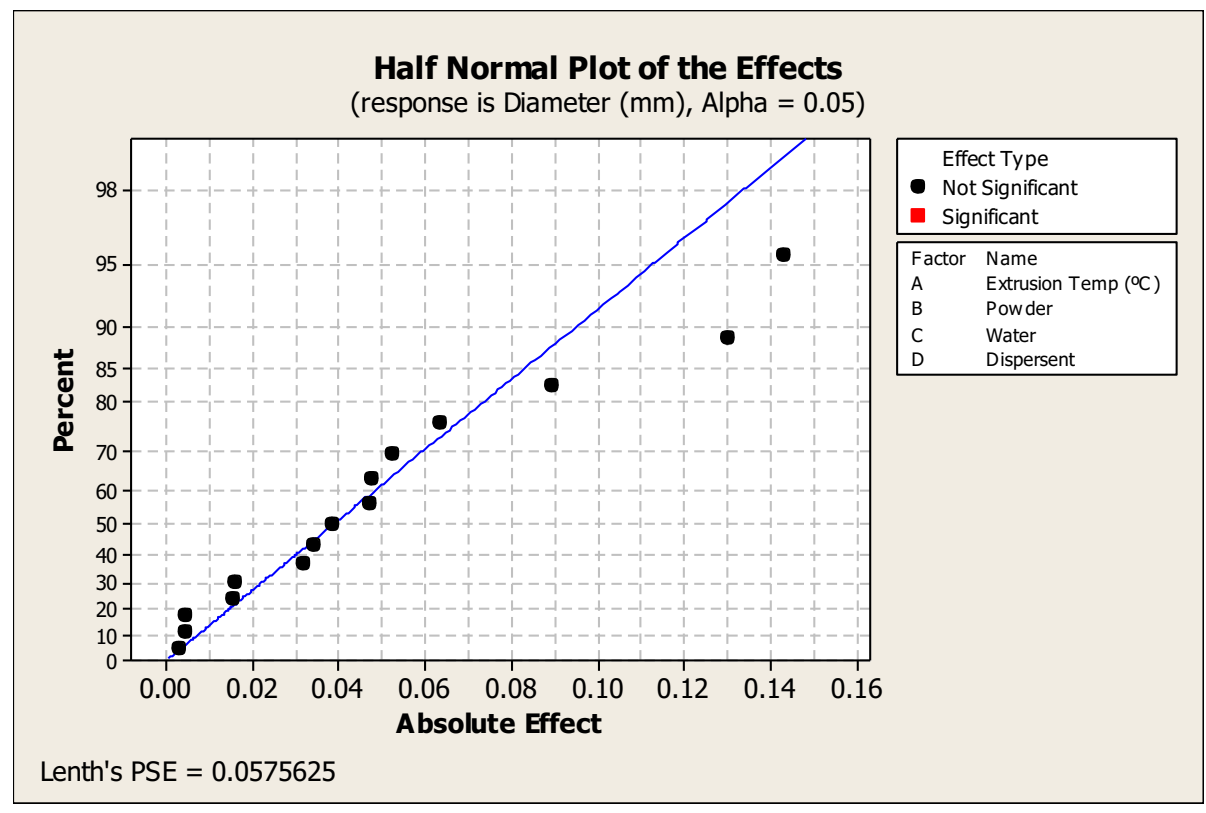

Figure 4-1: Initial Half Normal Plot for Diameter 


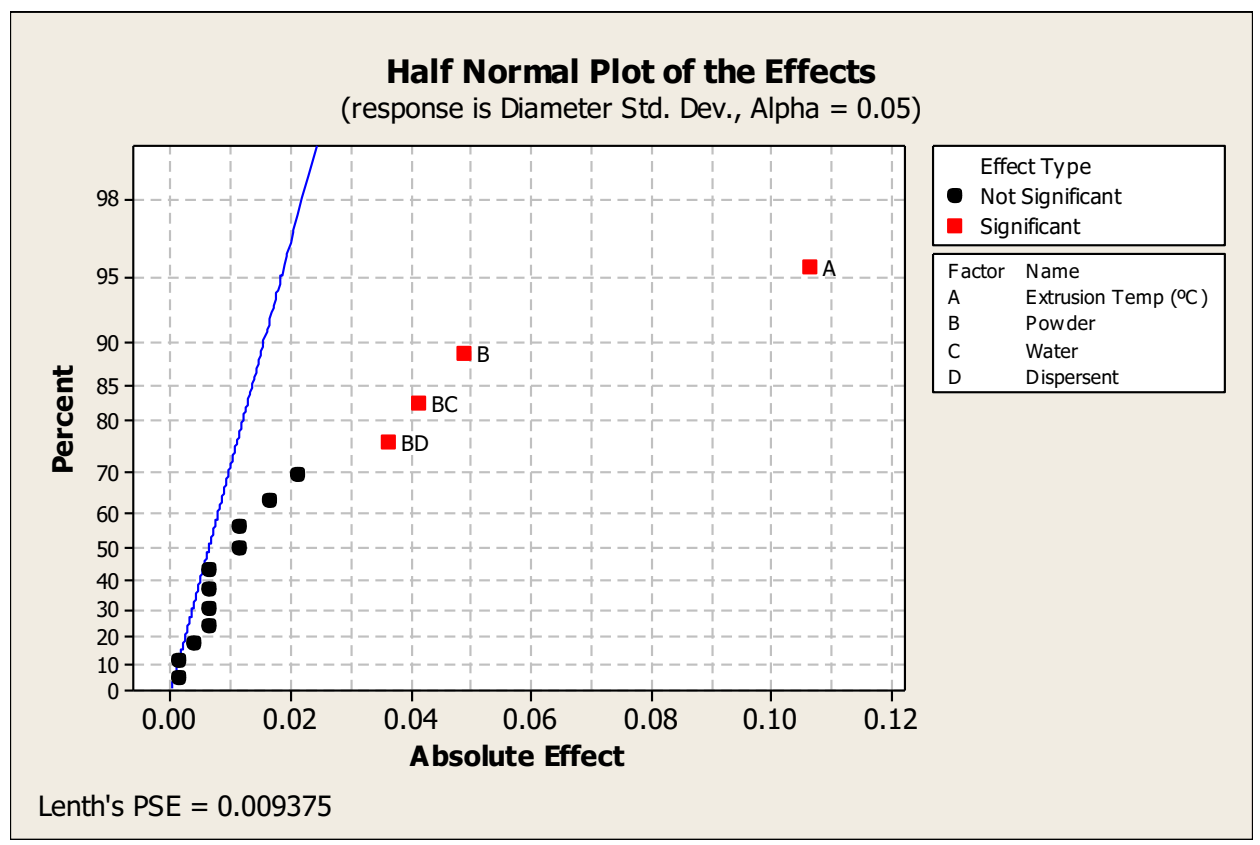

Figure 4-2: Initial Half Normal Plot for Diameter Standard Deviation

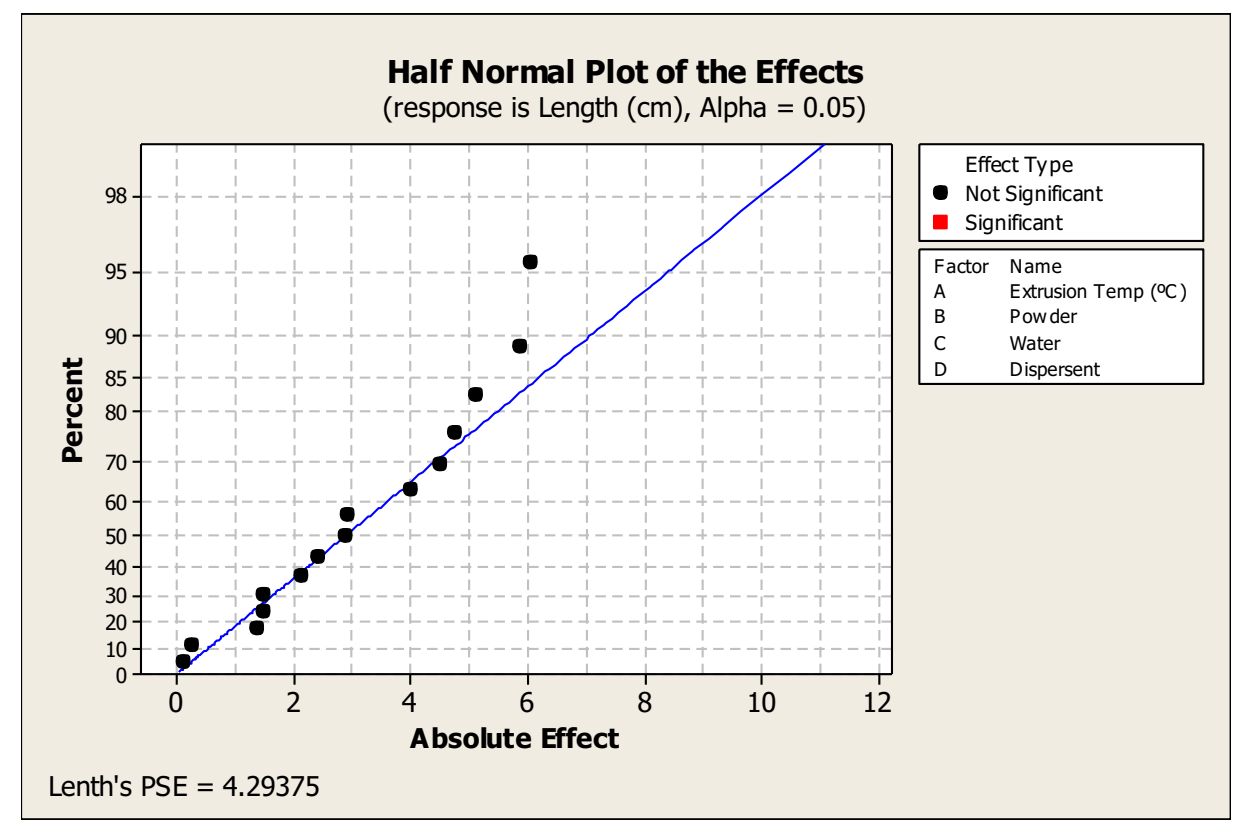

Figure 4-3: Initial Half Normal Plot for Length 


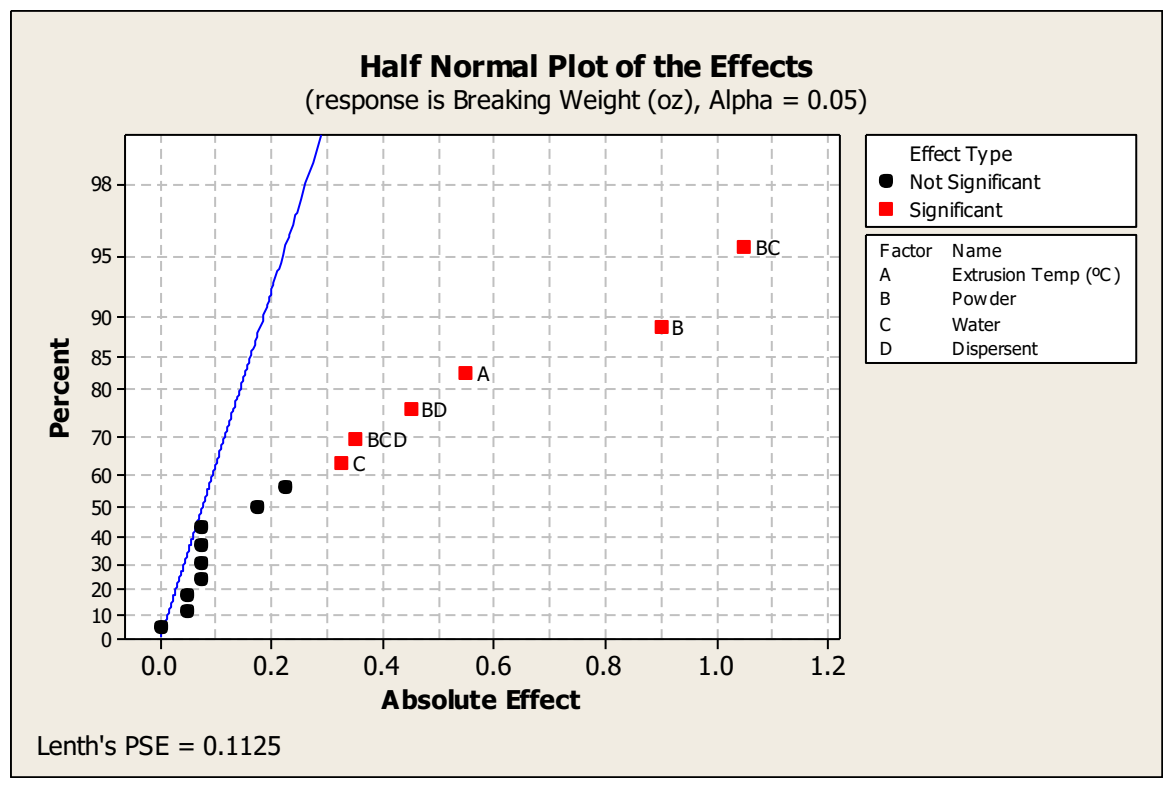

Figure 4-4: Initial Half Normal Plot for Breaking Weight

The insignificant factors were removed and the factorial analysis was run again, as is common practice to identify most accurately which factors are significant. The half normal plots for the second factorial analysis were identical for the responses diameter standard deviation and length, while the plots for diameter (Figure 4-5) and breaking weight (Figure 4-6) revealed some new significant terms which were not seen in the first analysis. Full factorial results with all of the corresponding $\mathrm{p}$ values can be found in Appendix $\mathrm{H}$. Table 4-1 summarizes the final significant terms along with the respective responses for which they were found to be significant. It was decided that because no terms were found to be significant for the length measurement, it was not a good quality predictor of the process. Due to this discovery, length was removed as a response for the response surface optimization and throughout the rest of the experiment. 




Figure 4-5: Second Analysis Half Normal Plot for Diameter

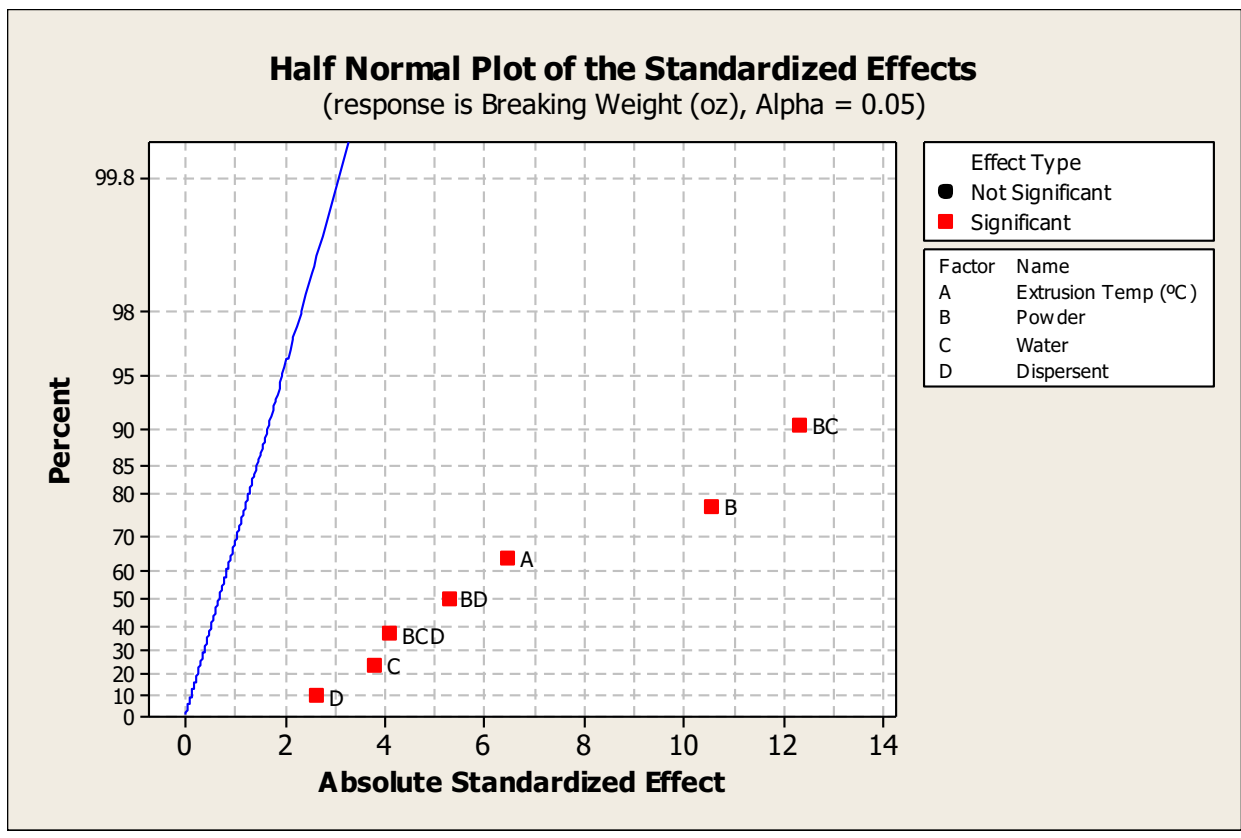

Figure 4-6: Second Analysis Half Normal Plot for Breaking Weight 
Table 4-1: Summary of Significant Terms Identified in Factorial Analysis

\begin{tabular}{|l|l|}
\hline Term & Response(s) of Significance \\
\hline A: Extrusion Temperature $\left({ }^{\circ} \mathrm{C}\right)$ & Diameter Std. Deviation, Breaking Weight \\
\hline B: Powder (Weight \%) & $\begin{array}{l}\text { Diameter, Diameter Std. Deviation, Breaking } \\
\text { Weight }\end{array}$ \\
\hline C: Water (Weight \%) & Diameter, Breaking Weight \\
\hline D: Dispersant (Weight \%) & Breaking Weight \\
\hline $\begin{array}{l}\text { BC: Interaction between Powder and } \\
\text { Water }\end{array}$ & $\begin{array}{l}\text { Diameter, Diameter Std. Deviation, Breaking } \\
\text { Weight }\end{array}$ \\
\hline $\begin{array}{l}\text { BD: Interaction between Powder and } \\
\text { Dispersant }\end{array}$ & $\begin{array}{l}\text { Diameter, Diameter Std. Deviation, Breaking } \\
\text { Weight }\end{array}$ \\
\hline $\begin{array}{l}\text { BCD: Interaction between Powder, } \\
\text { Water and Dispersant }\end{array}$ & Breaking Weight \\
\hline
\end{tabular}

The three-way interaction BCD (Figure 4-7) indicates that there is a relationship between the weight percentages of powder, water and dispersant in the mixture as they relate to breaking weight of the filament. The relationship is that a higher breaking weight, indicating a stronger filament, is the result of low levels of powder, water and dispersant. The main effect of term A (Figure 4-8) reveals that extrusion temperature has an impact on the quality of the filament for three of the responses. Extrusion at the high level, which is $85^{\circ} \mathrm{C}$, results in a higher breaking weight and a lower diameter standard deviation. 


\section{Interaction Plot for Breaking Weight (oz)}

Data Means

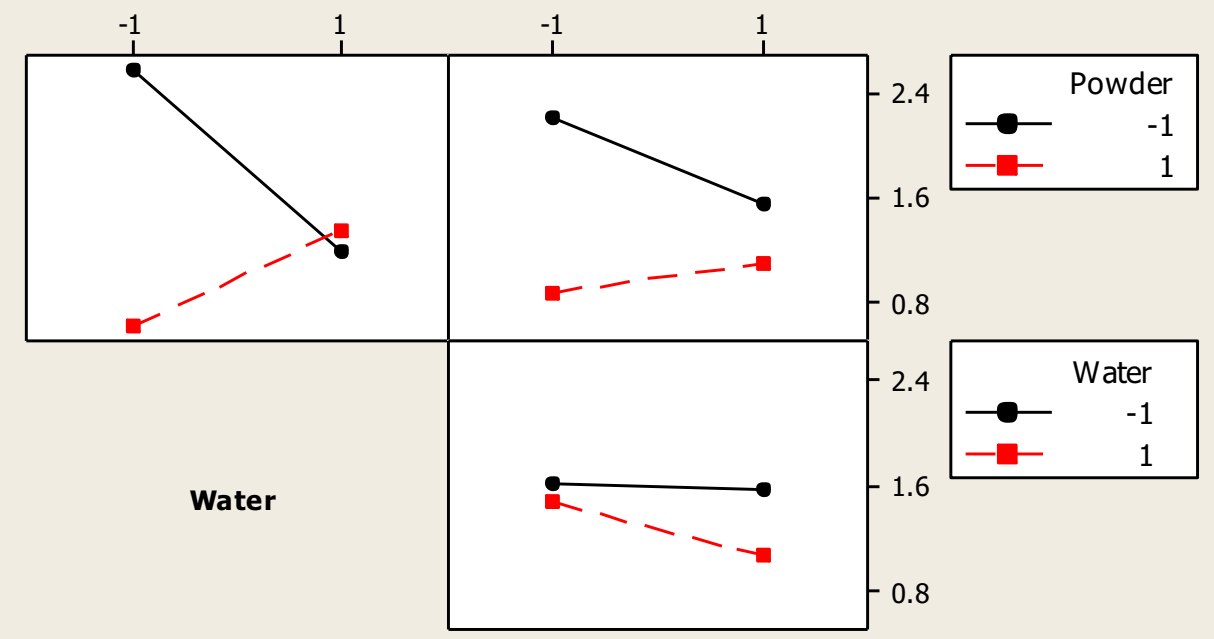

Figure 4-7: Interaction Effect between Powder, Water and Dispersant

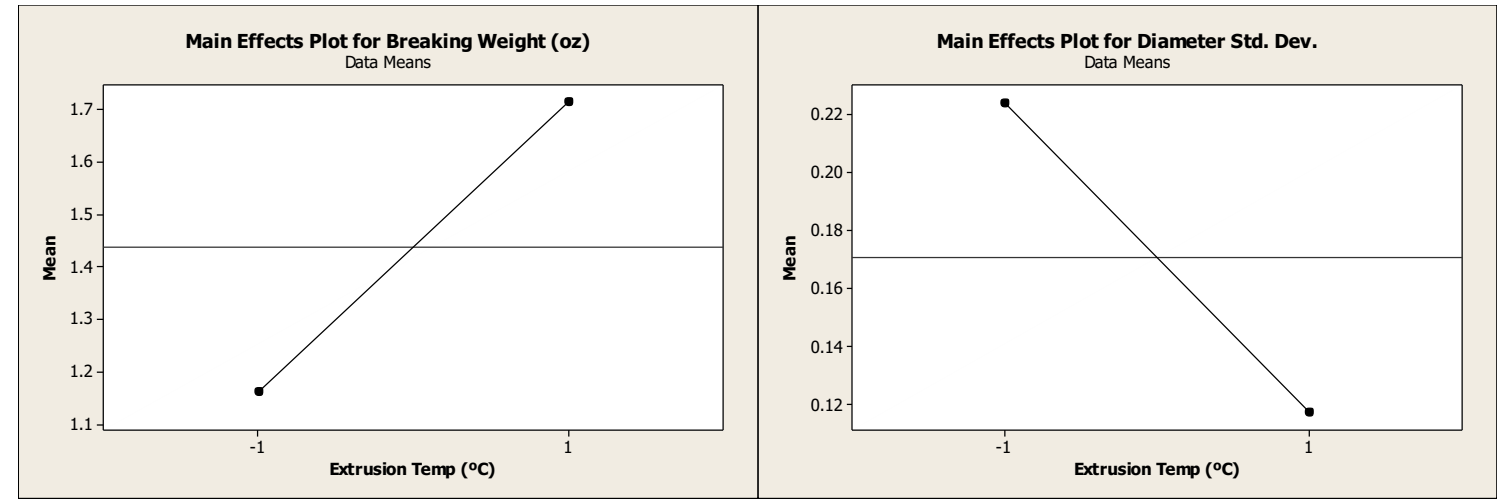

Figure 4-8: Main Effects for Extrusion Temperature

The purpose of the factorial analysis was to determine which factors were significant for predicting the quality of filament through the chosen responses, and through either main effects or interaction effects, extrusion temperature, and the weight percentages for powder, water and dispersant were all significant 
factors and would continue to be used throughout the rest of the experiment. The response surface optimization was the final step in the screening experiment to determine which levels of each of these factors would result in the best quality filament.

\subsection{Response Surface Optimization}

The purpose of the response surface analysis was to find the optimal levels of extrusion temperature and powder, water and dispersant compositions which contribute to making the strongest filament with the most consistent diameter. The response surface calculates compositions of different levels of each factor and gives a desirability factor based on how well they meet specified response goal values. The optimizer also allows for weights or levels or importance to be placed on responses, but for this experiment it was determined that all three responses carried equal importance. The goal values entered, summarized in Table 4-2, are either a target value, or minimized or maximized values. The diameter of the filament is dictated by the FDM equipment and must be $1.75 \mathrm{~mm}$ \pm 0.01 to work properly. The diameter standard deviation should be as small as possible, so it was set as a value to be minimized, and a higher breaking weight indicates higher strength in the filament so it was set to be maximized.

Additionally, the normality, equal variance and independence assumptions were all met (See Appendix I), giving validity to this model. 
Table 4-2: Response Surface Optimization Goal Values

\begin{tabular}{|l|l|l|l|l|}
\hline Response & Goal & Lower Value & Target Value & Upper Value \\
\hline Diameter $(\mathrm{mm})$ & Target & 1.74 & 1.75 & 1.76 \\
\hline $\begin{array}{l}\text { Diameter Standard } \\
\text { Deviation }\end{array}$ & Minimize & 0.00 & 0.00 & 0.15 \\
\hline $\begin{array}{l}\text { Breaking Weight } \\
(\mathrm{g})\end{array}$ & Maximize & 2.00 & 3.00 & 3.00 \\
\hline
\end{tabular}

The response optimizer gave several solutions, but the solution with the highest desirability factor is as follows:

\section{Response Optimization}

Global Solution

$\begin{array}{lll}\text { Extrusion Temperature }\left({ }^{\circ} \mathrm{C}\right) & = & 1 \\ \text { Powder (Weight \%) } & = & -0.752519 \\ \text { Water (Weight \%) } & = & -0.806189 \\ \text { Dispersant (Weight \%) } & = & -1\end{array}$

\section{Predicted Responses}

Diameter $(\mathrm{mm}) \quad=1.75000$, desirability $=1.000000$

Breaking Weight $(\mathrm{g}) \quad=2.71192$, desirability $=0.711917$

Diameter Standard Deviation $\quad=0.07141$, desirability $=0.523925$

Composite Desirability $=0.719835$

The global solution values refer to the high and low levels given to each factor so the translated solution is as follows:

$\begin{array}{lll}\text { Extrusion Temperature }\left({ }^{\circ} \mathrm{C}\right) & = & 85 \\ \text { Powder }(\text { Weight \%) } & = & 51 \\ \text { Water }(\text { Weight \%) } & = & 2 \\ \text { Dispersant (Weight \%) } & = & 1\end{array}$


The visual depiction of the optimal solution (Figure 4-9) shows how the levels of each factor effect each response. The red lines represent the optimal solutions and predict the responses with diameter right on the goal of $1.75 \mathrm{~mm}$ with a low standard deviation of 0.07 and breaking weight at $2.71 \mathrm{~g}$ which was close to the maximum breaking weight found while testing the filaments.

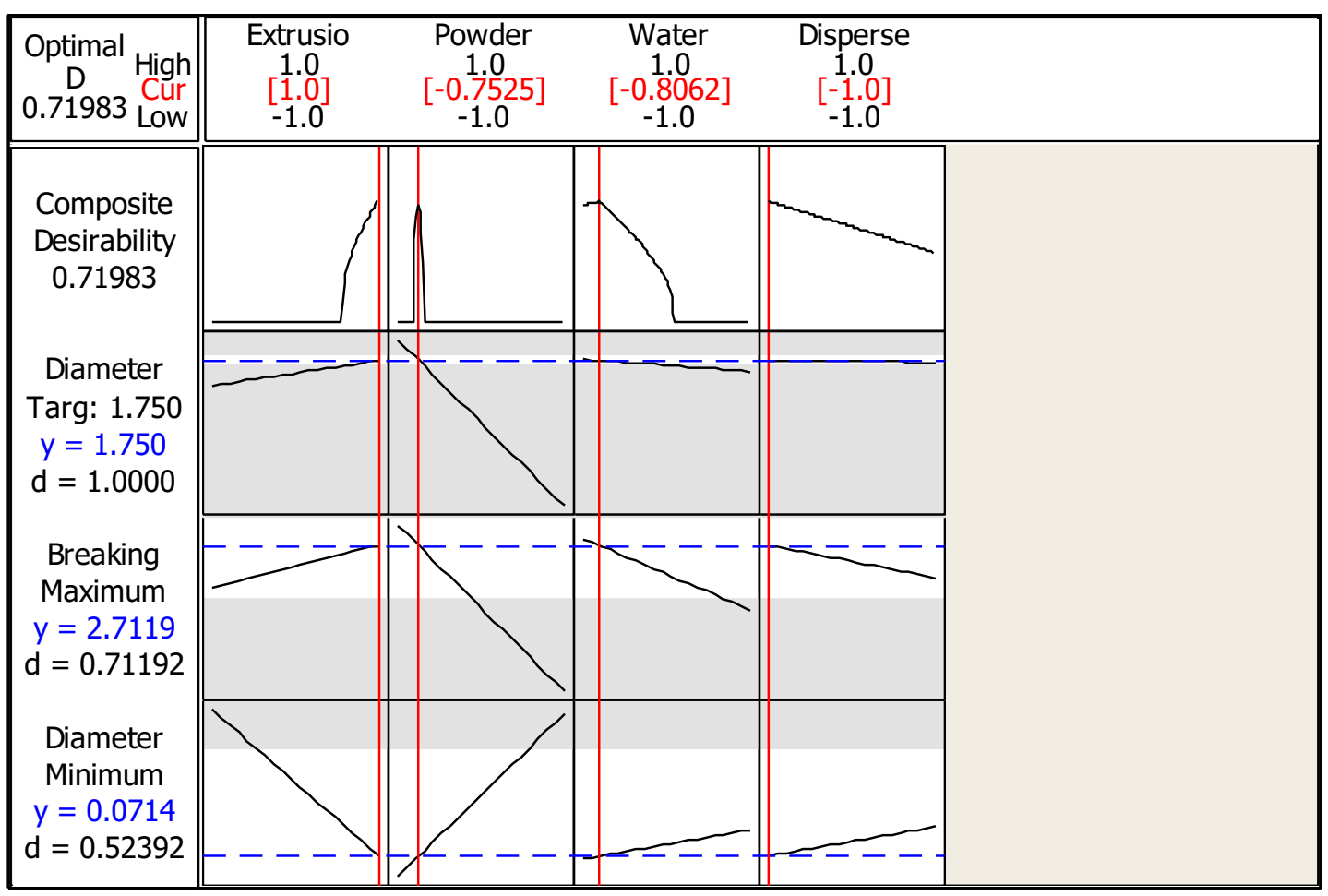

Figure 4-9: Visual Depiction of Response Surface Optimization

The solution found by the response surface optimizer gives a suggested extrusion temperature of $85^{\circ} \mathrm{C}$, and weight percentages for the three components. The official experiment mixture composition was decided to be $51 \%$ zirconia powder, $2 \%$ water, $1 \%$ dispersant and the remaining $46 \%$ was the acrylic binder. Full results of the response surface analysis can be seen in Appendix J. 


\subsection{Analysis of Optimized Filament}

Three replicates of the optimal experiment were performed with 12 segments per replicate for a total of 36 segments. All of the response variables were measured for each of the 36 segments to determine whether the process was repeatable and consistent and to assess the quality of the results of the chosen parameters (Summary of Results in Table 4-3). As had been done in the measurements of the filament in the screening phase, diameter measurements were taken in ten locations down the length of each segment and taken as an average for the diameter response.

Table 4-3: Summary of Optimized Filament Measurements

\begin{tabular}{|l|l|l|l|}
\hline & $\begin{array}{l}\text { Predicted } \\
\text { Response } \\
\text { Response Surface }\end{array}$ & $\begin{array}{l}\text { Average Actual } \\
\text { Response }\end{array}$ & $\begin{array}{l}\text { Difference } \\
\text { (Actual-Predicted) }\end{array}$ \\
\hline Diameter $(\mathbf{m m})$ & 1.7500 & 1.7502 & 0.0002 \\
\hline $\begin{array}{l}\text { Diameter Standard } \\
\text { Deviation }\end{array}$ & 0.0714 & 0.0669 & -0.0045 \\
\hline Breaking Weight (g) & 2.7119 & 2.7333 & 0.0214 \\
\hline
\end{tabular}

The filament diameter was within the $1.75 \mathrm{~mm} \pm 0.01$ specification with an average of $1.7502 \mathrm{~mm}$ and the diameter standard deviation was lower than predicted at 0.0669 . The breaking weight measurements proved to be slightly better than predicted as well with an average of $2.7333 \mathrm{~g}$. 


\subsection{FDM Printing Trial Findings}

As introduced earlier on, a FDM system was built for the trials in order to avoid damaging the existing 3D printers in the lab. Since no one has ever attempted to print with zirconia and acrylic binder there was uncertainty associated with how it would impact the equipment. Filament was fed through the gripping wheels operated by a stepper motor until it reached the hot end. As can be seen in Figure 4-10, the filament unfortunately did not have enough strength to act as a piston and it buckled when the tip reached the hot end.

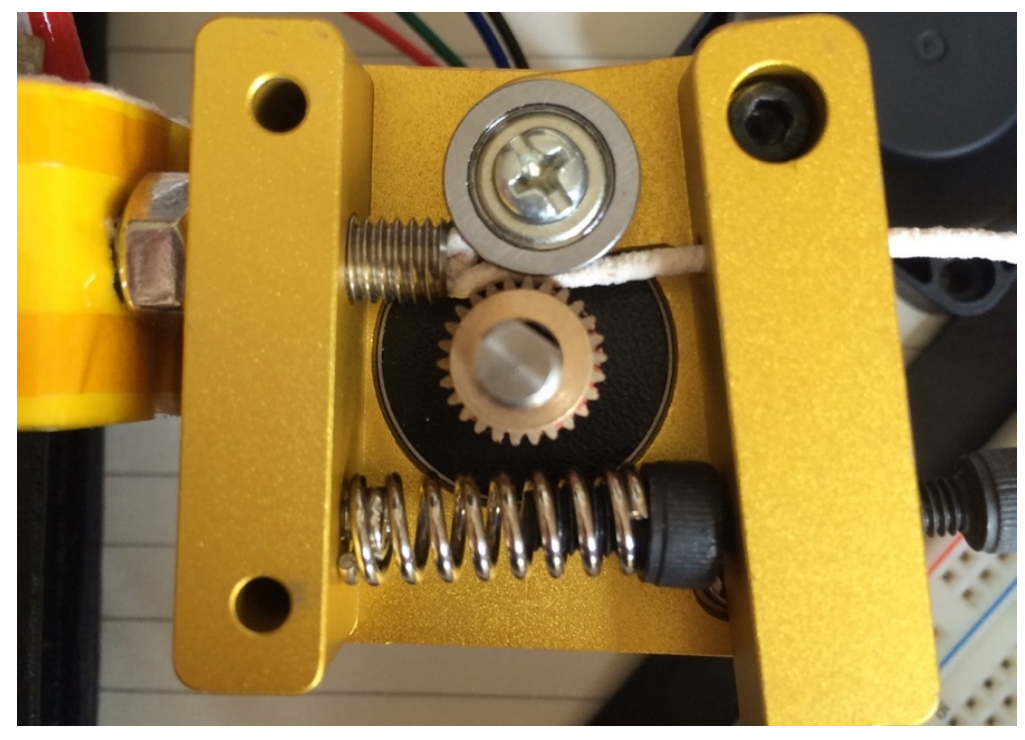

Figure 4-10: Filament Buckling

In order to assess the melting characteristics of the material, a small segment of the ceramic filament was fed into the system, followed by a plastic filament (Shown in Figure 4-11). With the more rigid plastic filament acting as a piston, the ceramic was successfully melted by the hot end and simulated printing in an FDM system (See Figure 4-12). 


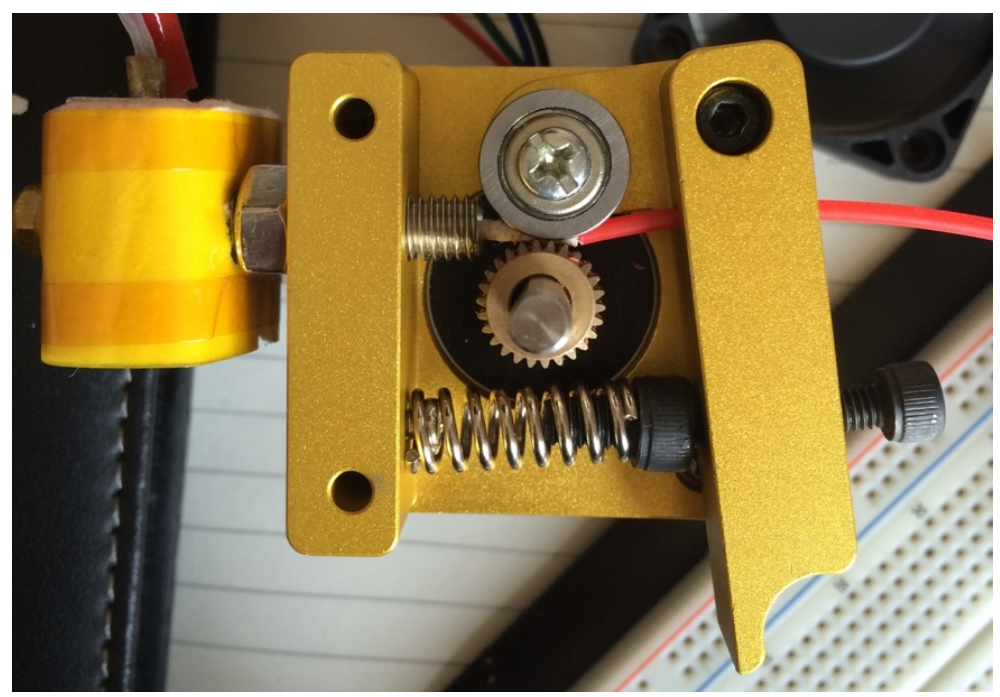

Figure 4-11: Ceramic Filament with ABS Plastic Filament as Piston

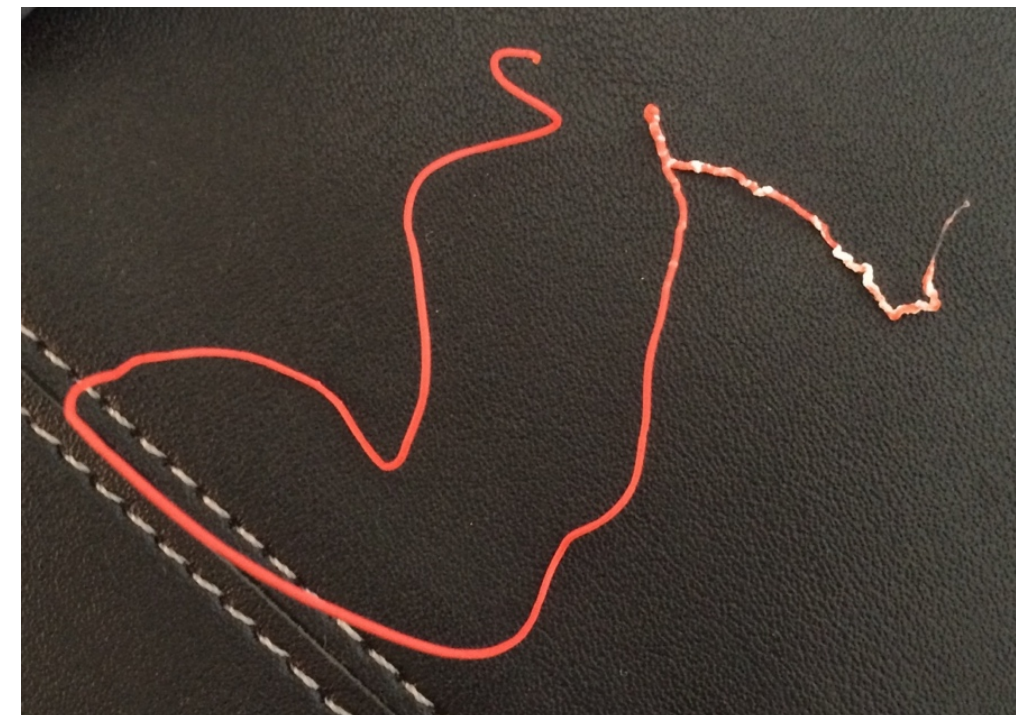

Figure 4-12: Printed Ceramic Filament

The resulting filament was a mix of ceramic material and ABS plastic material and given the higher rigidity of the ABS plastic, much more plastic made it out of the hot end as compared to ceramic. It would be difficult to print any parts with only the ceramic filament since it does not have enough strength and rigidity to be pushed through the hot end by the system. 


\subsection{Steps for Further Development}

In order to develop the acrylic binder and zirconia powder concept, other additives would need to be considered. It is possible that including an epoxy or other strengthening additives could reinforce the mixture, given that it could be burned out after the printing process. A polypropylene binder system similar to those used by Rutgers University could be another solution, or another low melting temperature polymer such as EVA. Adding more components to the acrylic binder system or using a binder system like polypropylene or EVA would require heated mixing equipment and laboratory resources conducive to mixing chemicals.

Another area which may have restricted the scope of experimentation was the filament extrusion equipment used. Although it works great for plastic materials, the filastruder may not be the best equipment solution for use with wet mixtures. Using a single screw extruder could improve the filament processing step, although buying or building a screw extrusion system with the correct heat elements could be expensive and the temperature may be hard to keep uniform. Without trying this type of equipment, it's impossible to know whether it would produce filament with the level of diameter consistency seen from the filastruder. Beyond the filastruder, the FDM printer system also dictated the properties of the materials. It could be possible to develop a new method of feeding material into the hot end, for example a chamber where the wet mixture is placed and 
compressed, rather than needing to be in the form of a dry, stiff filament. There are many feasibility issues with this idea, such as the presence of air pockets, but it may be that by eliminating the step of filament processing if the system could use another form of feedstock could eliminate a lot of the issues in the FDC process. 


\section{CHAPTER 5 - SUMMARY AND CONCLUSIONS}

Although additive manufacturing has numerous benefits, there are also downsides to the technology. For FDC in particular, slow fabrication rates due to the layer by layer build process as well as the binder removal process which can take several hours, limits feasibility for this manufacturing method on a large scale. Additionally, the sensitivity of the material composition can lead to thermal gradients throughout the part especially during the printing portion of the process which requires the utmost precision in the temperatures used. Lastly, it's difficult to eliminate the presence of porosity in any type of ceramic and those produced by FDC are no exception. When starting with ceramic powder and compounding the material, it can be difficult to ensure homogeneity of the final mixture, and any inhomogeneity leads to pores within the end part resulting in reduced strength and increased risk of micro cracking and large scale fracture (Eckel, Zhou, Martin, Jacobsen, Carter \& Schaedler, 2016).

The purpose of this thesis was to try to address some of the ceramic processing limitations by exploring the use of previously untried materials in the process of Fused Deposition of Ceramics. In particular, the research question was: What are the effects of combining zirconia powder and an acrylic binder system in the process of creating ceramic filaments to be used in FDC? It was determined that the filament produced by the zirconia and particular Dow acrylic binder chosen was not robust enough to withstand 3D printing in an FDM system. 


\subsection{Contributions}

Although parts were not printed successfully, this experiment proved that acrylic binder systems do have the melting characteristics to be used in the FDM system. Tuning the material to maintain these melting properties while being given added strength to withstand the printing process could result in usable ceramic parts. With little existing research on acrylic binder systems or zirconia in the area of FDC, this effort revealed a lot about the materials which could aid in future experimentation in this realm.

Some aspects of the experiment which worked well and could be carried over to future similar experiments include the filament breaking weight measurement and the FDM simulator. Measuring the weight it requires to break a segment of filament in tension could be developed into a characteristic which determines that filament's feasibility in the FDM process because it indicates how strong the filament is. The FDM simulator system was a great addition to this experiment because there were unforeseen technical issues with the filament when it was fed into the FDM system which were easily fixed given that an entire printer system didn't have to be disassembled. The most important part of an FDM printer when determining initial feasibility of a material is the material being fed into and extruded through the hot end, so honing in on this system and duplicating it in a tester system avoided damaging any expensive FDM equipment. 


\subsection{Future Work}

As mentioned at the end of the results section, there are many possible avenues to pursue FDC with zirconia whether or not acrylic is the binder used. Figure 5-1 on the next page outlines barriers and steps for development associated with the FDC process steps which were identified through this experiment effort.

Retrofitting the acrylic binder system with strengthening additives has high potential to create filament with the right characteristics for the FDM system, as it already possesses elasticity, flexibility and was produced with highly consistent diameter. Pursuing a different type of binder such as polypropylene or EVA could be successful as well, though heated compounding equipment would be necessary to do such research. Experiments including this one and those performed in past years by other groups have shown promise in FDC, but much more research is necessary in order to fully develop the concept enough for mainstream use. 


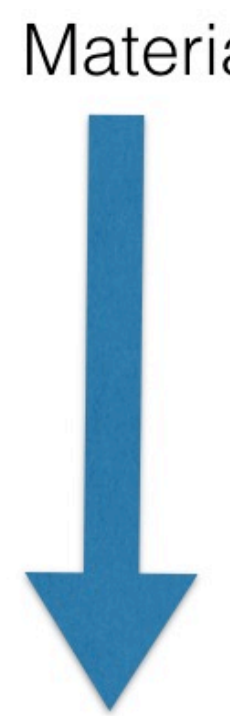

\section{Barriers}

- Balancing melting characteristics with strength

- Thorough mixing necessary to break up and distribute components evenly

\section{Steps for Development}

- Investigate additives to acrylic binder systems for increased strength

- Experiment with other low melting temperature polymers (EVA, etc.)

- Create a mixing set up which automates mixing process with varying levels of shear and heat and also measures the viscosity of the mixture

- Develop methods for characterizing materials after the compounding stage to assess their feasibility for FDC without having to go through the process of creating filament (Example: Column strength measurement)

\section{Filament Processing}

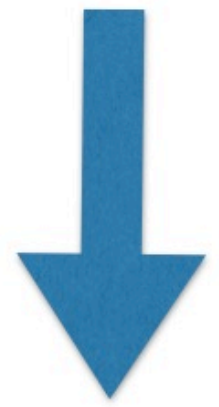

\section{Barriers}

- Limitations on materials which can be used with existing extrusion technology

\section{Steps for Development}

- Look into new extrusion technologies better equipped to handle liquids

- Develop a process to measure column strength in filament to assess it's ability to withstand the FDM process

\section{D Printing}

\section{Barriers}

- Requirement for material to be in filament form

\section{Steps for Development}

- Develop a new 3D printing technology which extrudes printed paths from a liquid or semi liquid form

Figure 5-1: Future Steps for FDC Development 


\section{REFERENCES}

Advanced Ceramics I Zirconia Powders. (n.d.). Retrieved January 11, 2016, from http://www.tosoh.com/our-products/advanced-materials/zirconia-powders

Agarwala, M. K., Jamalabad, V. R., Langrana, N. A., Safari, A., Whalen, P. J., \& Danforth, S. C. (1996). Structural quality of parts processed by fused deposition. Rapid Prototyping Journal, 2(4), 4-19. Retrieved from http://ezproxy.lib.calpoly.edu/login?url=http://search.proquest.com/docview /214023306?accountid=10362

Agarwala, M.K., van Weeren, R., Bandyopadhyay, A., Safari, A. \& Danforth, S.C. (1996). Filament Feed Materials for Fused Deposition Processing of Ceramics and Metals. Retrieved from Solid Freeform Fabrication Symposium Manuscripts

Agarwala, M.K., van Weeren, R., Bandyopadhyay, A., Whalen, P.J., Safari, A. \& Danforth, S.C. (1996). "Fused Deposition of Ceramics and Metals: An Overview," ibid., Reference \#1, Vol. 7, 1996.

Agarwala, M.K., van Weeren, R., Vaidyanathan, R., Bandyopadhyay, A., Carrasquillo, G., Jamalabad, V., Langrana, N., Safari, A., Garofalini, S.H. \& Danforth, S.C. (1995). "Structural Ceramics by Fused Deposition of Ceramics," ibid., Reference \#1, Vol. 6, 1995, pp.1-8.

Aluminum Oxide, Al2O3 Ceramic Properties. (n.d.). Retrieved April 26, 2016, from http://accuratus.com/alumox.html 
Bandyopadhyay, A., Das, K., Marusich, J., \& Onagoruwa, S. (2006). Application of fused deposition in controlled microstructure metal-ceramic composites. Rapid Prototyping Journal, 12(3), 121-128.

doi:http://dx.doi.org/10.1108/13552540610670690

Bellini, A., Shor, L., \& Guceri, S. I. (2005). New developments in fused deposition modeling of ceramics. Rapid Prototyping Journal, 11(4), 214-220. Retrieved from http://ezproxy.lib.calpoly.edu/login?url=http://search.proquest.com/docview $/ 214023802$ ?accountid=10362

Boschetto, A., \& Bottini, L. (2014). Accuracy prediction in fused deposition modeling. International Journal Of Advanced Manufacturing Technology, 73(5-8), 913-928. doi:10.1007/s00170-014-5886-4

Ceramic history. (n.d.). Retrieved May 02, 2016, from http://depts.washington.edu/matseed/mse_resources/Webpage/Ceramics/ ceramichistory.htm

Crockett, R.S. \& Calvert, P.D. (1997). Rheology and Solid Freeform Fabrication: Modeling Material Flow in Deposition Techniques. Retrieved from Solid Freeform Fabrication Symposium Manuscripts.

Crockett, R.S., O’Kelly, J., Calvert, P.D., Fabes, B.D., Stuffle, K., Creegan, P. \& Hoffman, R. (1995). Predicting and Controlling Resolution and Surface Finish of Ceramic Objects Produced by Stereodeposition Processes. Retrieved from Solid Freeform Fabrication Symposium Manuscripts. 
DURAMAXTM B-1000 Ceramic Binder Technical Data Sheet, Rohm and Haas Company, FCC-339, December 1996 (revised 2008), page 1.

DURAMAXTM B-1022 Ceramic Binder Technical Data Sheet, Rohm and Haas Company, FC-422, January 1999 (revised 2008), page 1. DURAMAXTM D-3005 Dispersant Technical Data Sheet, Rohm and Haas Company, FC-333, April 1997 (revised 2008), page 1.

DURAMAXTM HA-12 Ceramic Binder Technical Data Sheet, Rohm and Haas Company, FC-333, April 1997 (revised 2008), page 1.

Eckel, Z., Zhou, C., Martin, J., Jacobsen, A., Carter, W., \& Schaedler, T. (2016). Additive manufacturing of polymer-derived ceramics. Science, 351(6268), 58-62. Retrieved January 9, 2016, from sciencemag.org FDM Technology. (nod). Retrieved January 10, 2016, from http://www.stratasys.com/3d-printers/technologies/fdm-technology

Fodran, E., Koch, M. \& Menon, U. (1996). Mechanical and Dimensional Characteristics of Fused Deposition Modeling Build Styles. Retrieved from Solid Freeform Fabrication Symposium Manuscripts.

Gasdaska, C., Clancy, R., Ortiz, M. \& Jamalabad, V. (1998). Functionally Optimized Ceramic Structures. Retrieved from Solid Freeform Fabrication Symposium Manuscripts.

Griffin, E. Alair \& McMillin, S. (1995). Selective Laser Sintering and Fused Deposition Modeling Processes for Functional Ceramic Parts. Retrieved from Solid Freeform Fabrication Symposium Manuscripts 
Kantaros, A., \& Karalekas, D. (2013). Fiber Bragg grating based investigation of residual strains in ABS parts fabricated by fused deposition modeling process. Materials \& Design, 5044-50. doi:10.1016/j.matdes.2013.02.067 LaMonica, Martin. "Additive Manufacturing." MIT Technology Review (2013): n.p. MIT Technology Review. 23 Apr. 2013. Web. 22 Apr. 2016.

McNulty, T.F., Mohammadi, F., Bandyopadhyay, A., Shanefield, D.J., Danforth, S.C. \& Safari, A. (1998) "Development of a binder formulation for fused deposition of ceramics", Rapid Prototyping Journal, Vol. 4 Iss: 4, pp.144 150

Onagoruwa, S., Bose, S. \& Bandyopadhyay, A. (2001). Fused Deposition of Ceramics (FDC) and Composites. Retrieved from Solid Freeform Fabrication Symposium Manuscripts Oxide Ceramics - Zirconium Oxide (ZrO2). (n.d.). Retrieved April 26, 2016, from https://www.ceramtec.com/ceramic-materials/zirconium-oxide/

Sabourin, E., Houser, S.A. \& Bohn, J.H. (1997), "Accurate exterior, fast interior layered manufacturing", Rapid Prototyping Journal, Vol. 3 No. 2, pp. 4452.

Sintering in the Powder Metallurgy Process. (n.d.). Retrieved from http://www.ipmd.net/Introduction_to_powder_metallurgy/Sintering

Smith, W. C., \& Dean, R. W. (2013). Structural characteristics of fused deposition modeling polycarbonate material. Polymer Testing,32(8), 1306-1312. doi:10.1016/j.polymertesting.2013.07.014 
Steyer, T. E. (2013). Shaping the Future of Ceramics for Aerospace Applications. International Journal of Applied Ceramic Technology, 10(3), 389+. Retrieved from http://go.galegroup.com/ps/i.do?id=GALE\%7CA327557191\&v=2.1\&u=calp olyw_csu\&it=r\&p=AONE\&sw=w\&asid=2bc132fba49756922379bc34b96cc e34

Vaidyanathan, R., Walish, J., Lombardi, J. L., Kasichainula, S., Calvert, P. \& Cooper, K.C. (2000). The extrusion freeforming of functional ceramic prototypes. JOM, 52(12), 34. Retrieved from http://ezproxy.lib.calpoly.edu/login?url=http://search.proquest.com/docview /232553839?accountid=10362

Venkataraman, N., Rangarajan, S., Matthewson, M. J., Harper, B., Safari, A., Danforth, S. C., Wu, G., Langrana, N., Guceri, S. \& Yardimci, A. (2000). Feedstock material property - process relationships in fused deposition of ceramics (FDC). Rapid Prototyping Journal, 6(4), 244-252. Retrieved from http://ezproxy.lib.calpoly.edu/login?url=http://search.proquest.com/docview $/ 214013888$ ?accountid=10362

Walton, J. (2016). Ceramic 3D printing breakthrough has aviation implications Runway Girl. Retrieved January 10, 2016, from https://www.runwaygirlnetwork.com/2016/01/03/ceramic-3d-printingbreakthrough-has-aviation-implications/ 
Zirconium Oxide, ZrO2 Ceramic Properties. (2013). Retrieved April 26, 2016, from http://accuratus.com/zirc.html 


\section{APPENDICES}

\section{Appendix A: Summary of Previous FDC Experiments}

\begin{tabular}{|c|c|c|c|c|c|}
\hline Experiment & $\begin{array}{l}\text { Ceramic } \\
\text { Powder }\end{array}$ & Binder & $\begin{array}{l}\text { Filament } \\
\text { Processing }\end{array}$ & $\begin{array}{l}\text { Printing } \\
\text { Process }\end{array}$ & $\begin{array}{l}\text { Post } \\
\text { Processing }\end{array}$ \\
\hline $\begin{array}{l}\text { Griffin et al. } \\
\text { Lone Peak } \\
\text { (1995) }\end{array}$ & $\begin{array}{l}\mathrm{Al} 2 \mathrm{O} 3 \\
45-55 \%\end{array}$ & Thermoplastic & $\mathrm{N} / \mathrm{A}$ & $\begin{array}{l}\text { Stratasys 3D } \\
\text { Modeler }\end{array}$ & $\begin{array}{l}\text { Debinding: } \\
\text { Slowly heated in } \\
\text { air up to } 600^{\circ} \mathrm{C} \\
\text { Sintering: In air } \\
\text { at } 1550 \mathrm{C} \text { for } 2 \\
\text { hours }\end{array}$ \\
\hline $\begin{array}{l}\text { Argarwala } \\
\text { et al. (1995, } \\
1996)\end{array}$ & $\begin{array}{l}\text { Si3N4, } \\
\text { SiO2, } \\
\text { Al2O3, PZT, } \\
\text { SS, WC-Co } \\
50-65 \%\end{array}$ & $\begin{array}{l}\text { RU } \\
\text { Polypropylene } \\
\text { Binder series }\end{array}$ & $\begin{array}{l}\text { Single screw } \\
\text { extruder } \\
\text { Temp: } 70- \\
200 \% \\
\text { Rate: } \\
30 \mathrm{~mm} / \mathrm{min} \text {, } \\
\text { Length: } 8-12 \\
\text { in }\end{array}$ & $\begin{array}{l}\text { Stratasys 3D } \\
\text { modeler }\end{array}$ & $\begin{array}{l}\text { Debinding: } \\
\text { Embedded in } \\
\text { charcoal } / \\
\text { alumina at } \\
1^{\circ} \mathrm{C} / \mathrm{min} \text { in } \\
\text { nitrogen, } 250- \\
450^{\circ} \mathrm{C} \text { for } \\
\text { several hours } \\
\text { Sintering: } \\
600^{\circ} \mathrm{C}+\end{array}$ \\
\hline $\begin{array}{l}\text { Mcnulty et } \\
\text { al. (1998) }\end{array}$ & $\begin{array}{l}\text { Piezoelectric } \\
\text { ceramic } \\
\text { devices } \\
55-60 \%\end{array}$ & $\begin{array}{l}\text { RU } \\
\text { Polypropylene } \\
\text { Binder series }\end{array}$ & $\begin{array}{l}\text { Capillary } \\
\text { extrusion } \\
\text { Rate: } \\
1 \mathrm{~mm} / \mathrm{min}, \\
\text { Temp: } 100^{\circ} \mathrm{C} \text {, } \\
\text { Length: } 50 \mathrm{~cm}\end{array}$ & $\begin{array}{l}\text { Stratasys 3D } \\
\text { modeler } \\
\text { Hot end temp: } \\
165-170^{\circ} \mathrm{C} \\
\text { Build envelope } \\
\text { temp: } 40^{\circ} \mathrm{C}\end{array}$ & $\begin{array}{l}\text { Debinding: } \mathrm{PZT} \\
\text { granules as } \\
\text { setter powder, } \\
30^{\circ} \mathrm{C} / \text { hour from } \\
\text { room temp to } \\
500^{\circ} \mathrm{C} \\
\text { Sintering: } 4 \\
\text { hours at } 500^{\circ} \mathrm{C}\end{array}$ \\
\hline $\begin{array}{l}\text { Onagoruwa } \\
\text { et al. (2001) }\end{array}$ & $\begin{array}{l}\text { Mullite } \\
\% \text { N/A }\end{array}$ & Polypropylene & $\begin{array}{l}\text { Screw } \\
\text { extrusion: } 7 \\
\text { rpm, } 160- \\
170^{\circ} \mathrm{C}\end{array}$ & $\begin{array}{l}\text { Stratasys FDM } \\
1650 \\
\text { Hot end temp: } \\
235-237^{\circ} \mathrm{C} \text {, } \\
\text { Envelope temp: } \\
48^{\circ} \mathrm{C}\end{array}$ & \\
\hline $\begin{array}{l}\text { Crockett et } \\
\text { al. (1995) }\end{array}$ & $\begin{array}{l}\mathrm{SiC}, \mathrm{Al} 2 \mathrm{O} 3, \\
\text { SiO2, nylon } \\
\% \mathrm{~N} / \mathrm{A}\end{array}$ & $\begin{array}{l}\text { Thermoplastic, } \\
\text { acrylic, sol-gel }\end{array}$ & $\mathrm{N} / \mathrm{A}$ & $\mathrm{N} / \mathrm{A}$ & $\begin{array}{l}\text { Debinding: } 2- \\
\text { hour ramp to } \\
200^{\circ} \mathrm{C}, 4 \text {-hour } \\
\text { ramp to } 900^{\circ} \mathrm{C} \\
\text { Sintering: Slow } \\
\text { ramp to } 1100- \\
1500^{\circ} \mathrm{C}\end{array}$ \\
\hline
\end{tabular}


Appendix B: ANOVA Extrusion Temp vs. Diameter Assumptions

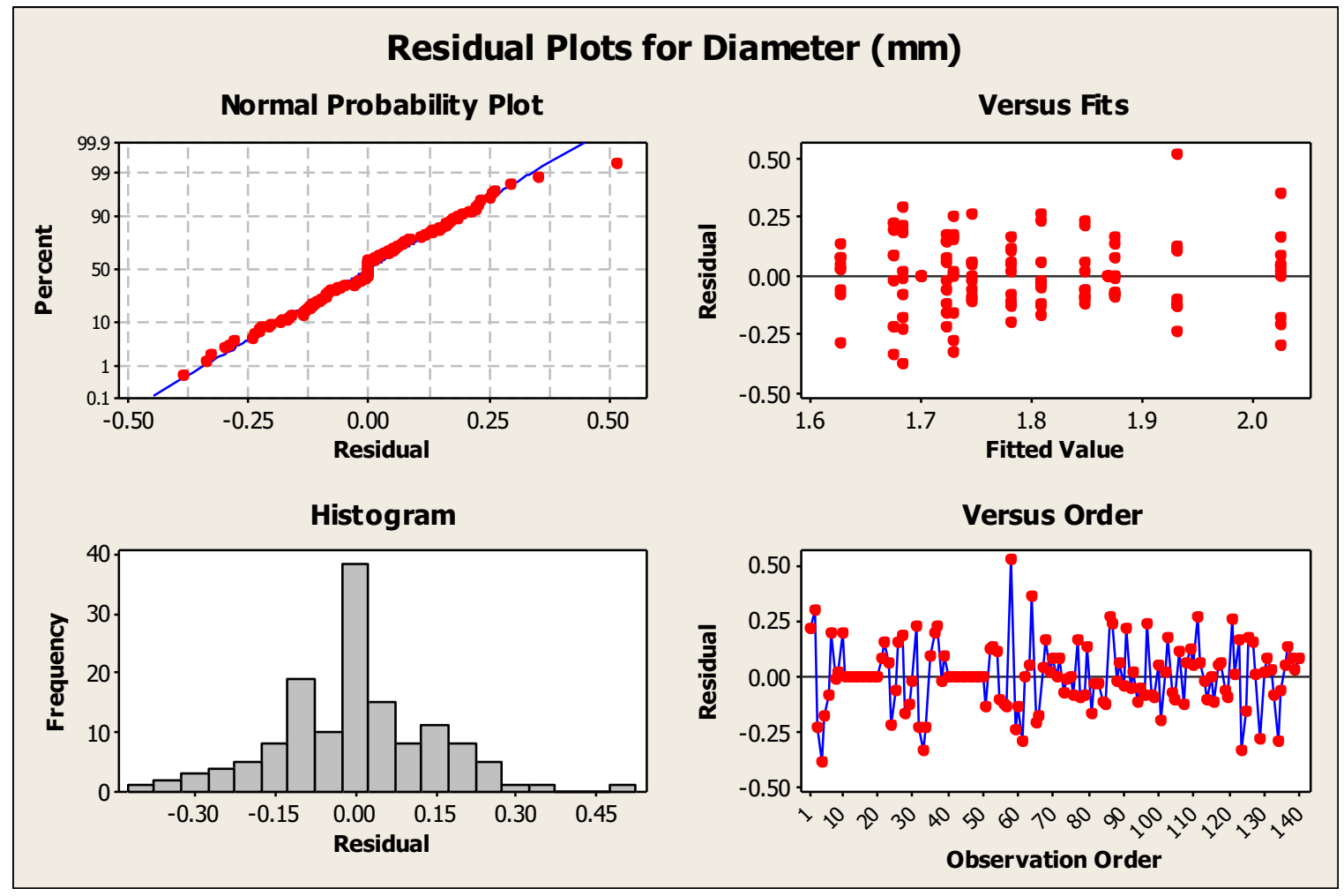


Appendix C: Factorial Analysis Residual Plots for Diameter

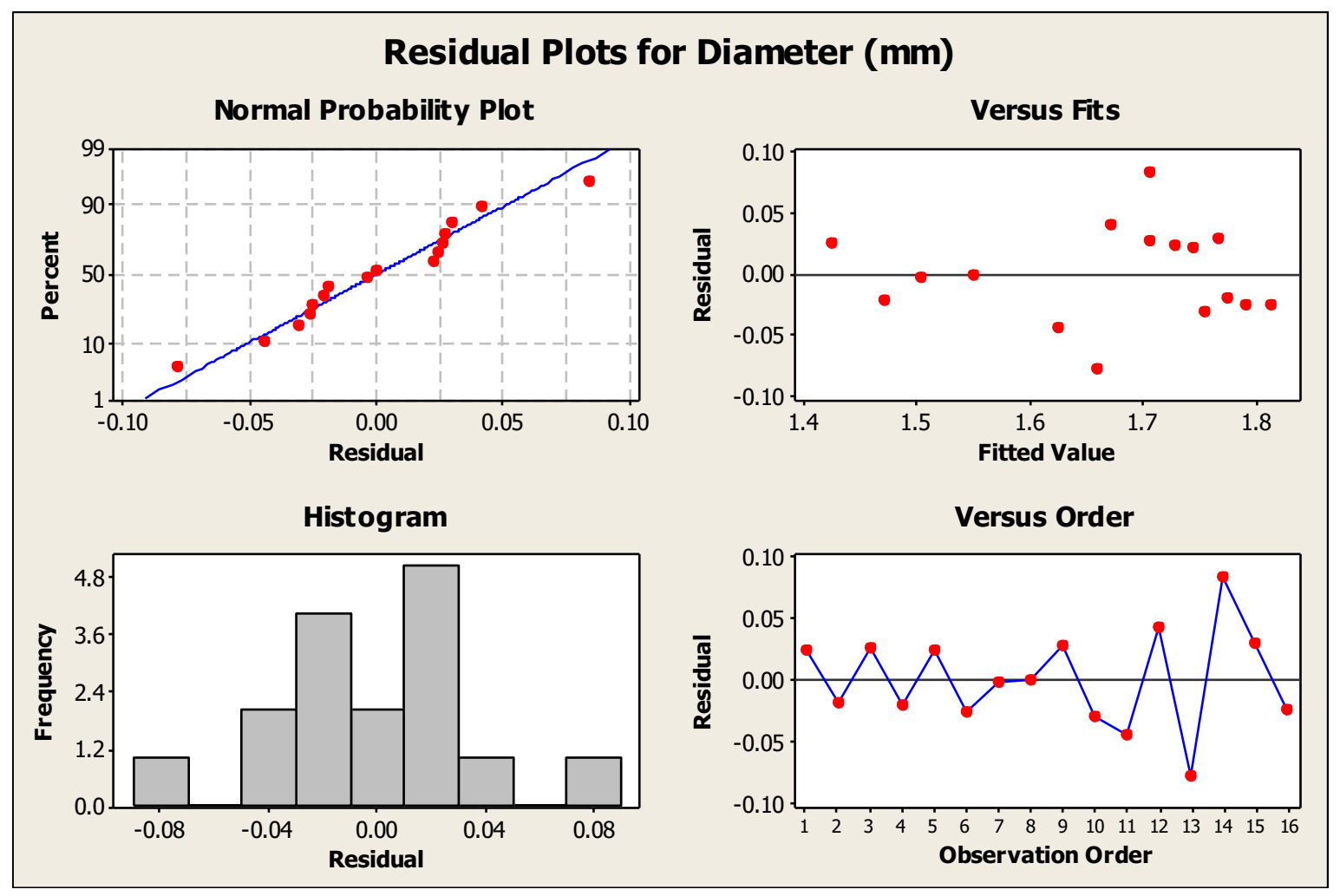




\section{Appendix D: Factorial Analysis Residual Plots for Diameter Standard}

\section{Deviation}

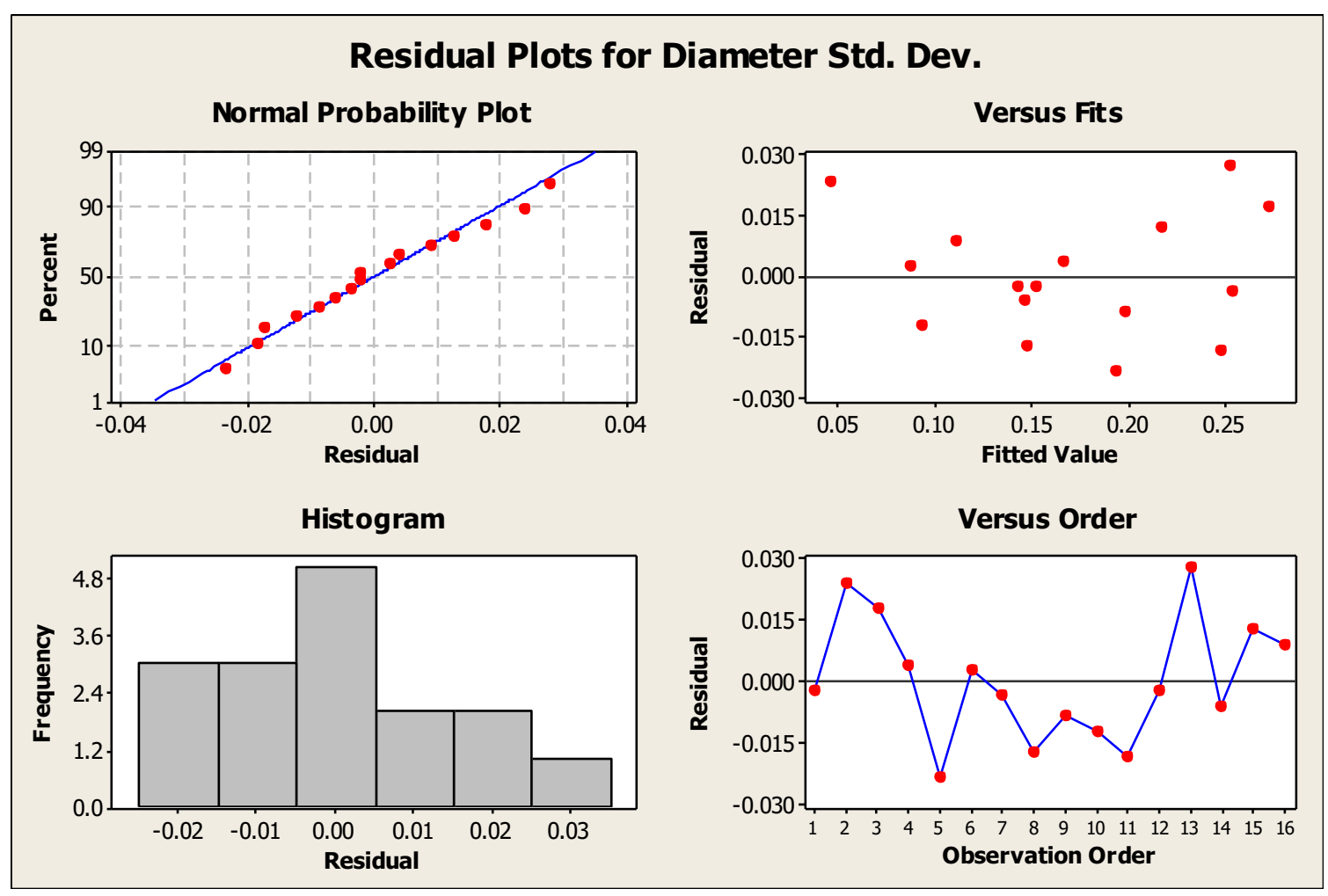


Appendix E: Factorial Analysis Residual Plots for Length

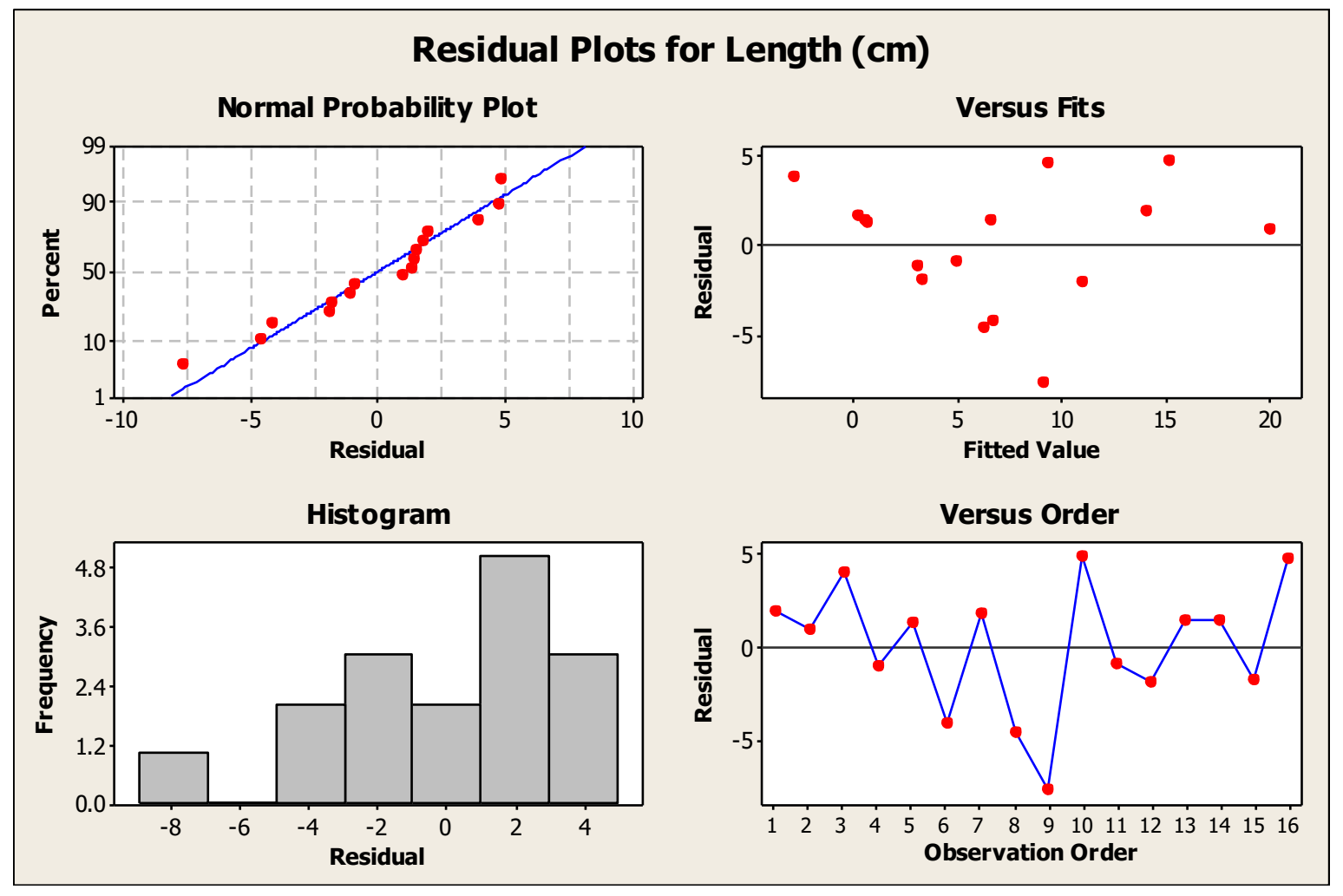




\section{Appendix F: Factorial Analysis Residual Plots for Length}

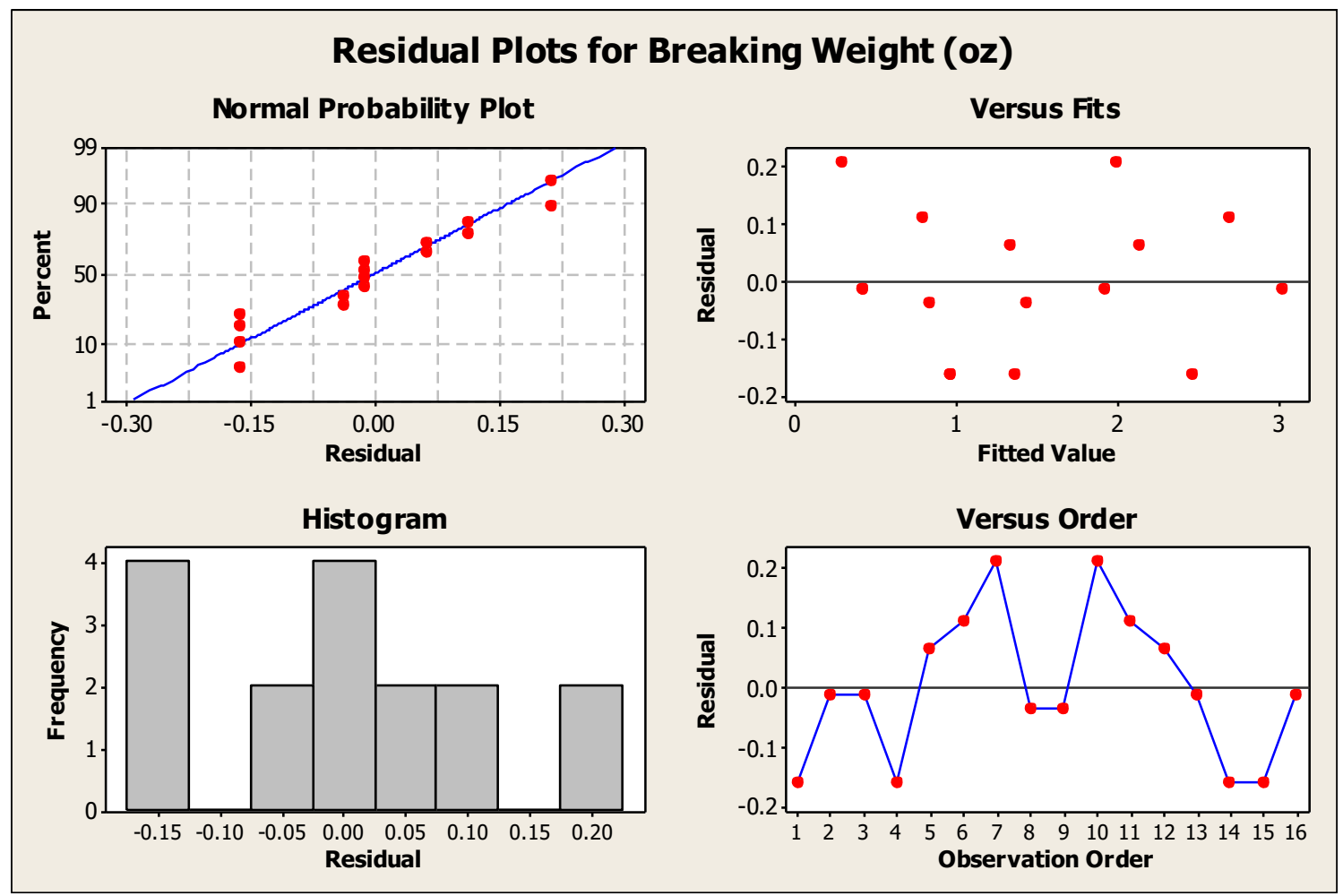




\section{Appendix G: Results for First Factorial Analysis (Listed by Response) Factorial Fit: Diameter $(\mathrm{mm})$ versus Extrusion Temp $\left({ }^{\circ} \mathrm{C}\right)$, Powder, ...}

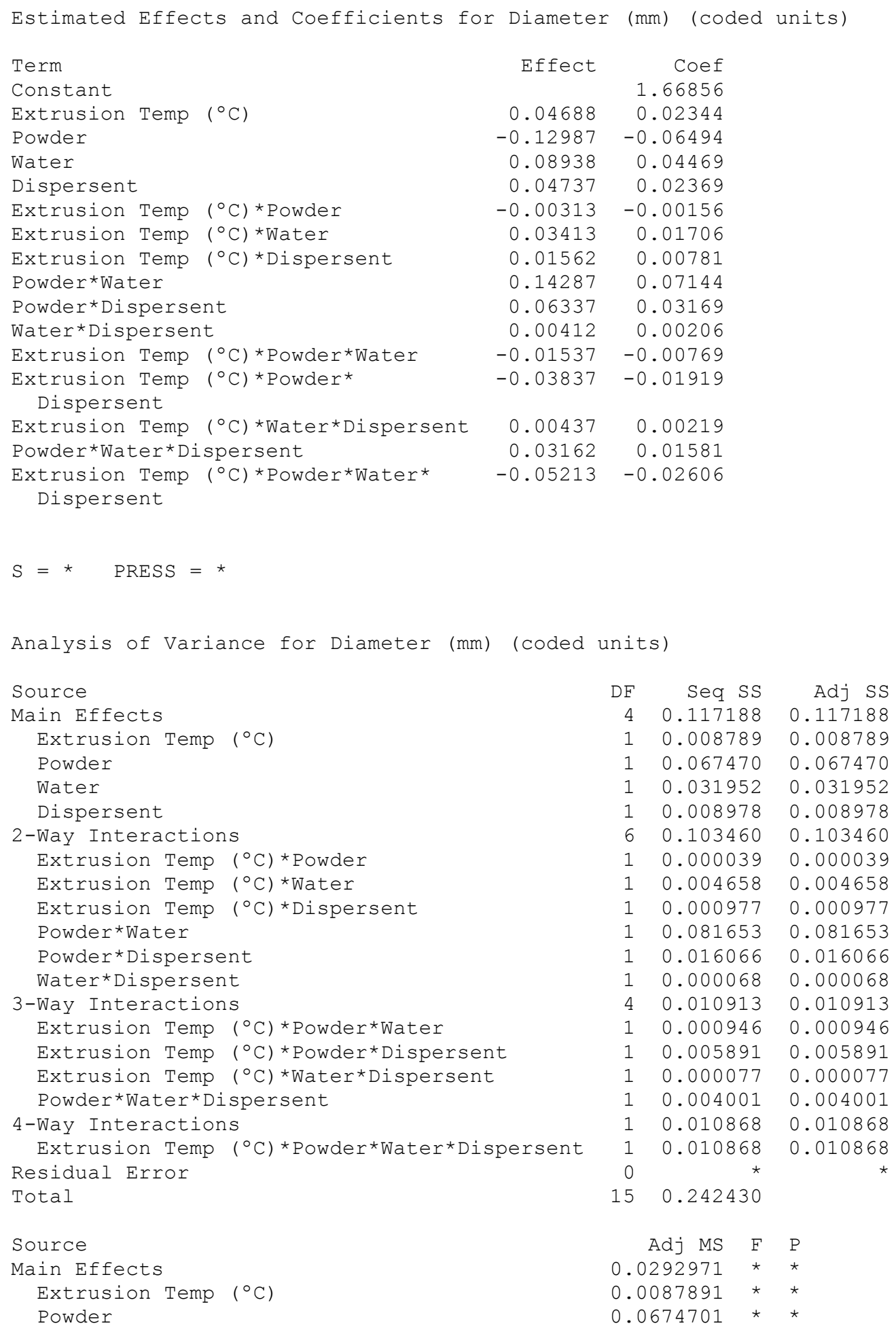




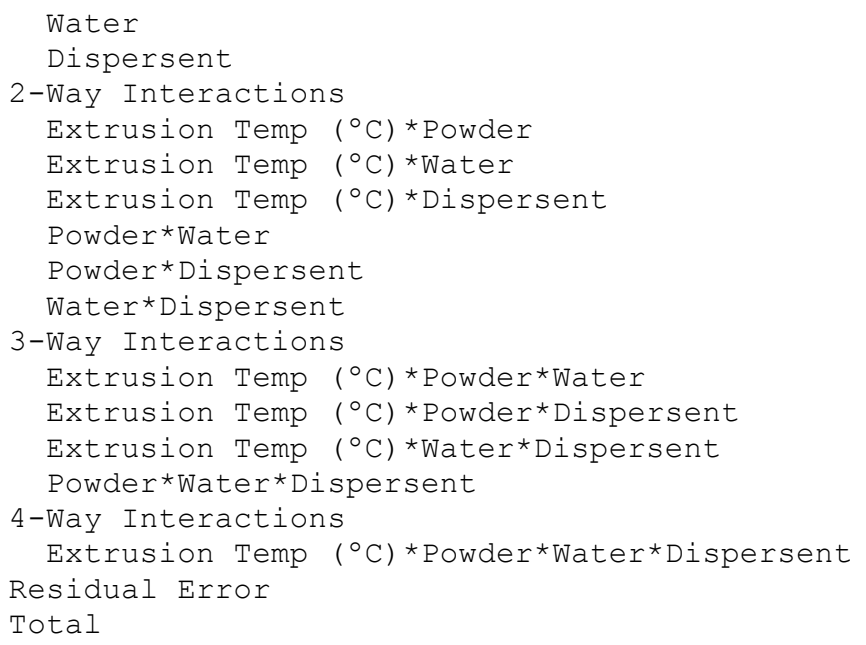

\section{Factorial Fit: Length $(\mathrm{cm})$ versus Extrusion Temp $\left({ }^{\circ} \mathrm{C}\right)$, Powder, ...}

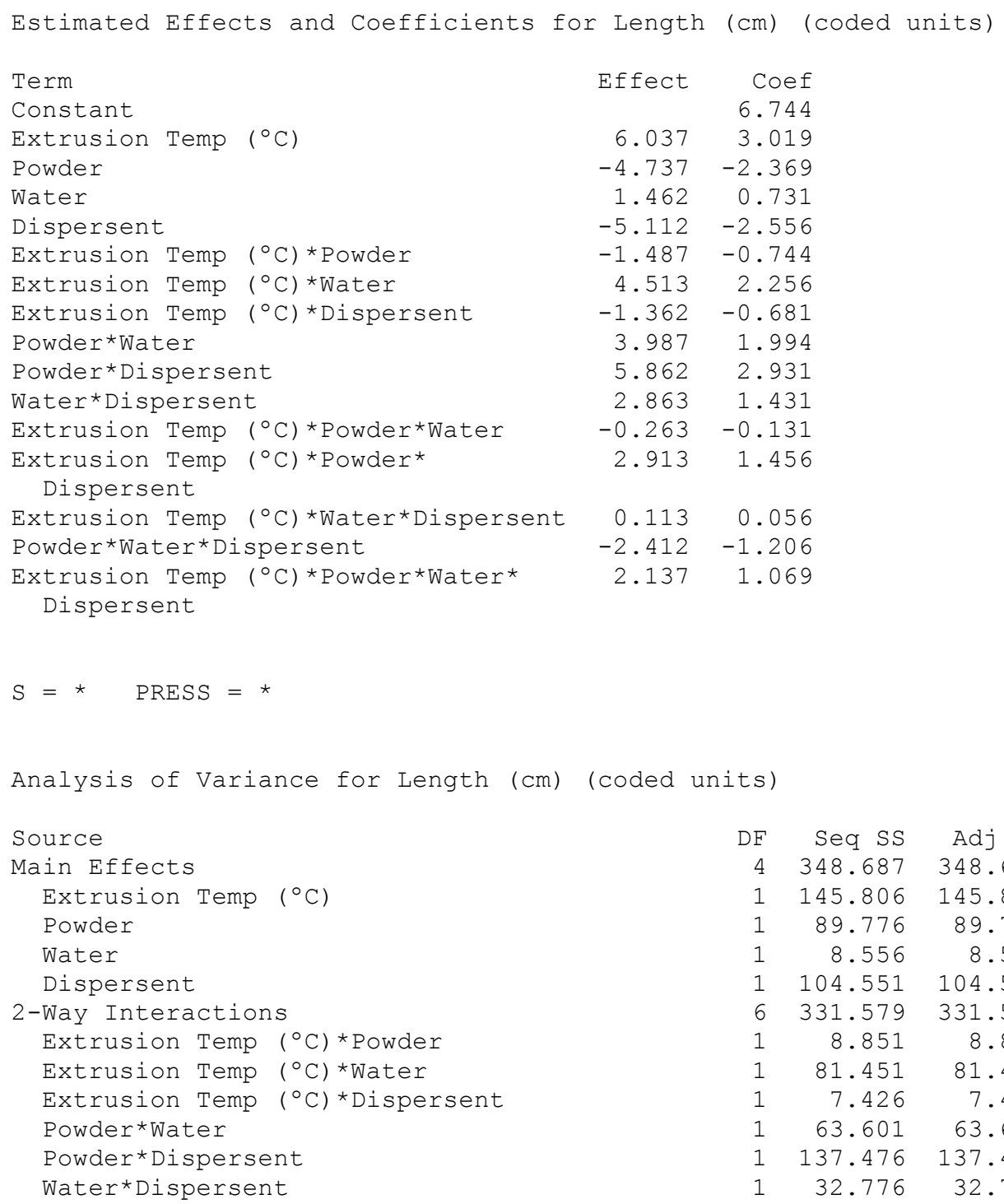

$\begin{array}{rr}\text { Effect } & \text { Coef } \\ & 6.744 \\ 6.037 & 3.019 \\ -4.737 & -2.369 \\ 1.462 & 0.731 \\ -5.112 & -2.556 \\ -1.487 & -0.744 \\ 4.513 & 2.256 \\ -1.362 & -0.681 \\ 3.987 & 1.994 \\ 5.862 & 2.931 \\ 2.863 & 1.431 \\ -0.263 & -0.131 \\ 2.913 & 1.456 \\ & \\ 0.113 & 0.056 \\ -2.412 & -1.206 \\ 2.137 & 1.069\end{array}$

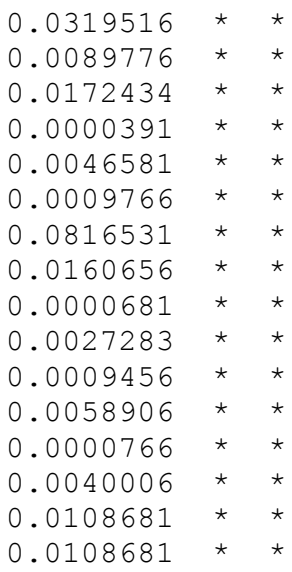

* 


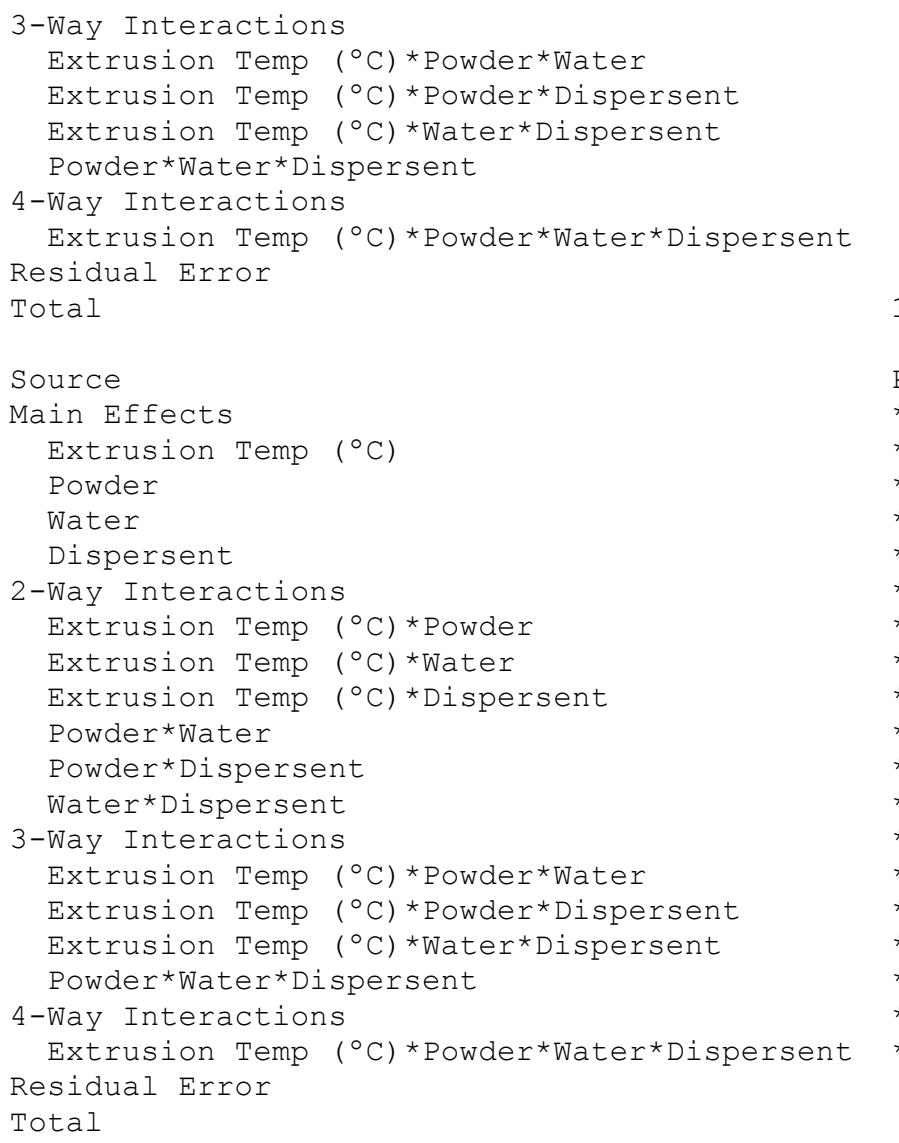

\section{Factorial Fit: Breaking Weight versus Extrusion Temp (, Powder, ...}

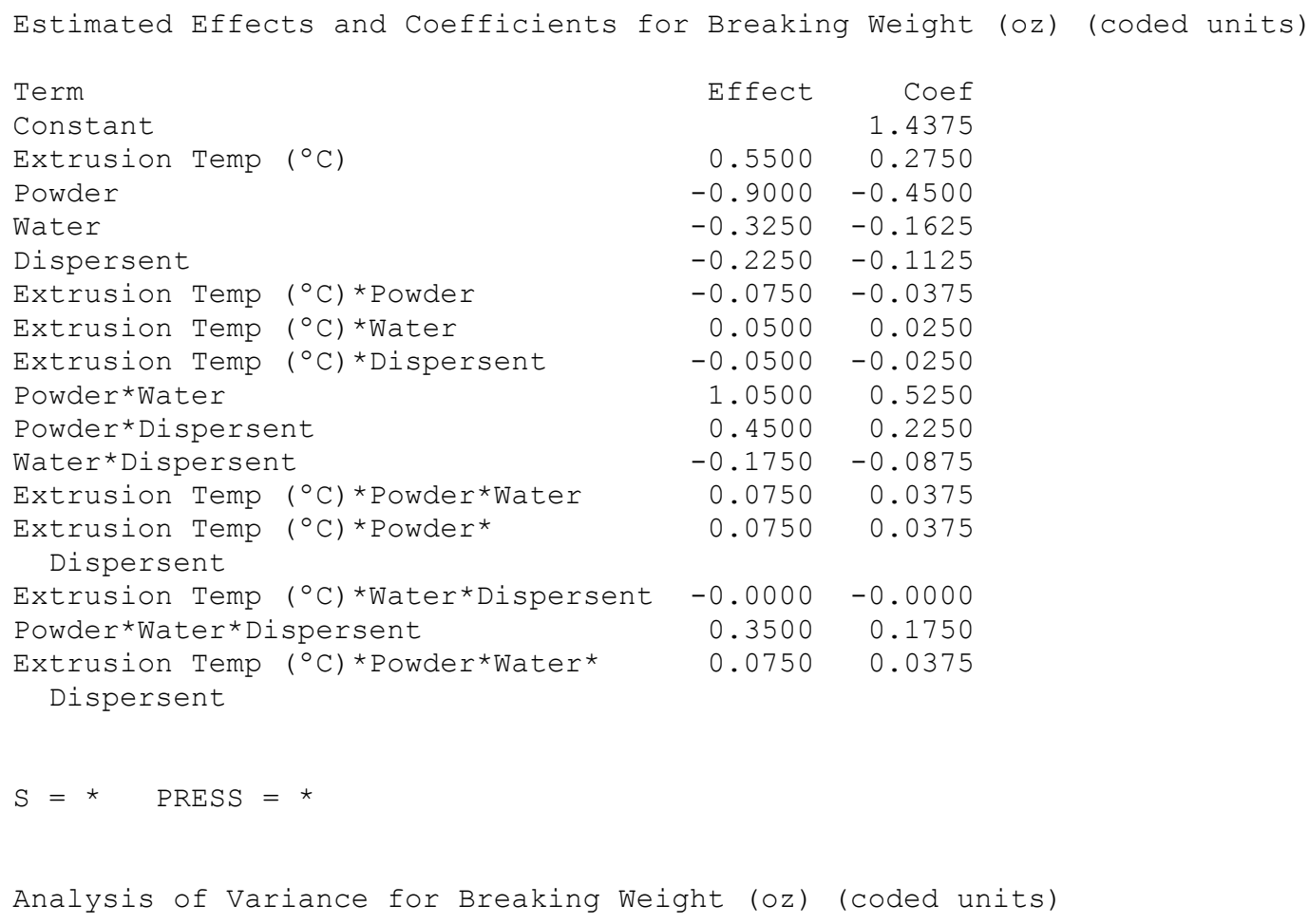




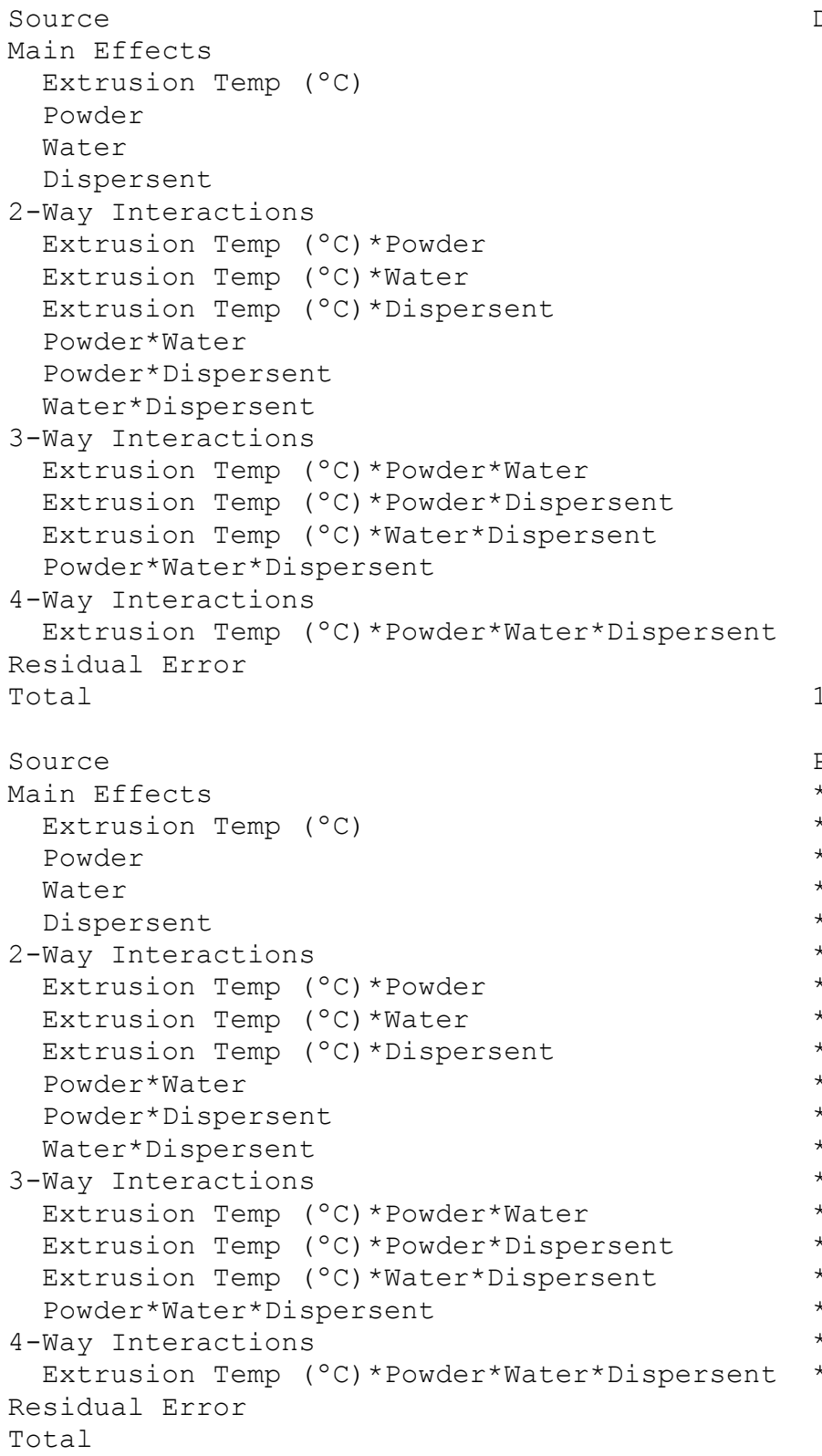

\section{Factorial Fit: Diameter Std. De versus Extrusion Temp (, Powder, ...}

$\begin{array}{lrr}\text { Estimated Effects and Coefficients for Diameter Std. Dev. } & \text { Coef } \\ \text { Term } & \text { Effect } & 0.17063 \\ \text { Constant } & -0.10625 & -0.05312 \\ \text { Extrusion Temp }\left({ }^{\circ} \mathrm{C}\right) & 0.04875 & 0.02437 \\ \text { Powder } & 0.01125 & 0.00562 \\ \text { Water } & 0.01125 & 0.00562 \\ \text { Dispersent } & -0.00375 & -0.00188 \\ \text { Extrusion Temp }\left({ }^{\circ} \mathrm{C}\right){ }^{*} \text { Powder } & -0.00625 & -0.00312 \\ \text { Extrusion Temp }\left({ }^{\circ} \mathrm{C}\right){ }^{*} \text { Water } & -0.00625 & -0.00313 \\ \text { Extrusion Temp }\left({ }^{\circ} \mathrm{C}\right){ }^{*} \text { Dispersent } & -0.04125 & -0.02063 \\ \text { Powder*Water } & -0.03625 & -0.01813 \\ \text { Powder*Dispersent } & 0.02125 & 0.01063\end{array}$




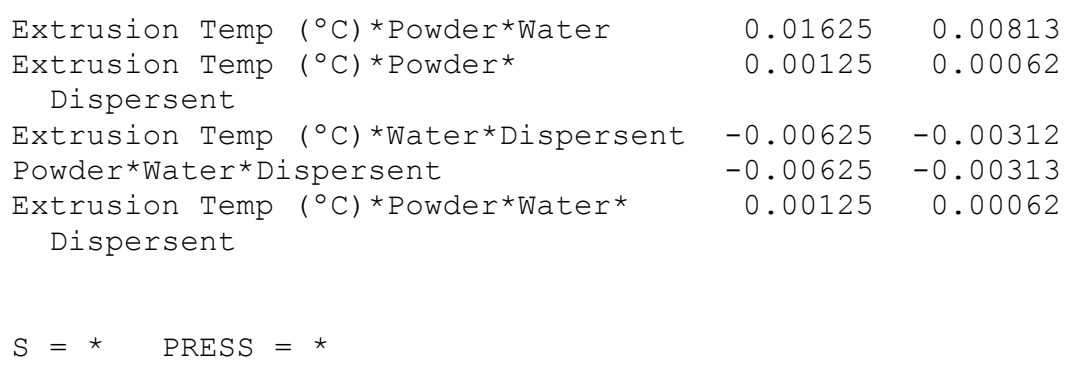

$\begin{array}{rrr}\text { DF } & \text { Seq SS } & \text { Adj SS } \\ 4 & 0.0556750 & 0.0556750 \\ 1 & 0.0451563 & 0.0451563 \\ 1 & 0.0095062 & 0.0095062 \\ 1 & 0.0005063 & 0.0005062 \\ 1 & 0.0005063 & 0.0005062 \\ 6 & 0.0142375 & 0.0142375 \\ 1 & 0.0000562 & 0.0000563 \\ 1 & 0.0001562 & 0.0001562 \\ 1 & 0.0001562 & 0.0001563 \\ 1 & 0.0068063 & 0.0068063 \\ 1 & 0.0052562 & 0.0052563 \\ 1 & 0.0018062 & 0.0018062 \\ 4 & 0.0013750 & 0.0013750 \\ 1 & 0.0010563 & 0.0010563 \\ 1 & 0.0000062 & 0.0000062 \\ 1 & 0.0001562 & 0.0001562 \\ 1 & 0.0001563 & 0.0001563 \\ 1 & 0.0000062 & 0.0000062 \\ 1 & 0.0000062 & 0.0000062 \\ 0 & & \\ 15 & 0.0712937 & \end{array}$

\begin{tabular}{|c|c|}
\hline J & \\
\hline 0.0139188 & * \\
\hline .0451563 & * \\
\hline .009506 & * \\
\hline .000506 & * \\
\hline 00050 & $\star$ \\
\hline 37 & * \\
\hline مחم & * \\
\hline .00 & * \\
\hline$\sigma_{0}$ & * \\
\hline & * \\
\hline 0 & . \\
\hline . & * \\
\hline .00 & * \\
\hline .001 & * \\
\hline 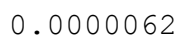 & * \\
\hline .00 & * \\
\hline & * \\
\hline 0 & * \\
\hline & \\
\hline
\end{tabular}




\section{Appendix H: Results for Second Factorial Analysis (Listed by Response) Factorial Fit: Diameter $(\mathrm{mm})$ versus Extrusion Temp $\left({ }^{\circ} \mathrm{C}\right)$, Powder, ...}

\begin{tabular}{|c|c|c|c|c|c|}
\hline Term & Effect & Coef & SE Coef & $\mathrm{T}$ & $\mathrm{P}$ \\
\hline Constant & & 1.66856 & 0.01356 & 123.09 & 0.000 \\
\hline Extrusion Temp $\left({ }^{\circ} \mathrm{C}\right)$ & 0.04688 & 0.02344 & 0.01356 & 1.73 & 0.122 \\
\hline Powder & -0.12987 & -0.06494 & 0.01356 & -4.79 & 0.001 \\
\hline Water & 0.08938 & 0.04469 & 0.01356 & 3.30 & 0.011 \\
\hline Dispersent & 0.04737 & 0.02369 & 0.01356 & 1.75 & 0.119 \\
\hline Powder*Water & 0.14287 & 0.07144 & 0.01356 & 5.27 & 0.001 \\
\hline Powder*Dispersent & 0.06337 & 0.03169 & 0.01356 & 2.34 & 0.048 \\
\hline Powder*Water*Dispersent & 0.03162 & 0.01581 & 0.01356 & 1.17 & 0.277 \\
\hline - & .0940 & & & & \\
\hline $\mathrm{R}-\mathrm{Sq}=90.30 \%$ & $=61.19 \%$ & $\mathrm{R}-\mathrm{Sq}$ & $(j)=81$ & $31 \%$ & \\
\hline
\end{tabular}

Analysis of Variance for Diameter (mm) (coded units)

\begin{tabular}{|c|c|c|c|c|c|c|}
\hline Source & $\mathrm{DF}$ & Seq SS & Adj $S S$ & Adj MS & $\mathrm{F}$ & $\mathrm{P}$ \\
\hline Main Effects & 4 & 0.117188 & 0.117188 & 0.029297 & 9.96 & 0.003 \\
\hline Extrusion Temp $\left({ }^{\circ} \mathrm{C}\right)$ & 1 & 0.008789 & 0.008789 & 0.008789 & 2.99 & 0.122 \\
\hline Powder & 1 & 0.067470 & 0.067470 & 0.067470 & 22.95 & 0.001 \\
\hline Water & 1 & 0.031952 & 0.031952 & 0.031952 & 10.87 & 0.011 \\
\hline Dispersent & 1 & 0.008978 & 0.008978 & 0.008978 & 3.05 & 0.119 \\
\hline 2-Way Interactions & 2 & 0.097719 & 0.097719 & 0.048859 & 16.62 & 0.001 \\
\hline Powder*Water & 1 & 0.081653 & 0.081653 & 0.081653 & 27.77 & 0.001 \\
\hline Powder*Dispersent & 1 & 0.016066 & 0.016066 & 0.016066 & 5.46 & 0.048 \\
\hline 3-Way Interactions & 1 & 0.004001 & 0.004001 & 0.004001 & 1.36 & 0.277 \\
\hline Powder*Water*Dispersent & 1 & 0.004001 & 0.004001 & 0.004001 & 1.36 & 0.277 \\
\hline Residual Error & 8 & 0.023523 & 0.023523 & 0.002940 & & \\
\hline
\end{tabular}

Factorial Fit: Length $(\mathrm{cm})$ versus Extrusion Temp $\left({ }^{\circ} \mathrm{C}\right)$, Powder, ...

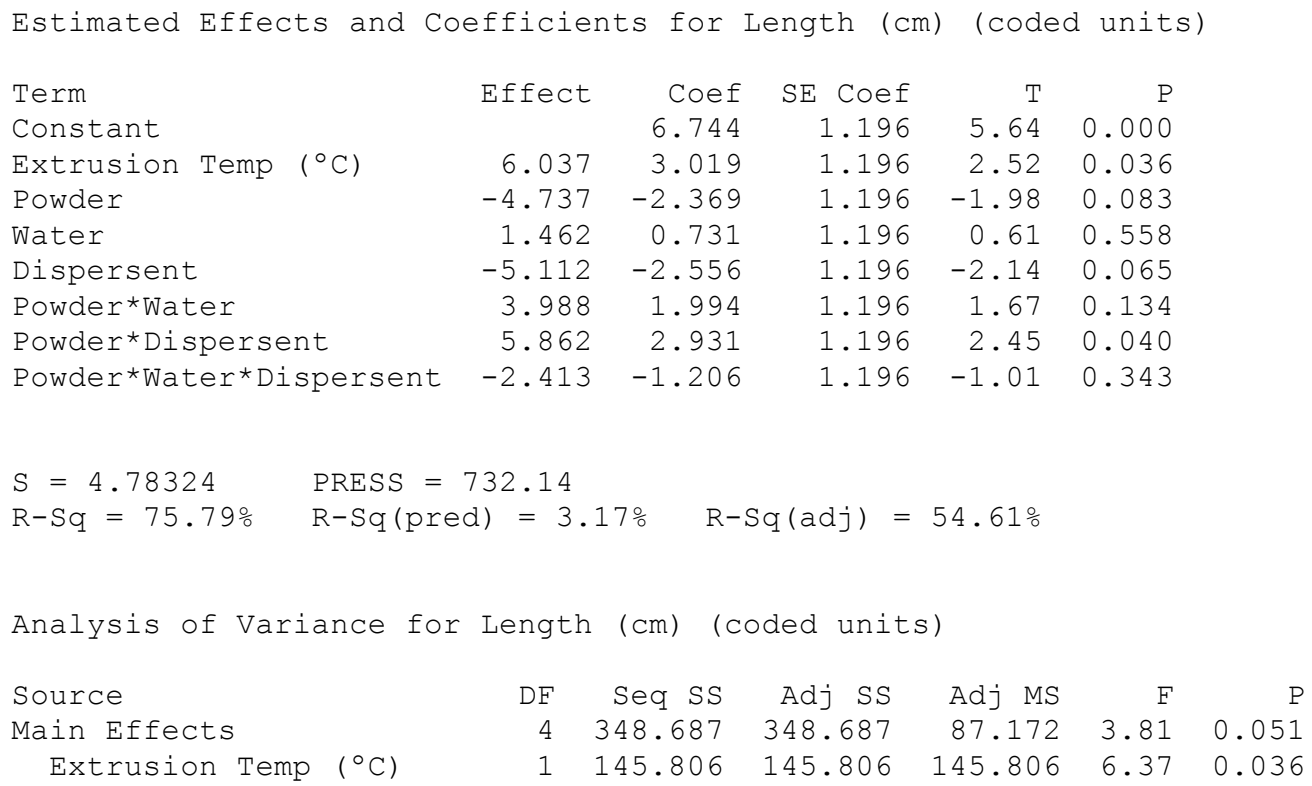




$\begin{array}{lrrrrrr}\text { Powder } & 1 & 89.776 & 89.776 & 89.776 & 3.92 & 0.083 \\ \text { Water } & 1 & 8.556 & 8.556 & 8.556 & 0.37 & 0.558 \\ \text { Dispersent } & 1 & 104.551 & 104.551 & 104.551 & 4.57 & 0.065 \\ \text { 2-Way Interactions } & 2 & 201.076 & 201.076 & 100.538 & 4.39 & 0.052 \\ \text { Powder*Water } & 1 & 63.601 & 63.601 & 63.601 & 2.78 & 0.134 \\ \text { Powder*Dispersent } & 1 & 137.476 & 137.476 & 137.476 & 6.01 & 0.040 \\ \text { 3-Way Interactions } & 1 & 23.281 & 23.281 & 23.281 & 1.02 & 0.343 \\ \text { Powder*Water*Dispersent } & 1 & 23.281 & 23.281 & 23.281 & 1.02 & 0.343 \\ \text { Residual Error } & 8 & 183.035 & 183.035 & 22.879 & & \\ \text { Total } & 15 & 756.079 & & & & \end{array}$

Factorial Fit: Breaking Weight versus Extrusion Temp (, Powder, ...

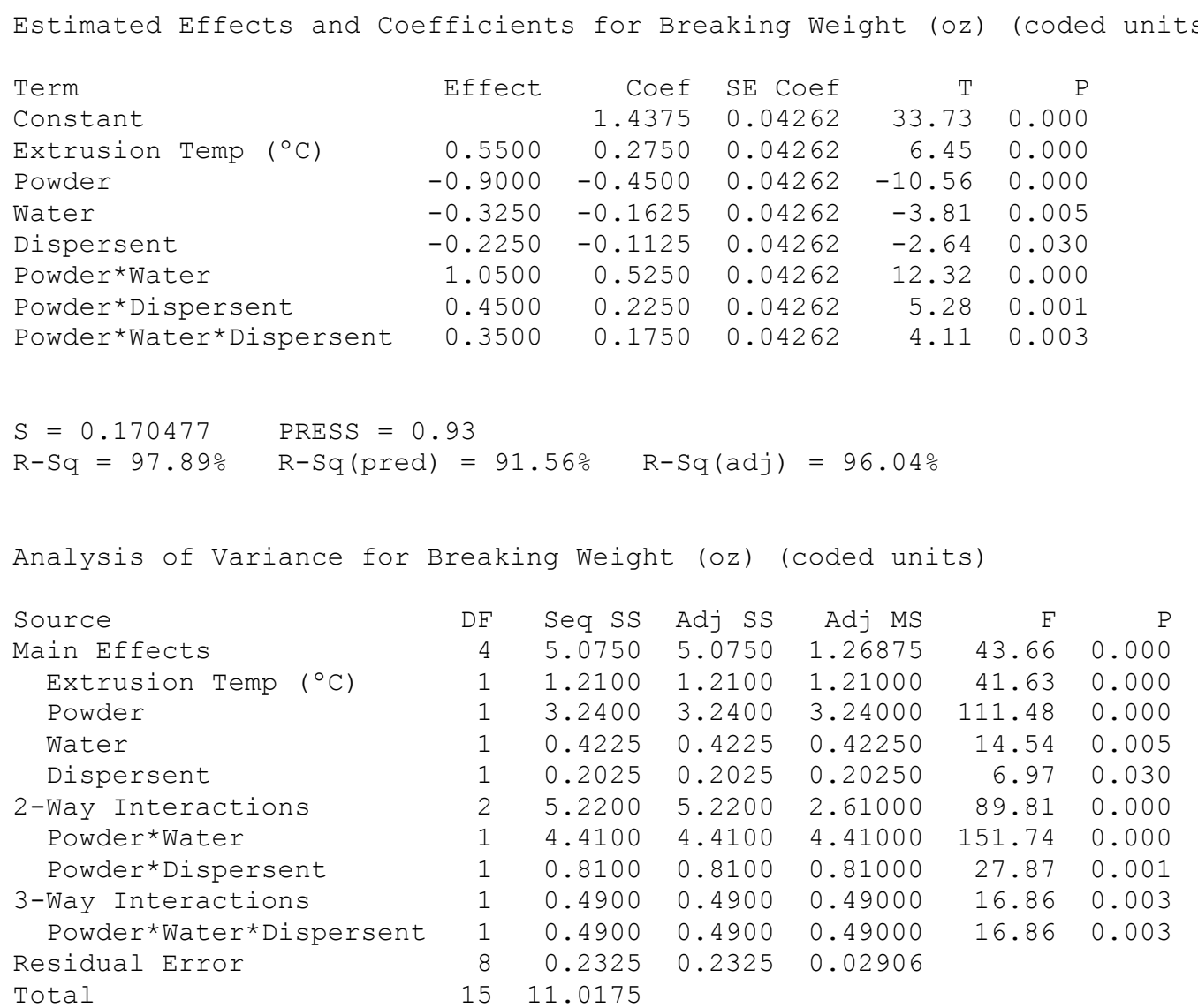

Factorial Fit: Diameter Std. De versus Extrusion Temp (, Powder, ...

$\begin{array}{lrrrrr}\text { Estimated Effects and Coefficients } & \text { for Diameter Std. Dev. (coded units } \\ \text { Term } & \text { Effect } & \text { Coef } & \text { SE Coef } & \mathrm{T} & \text { P } \\ \text { Constant } & & 0.17063 & 0.005154 & 33.11 & 0.000 \\ \text { Extrusion Temp }\left({ }^{\circ} \mathrm{C}\right) & -0.10625 & -0.05312 & 0.005154 & -10.31 & 0.000 \\ \text { Powder } & 0.04875 & 0.02437 & 0.005154 & 4.73 & 0.001 \\ \text { Water } & 0.01125 & 0.00562 & 0.005154 & 1.09 & 0.307 \\ \text { Dispersent } & 0.01125 & 0.00562 & 0.005154 & 1.09 & 0.307 \\ \text { Powder*Water } & -0.04125 & -0.02063 & 0.005154 & -4.00 & 0.004 \\ \text { Powder*Dispersent } & -0.03625 & -0.01813 & 0.005154 & -3.52 & 0.008 \\ \text { Powder*Water*Dispersent } & -0.00625 & -0.00313 & 0.005154 & -0.61 & 0.561\end{array}$

$S=0.0206155 \quad$ PRESS $=0.0136$ 


\begin{tabular}{|c|c|c|c|c|c|c|}
\hline $\mathrm{R}-\mathrm{Sq}=95.23 \%$ & $=$ & $.92 \%$ & $(\operatorname{adj})=$ & $06 \%$ & & \\
\hline Analysis of Variance for & $\mathrm{m}$ & er std. D & (coded & its) & & \\
\hline Source & $\mathrm{DF}$ & Seq SS & Adj SS & Adj MS & F & 2 \\
\hline Main Effects & 4 & 0.0556750 & 0.0556750 & 0.0139188 & 32.75 & 0.000 \\
\hline Extrusion Temp $\left({ }^{\circ} \mathrm{C}\right)$ & 1 & 0.0451563 & 0.0451563 & 0.0451563 & 106.25 & 0.000 \\
\hline Powder & 1 & 0.0095062 & 0.0095062 & 0.0095062 & 22.37 & 0.001 \\
\hline Water & 1 & 0.0005063 & 0.0005062 & 0.0005062 & 1.19 & 0.307 \\
\hline Dispersent & 1 & 0.0005063 & 0.0005062 & 0.0005062 & 1.19 & 0.307 \\
\hline 2-Way Interactions & 2 & 0.0120625 & 0.0120625 & 0.0060313 & 14.19 & 0.002 \\
\hline Powder*Water & 1 & 0.0068062 & 0.0068063 & 0.0068063 & 16.01 & 0.004 \\
\hline Powder*Dispersent & 1 & 0.0052563 & 0.0052563 & 0.0052563 & 12.37 & 0.008 \\
\hline 3-Way Interactions & 1 & 0.0001563 & 0.0001563 & 0.0001563 & 0.37 & 0.561 \\
\hline Powder*Water*Dispersent & 1 & 0.0001563 & 0.0001563 & 0.0001563 & 0.37 & 0.561 \\
\hline Residual Error & 8 & 0.0034000 & 0.0034000 & 0.0004250 & & \\
\hline Total & 15 & 0.0712938 & & & & \\
\hline
\end{tabular}




\section{Appendix I: Assumptions for Response Surface Analysis}
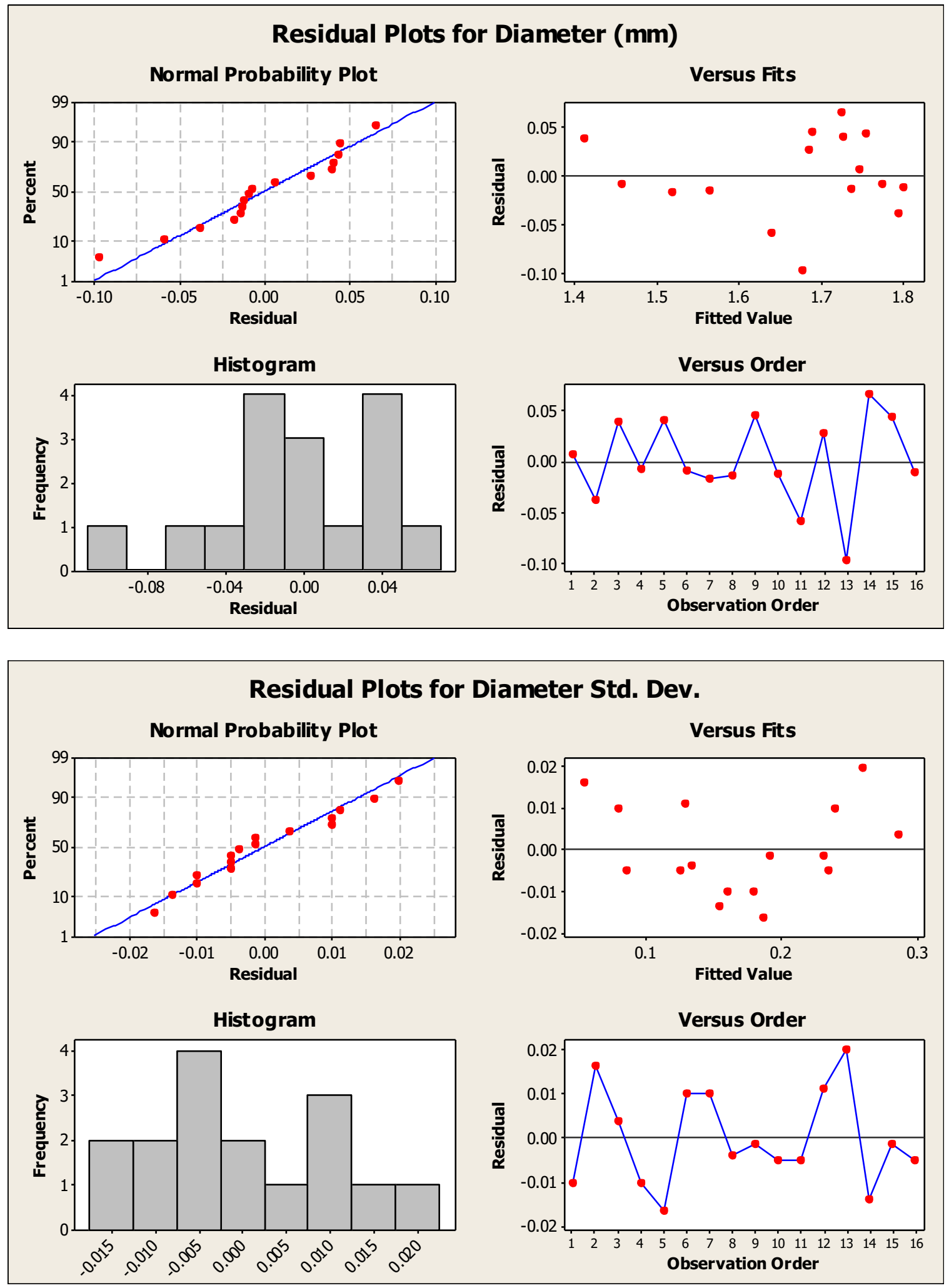


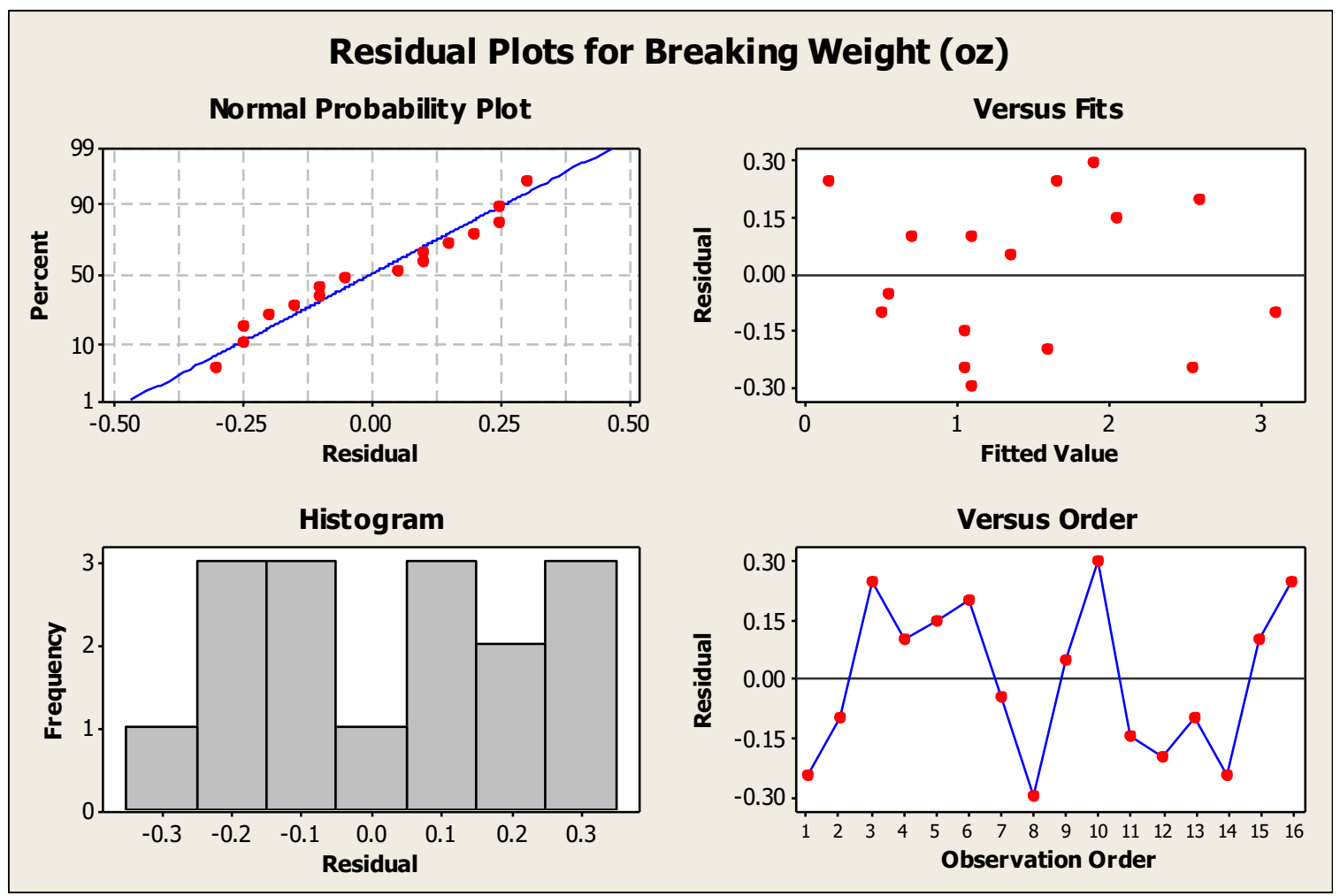




\section{Appendix J: Response Surface Optimization Results}

\section{Response Surface Regression: Diameter (mm versus Extrusion Te, Powder, ...}

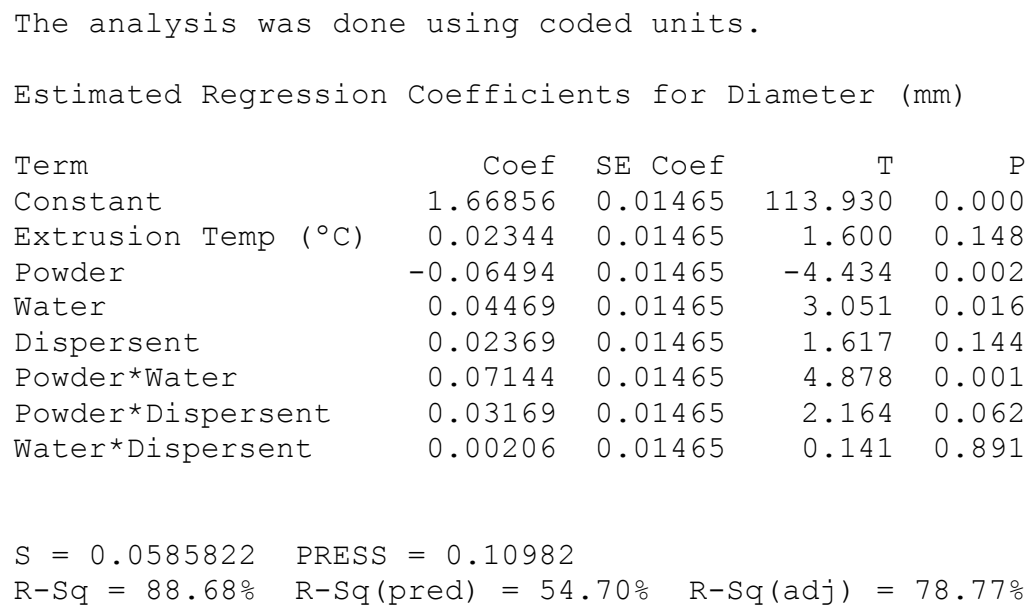




\section{Response Surface Regression: Length (cm) versus Extrusion Te, Powder, ...}

The analysis was done using coded units.

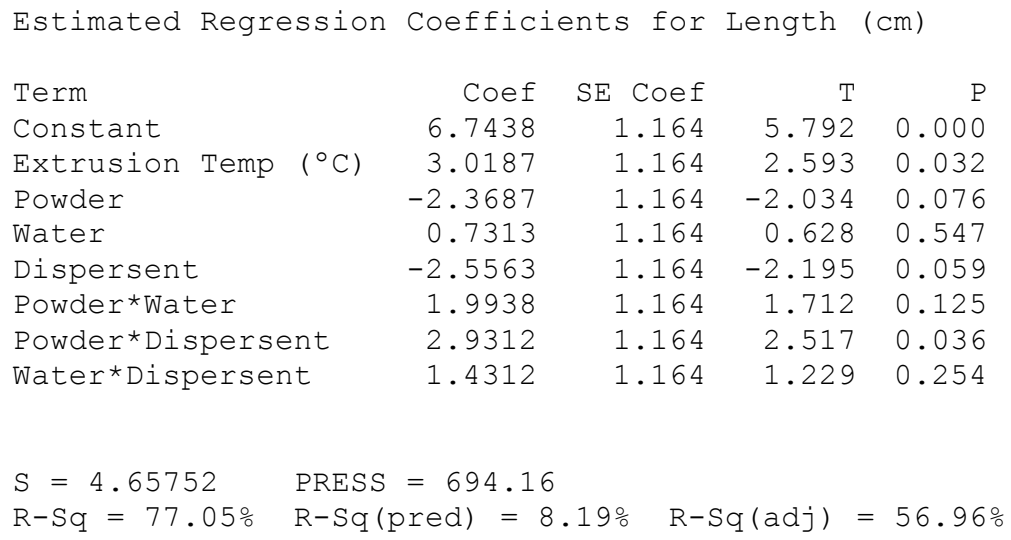




\section{Response Surface Regression: Breaking Wei versus Extrusion Te, Powder, ...}



Response Surface Regression: Diameter Std versus Extrusion Te, Powder, ...

The analysis was done using coded units.

Estimated Regression Coefficients for Diameter Std. Dev.

Term

Constant

$\begin{array}{rrrr}\text { Coef } & \text { SE Coef } & T & P \\ 0.170625 & 0.003698 & 46.145 & 0.000\end{array}$




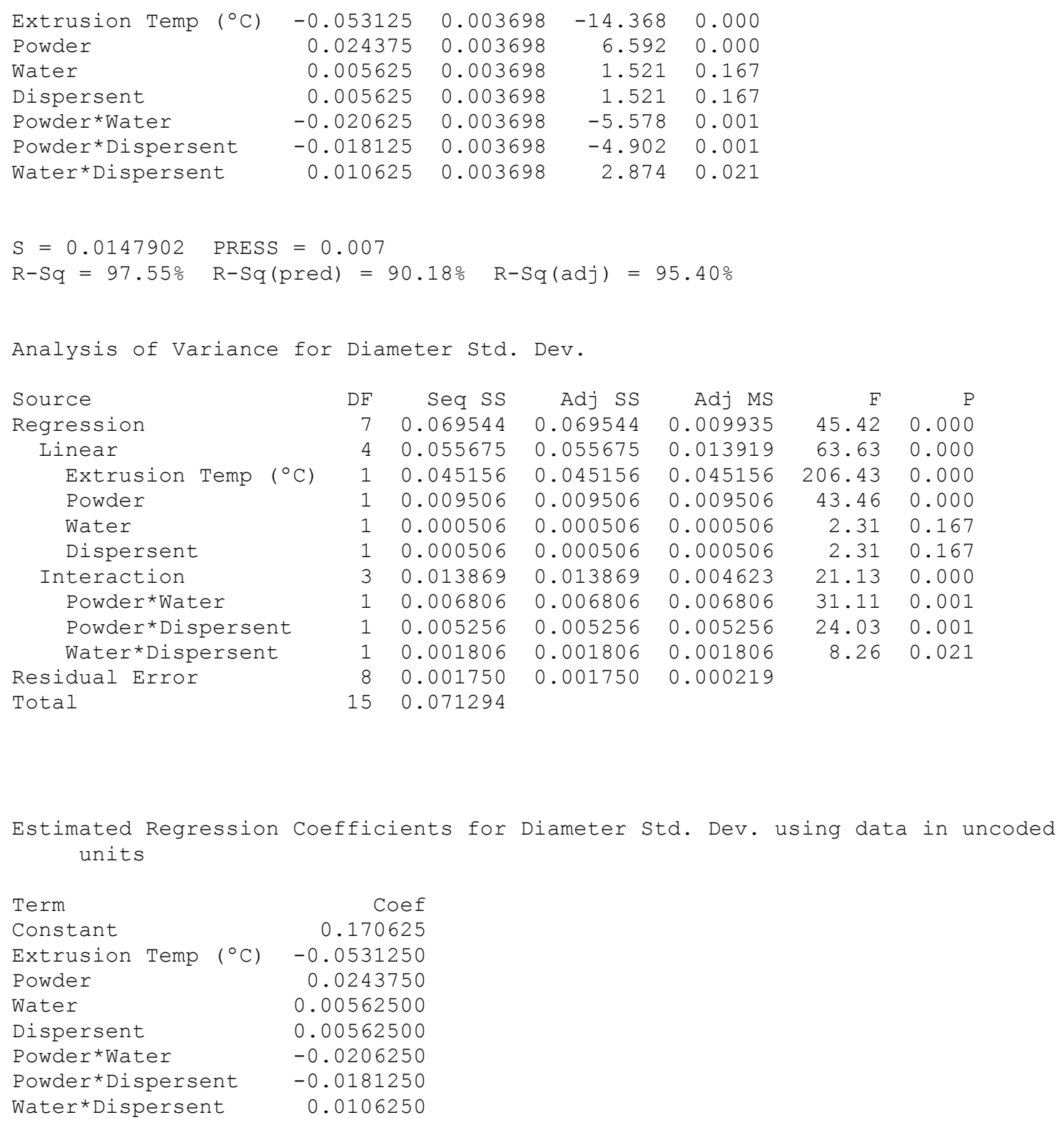




\section{Appendix K: Raw Data Used in Factorial and Response Surface Analyses}



